\title{
SIMONE MARCIELI SARTORETTO
}

AVALIAÇÃO DOS MECANISMOS ENVOLVIDOS NA REDUÇÃO DA CONTRAÇÃO VASCULAR EM AORTAS DE RATAS DIABÉTICAS: PAPEL DA INOS E INSULINA

Tese apresentada ao Programa de PósGraduação em Farmacologia do Instituto de Ciências Biomédicas da Universidade de São Paulo, para a obtenção do Título de Doutor em Ciências. 
SIMONE MARCIELI SARTORETTO

AVALIAÇÃO DOS MECANISMOS ENVOLVIDOS NA REDUÇÃO DA CONTRAÇÃO VASCULAR EM AORTAS DE RATAS DIABÉTICAS: PAPEL DA INOS E INSULINA

Tese apresentada ao Programa de PósGraduação em Farmacologia do Instituto de Ciências Biomédicas da Universidade de São Paulo, para a obtenção do Título de Doutor em Ciências

Área de concentração: Farmacologia

Orientadora: Profa. Dra. Eliana Hiromi Akamine

Versão original 
DADOS DE CATALOGAÇÃO NA PUBLICAÇÃO (CIP)

Serviço de Biblioteca e Informação Biomédica do

Instituto de Ciências Biomédicas da Universidade de São Paulo

reprodução não autorizada pelo autor

Sartoretto, Simone Marcieli.

Avaliação dos mecanismos envolvidos na redução da contração vascular em aortas de ratas diabéticas: papel da iNOS e insulina / Simone Marcieli Sartoretto. -- São Paulo, 2013.

Orientador: Profa. Dra. Eliana Hiromi Akamine.

Tese (Doutorado) - Universidade de São Paulo. Instituto de Ciências Biomédicas. Departamento de Farmacologia. Área de concentração: Farmacologia. Linha de pesquisa: Diabetes e alterações vasculares.

Versão do título para o inglês: Evaluation of the mechanisms involved in the reduced vascular contraction in aortas of diabetic female rats: role of iNOS and insulin.

1. Diabetes 2. iNOS 3. Fêmeas 4. Receptores de estrógeno

5. Reatividade vascular I. Akamine, Profa. Dra. Eliana Hiromi

II. Universidade de São Paulo. Instituto de Ciências Biomédicas.

Programa de Pós-Graduação em Farmacologia III. Título. 
Candidato(a): $\quad$ Simone Marcieli Sartoretto.

Título da Tese: $\quad$ Avaliação dos mecanismos envolvidos na redução da contração vascular em aortas de ratas diabéticas: papel da iNOS e insulina.

Orientador(a): $\quad$ Profa. Dra. Eliana Hiromi Akamine.

A Comissão Julgadora dos trabalhos de Defesa da Tese de Doutorado, em sessão pública realizada a considerou
( ) Aprovado(a)
( ) Reprovado(a)

\begin{tabular}{|c|c|}
\hline Examinador(a): & $\begin{array}{l}\text { Assinatura: } \\
\text { Nome: ........ } \\
\text { Instituição: }\end{array}$ \\
\hline Examinador(a): & $\begin{array}{l}\text { Assinatura: } \\
\text { Nome: ........ } \\
\text { Instituição: }\end{array}$ \\
\hline Examinador(a): & $\begin{array}{l}\text { Assinatura: } \\
\text { Nome: ........ } \\
\text { Instituição: }\end{array}$ \\
\hline Examinador(a): & $\begin{array}{l}\text { Assinatura: } \\
\text { Nome: ........ } \\
\text { Instituição: }\end{array}$ \\
\hline Presidente: & $\begin{array}{l}\text { Assinatura } \\
\text { Nome: .... } \\
\text { Instituição }\end{array}$ \\
\hline
\end{tabular}




\begin{tabular}{|l|l|}
\hline UNIVERSIDADE DE SÃO PAULO \\
INSTITUTO DE CIENCIAS BIOMÉDICAS \\
Cidade Universitária "Armando de Salles Oliveira" \\
Av. Prof. Lineu Prestes, 2415 - Cep. 05508-900 São Paulo, SP - Brasil \\
Telefone :(55) (011) 3091.7733 - telefax: (55) (011)3091-7438 \\
e-mail: cep@icb.usp.br \\
COMISSÃO DEÉTICA NO USO DE ANIMAL
\end{tabular}

Decl. CEUA.004.10

DECLARAÇ Ã O

Em adendo ao Certificado 007/04/CEEA, datado de 20.04.04 e por solicitação da Profa. Dra. Zuleica Bruno Fortes, responsável pela linha de Pesquisa, autorizo a inclusão do aluno Simone Marcieli Sartoretto ao projeto de pesquisa "Reatividade microcirculatória em patologias experimentais: Papel do endotélio", uma vez que se trata de utilização da mesma espécie animal e de métodos experimentais similares ao referido certificado.

São Paulo, 09 de fevereiro de 2010.

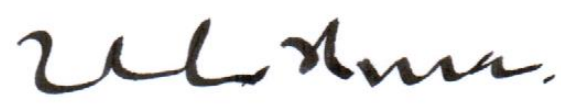

Prof. Dr. WOTHAN TAVARES DE LIMA Coordenador-CEUA- ICB/USP 
Aos meus pais, Luiz e Tania Sartoretto, pelo amor incondicional, por toda a dedicação e apoio que foram essenciais para continuar nessa caminhada.

Aos meus queridos irmãos, Julinho $e$ Tainarinha, agradeço a Deus por ter a oportunidade de ter irmãos tão maravilhosos e companheiros.

Muito obrigada. Amo vocês. 


\section{AGRADECIMENTOS}

Agradeço a Deus por ter colocado no meu caminho pessoas tão maravilhosas, verdadeiros anjos, que foram essenciais nesta caminha.

Às professoras Dra. Zuleica Bruno Fortes e Dra. Eliana Hiromi Akamine, minhas orientadoras, por todos esses anos de apoio e dedicação para minha formação. Obrigada pela oportunidade de trabalhar e aprender muito com vocês, mulheres incríveis e admiráveis.

À professora Dra. Maria Helena C. de Carvalho, pelo apoio e estrutura dos laboratórios.

Ao meu querido professor Dr. Roberto Kenji Nakamura Cuman, meus mais sinceros agradecimentos por me ensinar os primeiros passos na carreira científica.

Aos professores, funcionários e grandes amigos do laboratório de inflamação da UEM muito obrigada pelos ensinamentos e por todo apoio e amizade durante meus quatro anos de iniciação científica.

Ao meu grande amigo e irmão Gustavo Schimdt por todo carinho e incentivo para vir para São Paulo, com certeza você é um dos grandes responsáveis por esta conquista.

À minha querida irmã de coração Aline Buriola, pelo carinho, amizade e companheirismo.

À minha querida madrinha, Maíra, por tanto apoio e dedicação.

Às minhas amigas Cida, Rosa e Maristela, muito obrigada pela ajuda não só no laboratório, mas por sempre estar à disposição para ajudar em qualquer momento.

Aos grandes amigos e funcionários do laboratório de hipertensão: Martinha, Ritinha, Manoel e Antônio, pela maravilhosa convivência e pelo auxílio prestado.

À Dra. Graziela Ceravolo, muito obrigada por ter me acolhido em sua casa quando cheguei a São Paulo, pela amizade e por todos os ensinamentos que foram essenciais para a minha formação. 
Às minhas queridas amigas e professoras doutoras que tenho muito orgulho, Dra. Gisele Facholi Bonfim e Dra. Eveline Fonseca, pela amizade, apoio e convivência maravilhosa, amo vocês meninas e sinto demais a falta de vocês.

À minha querida amiga Dra. Karlinha Santiago por tantos anos de convivência maravilhosa, amizade e por tantas conversas e conselhos, obrigada por tudo Karlinha.

À minha querida amiga e inigualável Renée, obrigada por tanta amizade, por tantos abraços e por tanto carinho.

Aos meus queridos amigos que me acolheram com tanto carinho e que me ajudaram muito durante a pós-gradução e que sinto muita falta, Nubiazinha e Fernandinho.

Às meninas da farmácia pela convivência maravilhosa, Soninha e Fabiana.

Às minhas queridas amigas: gaúchas, Luzi e Fran Knebel, pelos momentos maravilhosos, pelo carinho e amizade e principalmente pelas ótimas conversas regadas a um bom chimarrão, a Fran Vasconcelos, pela amizade, pelos momentos de diversão e pela maravilhosa convivência.

As princesinhas do laboratório, Cinthya, Aline, Biazinha, Vanessa, Fernandinha e Aninha obrigada pela amizade, apoio e conselhos.

À minha amiga Karilane, pela amizade, carinho e pelas conversas tão confortantes.

À minha amiga Luciana, muito obrigada pelo carinho, atenção e amizade que foram essenciais para aliviar os momentos difíceis.

Ao meu amigo Tiago, companheiro de laboratório e de lutas políticas, obrigada por toda amizade e ensinamentos.

Às queridas secretárias do departamento de Farmacologia, que nunca mediram esforços pra sempre me ajudarem, Julieta, Selma, Camila e Monica.

À minha queridíssima amiga Suelen, pela amizade, pelo ombro amigo e momentos de diversão. 
Às queridas amigas Bazinha e Andrea por sempre estar a disposição em ajudar, aconselhar e fazer um ótimo Reiki, que foi essencial para manter o equilíbrio nessa caminhada.

Às minha amigas Veronica e Rai pelas maravilhosas conversas.

Aos alunos participantes do curso de verão obrigada pelos momentos de desafio e pelos agradáveis momentos durante a realização deste curso, tão trabalhoso, mas também tão gratificante.

Muito obrigada aos amigos do laboratório de fisiologia vascular: professora Luciana, Ana Paula Davel, Gisele e Camila pela amizade e pelas técnicas que aprendi.

À Fundação de Amparo à Pesquisa do Estado de São Paulo (FAPESP) pelo apoio financeiro.

Obrigada a todos que de forma direta ou indireta contribuíram muito para a minha formação acadêmica. Muito obrigada. 
"Somente quando temos coragem para enfrentar as coisas exatamente como elas são sem qualquer autoengano ou ilusão, é que uma luz surgirá dos acontecimentos, pela qual o caminho do sucesso poderá ser reconhecido". 


\section{RESUMO}

SARTORETTO, S. M. Avaliação dos mecanismos envolvidos na redução da contração vascular em aortas de ratas diabéticas: papel da iNOS e insulina. 2013. 93 f. Tese (Doutorado em Farmacologia) - Instituto de Ciências Biomédicas, Universidade de São Paulo, São Paulo, 2014.

Disfunção endotelial e aumento da pressão arterial são complicações comuns no diabetes, mas redução da reposta contrátil vascular e da pressão arterial foram observadas em ratos diabéticos. A contração à noradrenalina está reduzida também em aorta de ratas diabéticas. Inibição da atividade da iNOS corrige a pressão arterial reduzida em ratos diabéticos. O diabetes e alta concentração de glicose pode alterar o perfil de expressão dos receptores de estrógeno ESR1 e ERS2. Os efeitos cardiovasculares benéficos do estrógeno são mediados pelo receptor ESR1, sendo que a ativação do receptor ESR2 induz a expressão de fatores pró-inflamatórios, incluindo a iNOS. Além dos efeitos metabólicos, a insulina regula a produção de esteroides sexuais, mas seu efeito sobre os receptores desses esteroides e quanto desse efeito influencia seus efeitos vasculares não são bem entendidos. O objetivo do presente estudo foi investigar se, em ratas diabéticas, o aumento da expressão da iNOS/geração de NO pode ser responsável pela redução da contração vascular. Além disso, avaliamos o efeito do tratamento com insulina sobre a contratilidade vascular e a expressão de receptores de estrógeno em aorta de ratas diabéticas. Ratas Wistar (180-200 g) receberam injeção de aloxana ou salina e foram divididas em quatro grupos: controle, diabética, diabética tratada com $6 \mathrm{UI} /$ dia de insulina $\mathrm{NPH}$ durante 15 dias e diabética tratada com o inibidor da iNOS L-NIL (3 mg/kg/dia) durante 30 dias. Os tratamentos iniciaram-se 15 e 3 dias após a indução do diabetes, respectivamente. Trinta dias após a indução do diabetes, observamos aumentada expressão proteica da iNOS e de proteínas s-nitrosiladas em aorta e aumentada concentração plasmática de NO. O tratamento com insulina corrigiu estas alterações, contudo, sem ter normalizado a glicemia. O tratamento com L-NIL reduziu a expressão de proteínas s-nitrosiladas e a concentração de NO. Tanto a contração induzida por agonistas adrenérgicos quanto por cloreto de potássio foi reduzida em anéis de aorta sem endotélio de ratas diabéticas, porém os tratamentos com insulina e com L-NIL corrigiram apenas a resposta adrenérgica. Aumentada expressão dos receptores de estrógeno ESR2 e GPER também foi observada em aorta de ratas diabéticas, que foi corrigida pelo tratamento com insulina, mas não com L-NIL. O antagonismo agudo do ERS2 não teve efeito sobre a contração induzida pela noradrenalina em aorta de ratas controles e diabéticas. Nossos resultados mostram que o aumento da expressão da iNOS/geração de NO é responsável pela redução da resposta contrátil induzida por ativação de receptor adrenérgico, mas não daquela induzida por despolarização direta da membrana. A insulina modula negativamente a expressão da iNOS e dos receptores ESR2 e GPER em aorta de ratas diabéticas, efeito que pode contribuir com a restauração da contração induzida por agonistas adrenérgicos. O receptor ESR2 pode estar envolvido na redução da resposta a agonistas adrenérgicos, mas envolve mecanismos que não podem ser inibidos agudamente.

Palavras-chave: Diabetes. iNOS. Fêmeas. Receptores de estrógeno. Reatividade vascular. 


\begin{abstract}
SARTORETTO, S. M. Mechanisms involved in the reduced vascular contraction in aortas of diabetic female rats: a role of iNOS and insulin. 2013. 93 p. Ph. D. thesis (Pharmacology) - Instituto de Ciências Biomédicas, Universidade de São Paulo, São Paulo, 2014.

Endothelial dysfunction and increased blood pressure are common complications observed in diabetes. However reduced blood vessel contractile responses and mean arterial pressure have been found in diabetic male rats, whereas noradrenaline response is also reduced in aorta isolated from diabetic female rats. iNOS inhibition recovers the reduced blood pressure found in diabetic male rats. Diabetes and high levels of glucose alter the expression of estrogen receptor ESR1 and ERS2. The beneficial cardiovascular effects of estrogen are mediated by ESR1 and ESR2 activation induce the expression of pro-inflammatory factors, including iNOS. In addition to the metabolic effects, insulin also regulates the production of sex steroids, yet if insulin regulates the steroid receptors and how that impacts blood vessel responses is still not very well understood. The aim of this study was to investigate in diabetic female rats whether the increased expression of iNOS / NO bioavailability may contribute to the reduction of vascular contraction. Furthermore, we evaluated the effects of insulin therapy on vascular contractility and the expression of estrogen receptors in aorta of diabetic female rats. Female Wistar rats (180-200 g) were injected either with alloxan or saline and then divided in four groups: control, diabetic, diabetic treated with insulin NPH (6 IU/day, for 15 days), and diabetic treated with the iNOS inhibitor L-NIL (3 mg/kg/day, for 30 days). The treatments started out 15 or 3 days after diabetes induction, respectively. Thirty days after the induction, we observed increased protein expression of iNOS and protein s-nitrosylation in the aorta and higher levels of plasmatic NO. Insulin treatment corrected these changes, without normalizing blood glucose levels. L-NIL treatment reduced the expression of protein s-nitrosylation and NO levels. Diabetic female aorta, deprived of endothelium, had a reduced maximum response to noradrenaline, phenylephrine, and potassium chloride when compared to control counterparts, but insulin and L-NIL treatments only recovered the adrenergic response. Increased expression of estrogen receptors GPER and ESR2 was also observed in the aorta of diabetic female rats, which was corrected by insulin treatment, but not by L-NIL. An ESR2 antagonist had no effect on contractile responses to noradrenaline in aorta isolated from control and diabetic rats. Our results show that the increased expression of iNOS / NO generation is responsible for the reduction of the contractile response induced by activation of adrenergic receptors, but not by direct membrane depolarization. Insulin negatively modulates the expression of iNOS, ESR2, and GPER receptors in diabetic aortas; this effect may contribute to restore the adrenergic response. The ESR2 receptor may be involved in the reduction of the response to adrenergic agonists, but involve mechanisms that could not be acutely inhibited.
\end{abstract}


Keywords: Diabetes. iNOS. Female. Estrogen receptors. Vascular reactivity. 


\section{LISTA DE ILUSTRAÇÕES}

Figura 1 - Imunorreatividade da iNOS na camada média de aorta de ratas controles (CT), diabéticas (DB), diabéticas tratadas com insulina (DT-Ins) e diabéticas tratadas com L-NIL (DT-LNIL).

Figura 2 - Concentração plasmática de nitrito analisado pelo NOA (Nitric Oxide Analyzer) nas ratas controles (CT), diabéticas (DB), diabéticas tratadas com insulina (DT-Ins) e diabéticas tratadas com L-NIL (DT-LNIL). .46

Figura 3 - Expressão proteica da IL-1 $\beta$ em aorta de ratas controles (CT), diabéticas (DB), diabéticas tratadas com insulina (DT-Ins) e diabéticas tratadas com L-NIL (DTLNIL)......

Figura 4 - Curva concentração-resposta (A) e resposta máxima (B) para a noradrenalina em anéis de aorta sem endotélio de ratas controles (CT), diabéticas (DB) e diabéticas tratadas com insulina (DT-Ins).

Figura 5 - Curva concentração-resposta (A) e resposta máxima (B) para a noradrenalina em anéis de aorta sem endotélio de ratas controles (CT), diabéticas (DB) e diabéticas tratadas com insulina (DT-Ins).

Figura 6 - Curva concentração-resposta (A) e resposta máxima (B) para o cloreto de potássio $(\mathrm{KCl})$ em anéis de aorta sem endotélio de ratas controles (CT), diabéticas (DB) e diabéticas tratadas com insulina (DTIns)

Figura 7 - Curva concentração-resposta para a noradrenalina em anéis de aorta sem endotélio de ratas controles (A) e diabéticas (B) na ausência (-) e presença dos inibidores específicos da iNOS L-NIL $(10 \mu \mathrm{M})$ ou 1400W $(10 \mu \mathrm{M})$. .53

Figura 8 - Curva concentração-resposta (A) e resposta máxima (B) para noradrenalina em anéis de aorta sem endotélio de ratas controles (CT), diabéticas (DB) e diabéticas tratadas cronicamente com L-NIL (DT-LNIL).

Figura 9 - Curva concentração-resposta (A) e resposta máxima (B) para a fenilefrina em anéis de aorta sem endotélio de ratas controles (CT), diabéticas (DB) e diabéticas tratadas com L-NIL LNIL).

Figura 10 - Curva concentração-resposta (A) e resposta máxima (B) para o cloreto de potássio $(\mathrm{KCl})$ em anéis de aorta sem endotélio de ratas controles $(\mathrm{CT})$, diabéticas (DB) e diabéticas tratadas com L-NIL (DTLNIL). .58

Figura 11 - Expressão proteica de proteínas S-nitrosiladas em aorta de ratas controles (CT), diabéticas (DB), diabéticas tratadas com insulina (DT-Ins) e $\begin{array}{lllll}\text { diabéticas tratadas } & \text { com } & \text { L-NIL }\end{array}$ LNIL). 
Figura 12 - Expressão do receptor de estrógeno GPER em aorta de ratas controles (CT), diabéticas (DB), diabéticas tratadas com insulina (DT-Ins) e diabéticas tratadas com L-NIL (DT-LNIL).

Figura 13 - Expressão dos receptores de estrógeno GPER em aortas de ratas controles (CT), diabéticas (DB), diabéticas tratadas com insulina (DT-Ins) e $\begin{array}{lllll}\text { diabéticas } & \text { tratadas } & \text { com } & \text { L-NIL } & \text { (DT- }\end{array}$ LNIL).

Figura 14 - Expressão do receptor de estrógeno ESR2 em aortas de ratas controles (CT), diabéticas (DB), diabéticas tratadas com insulina (DT-Ins) e diabéticas tratadas com L-NIL (DT-LNIL).

Figura 15 - Curva concentração-resposta para a noradrenalina em anéis de aorta sem endotélio de ratas controles na presença de diferentes concentrações do antagonista do receptor ESR2 (PHTPP) 65

Figura 16 - Curva concentração-resposta para a noradrenalina em anéis de aortas sem endotélio de ratas diabéticas na presença de diferentes concentrações do antagonista do ESR2 (PHTPP). .66 


\section{LISTA DE TABELAS}

Tabela 1 - Parâmetros biológicos de ratas controles, diabéticas, diabéticas tratadas com insulina e diabéticas tratadas com L-NIL 30 dias após a indução do diabetes.

Tabela 2 - Glicemia de ratas diabéticas em diferentes tempos após a injeção de 2 e $4 \mathrm{UI}$ de insulina NPH.

Tabela 3 - Massa uterina e concentração de estradiol e progesterona em ratas controles, diabéticas, diabéticas tratadas com insulina e diabéticas tratadas com LNIL na fase diestro 30 dias após a indução do diabetes. 43

Tabela 4 - Pressão arterial (PA) sistólica e diastólica e frequência cardíaca (FC) de ratas controles, diabéticas, diabéticas tratadas com insulina e diabéticas tratadas com L-NIL 30 dias após a indução do diabetes. 44

Tabela 5 - Resposta máxima e sensibilidade à noradrenalina na ausência (-) e presença dos inibidores da iNOS L-NIL $(10 \mu \mathrm{M})$ ou 1400W $(10 \mu \mathrm{M})$ em anéis de aorta sem endotélio de ratas controles (CT) e diabéticas (DB). .54

Tabela 6 - Resposta máxima e sensibilidade à noradrenalina em anéis de aorta sem endotélio de ratas controles na presença de diferentes concentrações do antagonista do receptor ESR2 (PHTPP)

Tabela 7 - Resposta máxima e sensibilidade à noradrenalina em anéis de aorta sem endotélio de ratas diabéticas na presença de diferentes concentrações do antagonista do receptor

ESR2 (PHTPP). .66 


\section{LISTA DE ABREVIATURAS E SIGLAS}

ANOVA- análise de variância de uma via

BPM- batimentos por minuto

$\mathrm{Ca}^{2+-}$ Cálcio

CE 50 - concentração necessária para produzir $50 \%$ da resposta máxima

CEUA- Comissão de Ética no Uso de Animais

cNOS- óxido nítrico sintase constitutivas

CONCEA- Conselho Nacional de Controle de Experimentação Animal

CT- Ratas controle

DAB- Diaminobenzina

DB- Ratas diabéticas

dL- Decilitro

DT-INS- Ratas diabéticas tratadas com insulina

DT-LNIL- Ratas diabéticas tratadas com L-NIL

DTT- Ditiotreitol

EDTA- Ácido etilenodiaminotetracético

eNOS- Óxido nítrico sintase endotelial

epm- Erro padrão da média

Era- Receptor de estrógeno alfa

Erß- Receptor de estrógeno beta

ESR1- Receptor de estrógeno 1

ESR2- Receptor de estrógeno 2

FSH- Hormônio folículo estimulante

g- Gramas

G-15- $\quad\left(3 a S^{*}, 4 R^{*}, 9 b R^{*}\right)-4-(6-B r o m o-1,3-b e n z-o d i o x o l-5-y l)-3^{a}, 4,5,9 b-3 H-$

cyclopenta[c]quinoline

GAPDH- Gliceraldeído 3-fosfato desidrogenase

GLUT- Transportador de glicose

GPER- Receptor de estrógeno acoplado a proteína $\mathrm{G}$

$\mathrm{H}_{2} \mathrm{O}_{2}$ - Peróxido de hidrogênio

i.p- Intraperitoneal

ICB- Instituto de Ciências Biomédicas

IL-1 $\beta$ - interleucina 1 beta 
iNOS- Óxido nítrico sintase induzível

$\mathrm{IP}_{3}$-Inositol 1,4,5-trifosfato

$\mathrm{KCl}$ - Cloreto de potássio

$\mathrm{KCl}$ - Cloreto de potássio

$\mathrm{Kg}$-Quilogramas

LH- Hormônio luteinizante

L-NIL- N6-(1-iminoethyl)-L-lysine dihydrochoride

LPS- Lipopolissacarídeo

M- Molar

mg- Miligramas

mm- Milímetros

$\mathrm{mM}$ - Milimolar

mmHg- Milímetros de mercúrio

Mn-SOD- Superóxido dismutase mitocondrial

$\mathrm{NaCl}$ - Cloreto de sódio

ng- Nanogramas

nM- Nanomolar

nNOS- Óxido nítrico sintase neuronal

NO- Óxido nítrico

NOA- Nitric oxide analyzer

NOS- Óxido nítrico sintase

$\mathrm{NPH}$ - Neutral protamine Hagedorn

NT- Nitrotirosina

$\mathrm{ONOO}^{-}$- Peroxinitrito

PB- Tampão fosfato

PCR- Reação em cadeia de polimerase

$\mathrm{pD}_{2}$ - Logarítimo negativo da $\mathrm{CE}_{50}$

PFA- Paraformaldeído

pg- Picogramas

PHTPP- (4-[2-Phenyl-5,7-bis(trifluoromethyl-)pyrazolo[1,5-a]pyrimidin-3-yl]phenol

PMSF- Fluoreto de fenilmetil-sulfonil

RMax-Resposta máxima

RNA- Ácido Ribonucléico 
RNAm- Ácido ribonucleico mensageiro rpm- Rotações por minuto

SDS- Dodecil sulfato de sódio

SNO- S-nitrosotiol

UI- Unidades Internacionais

USP-Universidade de São Paulo

vs- Versus

a- alfa

$\mu \mathrm{L}$ - microlitros

$\mu \mathrm{g}$ - microgramas

$\mu \mathrm{M}$ - micromolar

$\mu \mathrm{UI}$ - Micro Unidades Internacionais 
1 INTRODUÇÃO

1.1 Diabetes mellitus e complicações vasculares........................................ 22

1.2 iNOS/geração de NO e alterações vasculares ...................................... 24

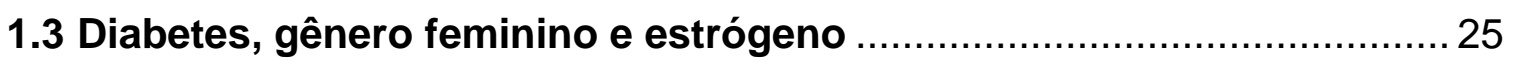

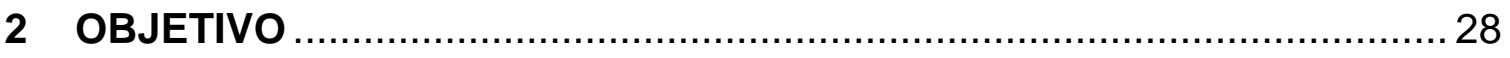

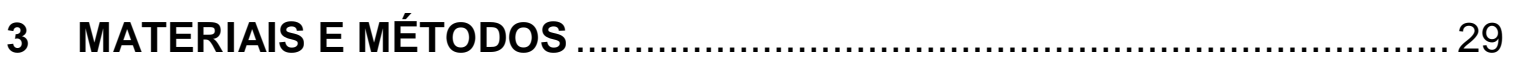

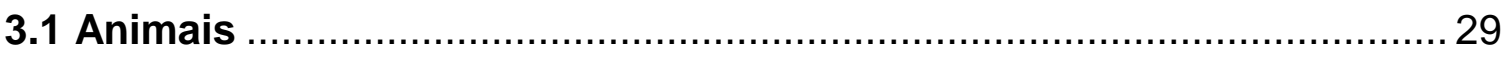

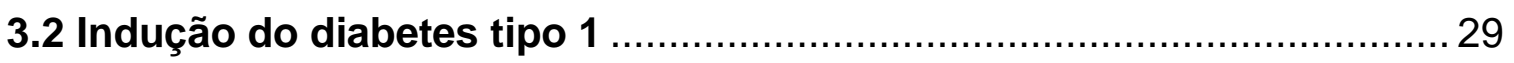

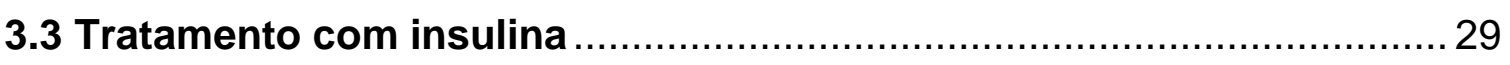

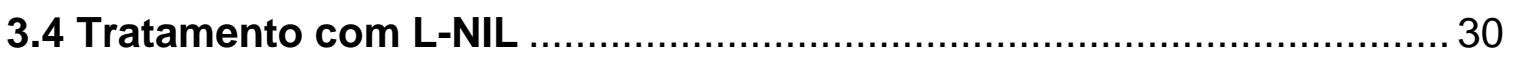

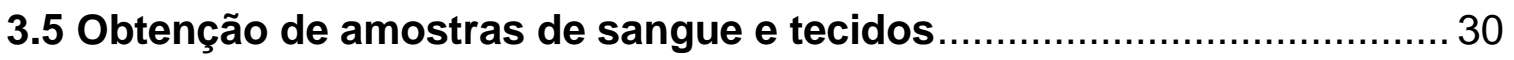

3.6 Caracterização das ratas após $\mathbf{3 0}$ dias da indução do diabetes …......... 31

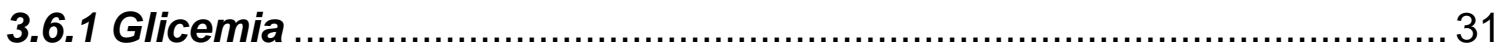

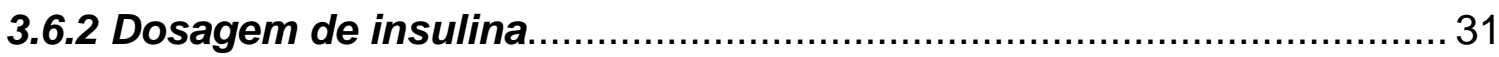

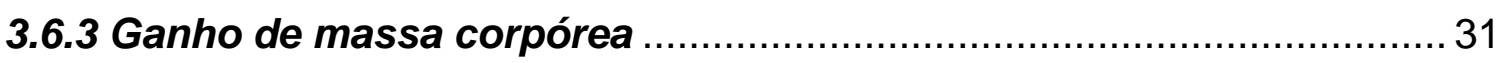

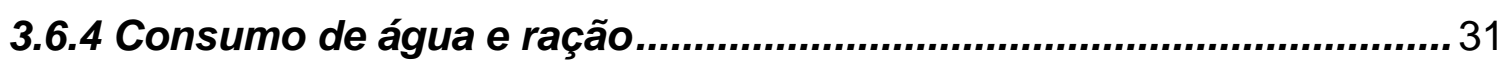

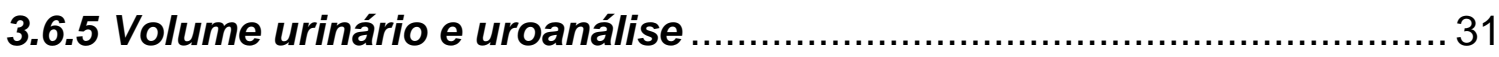

3.7 Massa do útero, estudo do ciclo estral e dosagem de hormônios sexuais

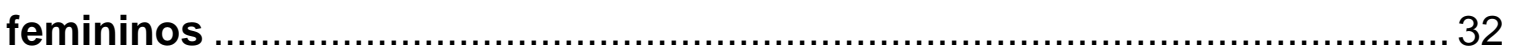

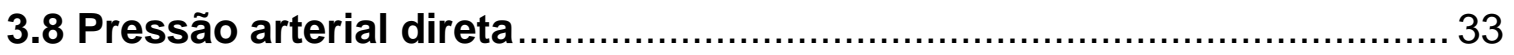

3.9 Dosagem plasmática de óxido nítrico …….......................................... 33

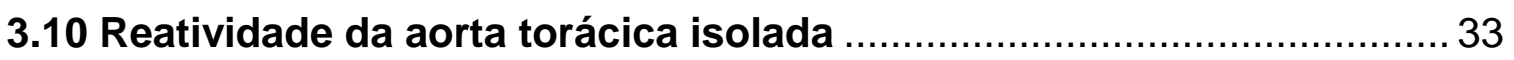

3.10.1 Avaliação da resposta vasoconstritora à noradrenalina ................... 34

3.10.2 Avaliação da resposta vasoconstritora à fenilefrina .......................... 34

3.10.3 Avaliação da resposta vasoconstritora ao cloreto de potássio $(\mathrm{KCl})$. 34

3.10.4 Avaliação da resposta vasoconstritora à noradrenalina na presença de

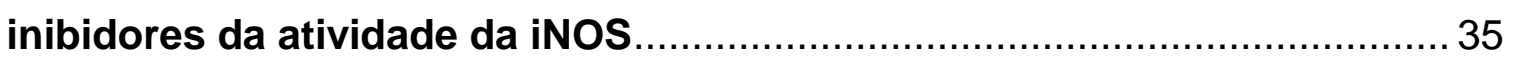

3.10.5 Avaliação da resposta vasoconstritora à noradrenalina na presença do antagonista do receptor para estrógeno ESR2 …................................... 35

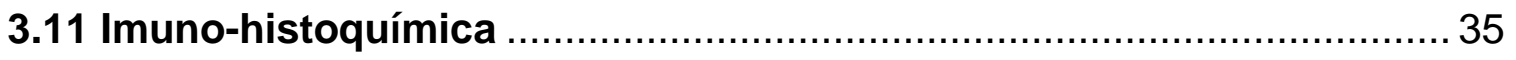

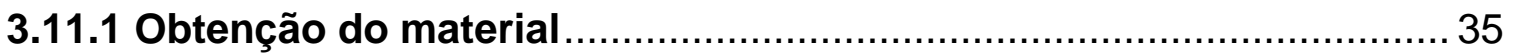


3.11.2 Reação de imunorreatividade 36

3.12 Western blot para receptor de estrógeno GPER e IL-1 $\beta \ldots \ldots \ldots \ldots \ldots \ldots \ldots . . . . . . . . . . .6$

3.13 Western blot para proteínas S-nitrosiladas ..................................... 37

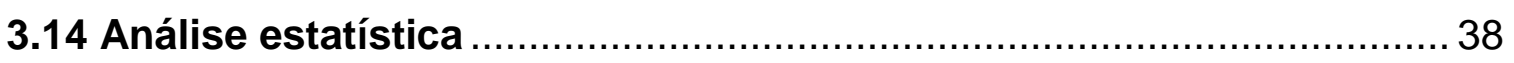

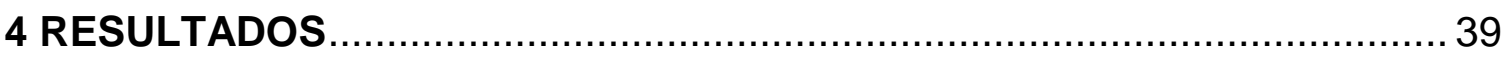

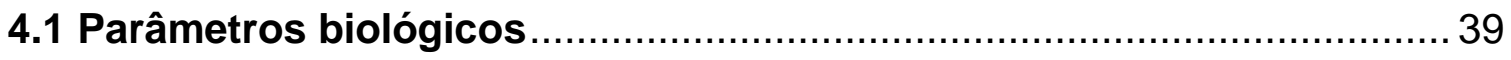

4.2 Glicemia em diferente tempos após a injeção de 2 e 4 UI de insulina NPH

4.3 Parâmetros do ciclo estral e de hormônios sexuais ................................. 43

4.4 Pressão arterial e frequência cardíaca

4.5 Imunorreatividade para a iNOS em aorta de ratas controles, diabéticas, diabéticas tratadas com insulina e diabéticas tratadas com L-NIL 45

4.6 Concentração plasmática de óxido nítrico de ratas controles, diabéticas, diabéticas tratadas com insulina e diabéticas tratadas com L-NIL 46

4.7 Expressão proteica da IL-1 $1 \beta$ em aorta de ratas controles, diabéticas, diabéticas tratadas com insulina e diabéticas tratadas com L-NIL

4.8 Resposta vasoconstritora em aorta de ratas controles, diabéticas e diabéticas tratadas com insulina ......................................................... 48

4.8.1 Resposta vasoconstritora à noradrenalina ...................................... 48

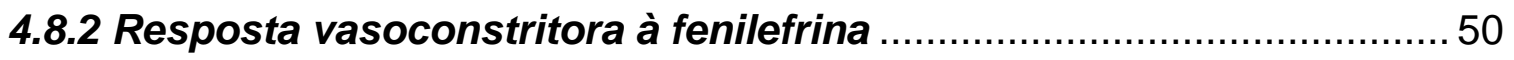

4.8.3 Resposta vasoconstritora ao cloreto de potássio ................................51

4.9 Resposta vasoconstritora à noradrenalina em aorta de ratas controles e diabéticas após a inibição aguda da iNOS

4.10 Resposta vasoconstritora em aorta de ratas controles, diabéticas e diabéticas tratadas cronicamente com L-NIL ............................................5 55

4.10.1 Resposta vasoconstritora à noradrenalina ........................................55

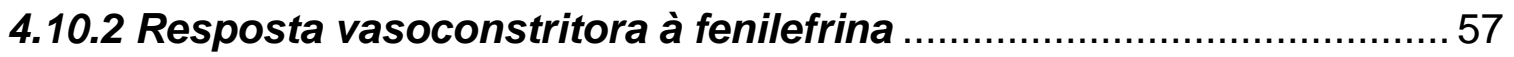

4.10.3 Resposta vasoconstritora ao cloreto de potássio ............................ 58

4.11 Expressão de proteínas S-nitrosiladas em aorta de ratas controles, diabéticas, diabéticas tratadas com insulina e diabéticas tratadas com L-NIL

4.12 Expressão proteica e imunorreatividade do receptor de estrógeno GPER 
4.13 Imunorreatividade para o receptor de estrógeno, ESR2, em aorta de ratas controles, diabéticas e diabéticas tratadas com insulina e diabéticas tratadas com L-NIL 63

4.14 Resposta vasoconstritora à noradrenalina em aorta de ratas controles $\mathrm{e}$ diabéticas após bloqueio agudo do receptor de estrógeno ESR2 ..............64

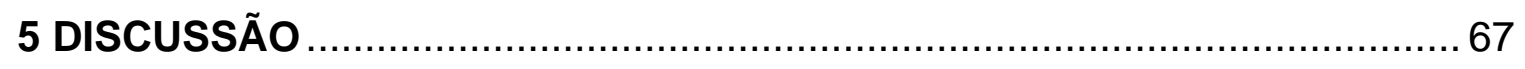

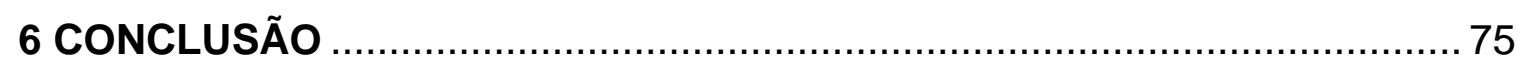

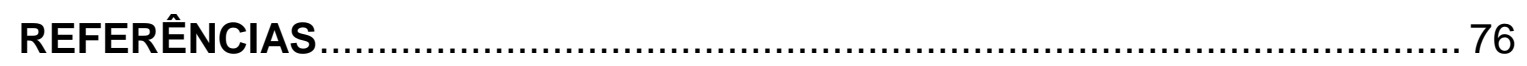

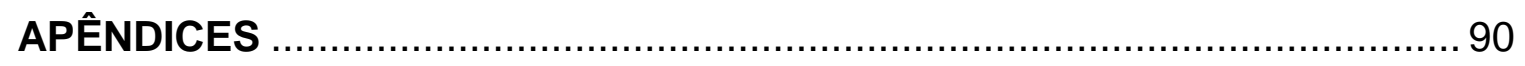

APÊNDICES A- Tabela dos parâmetros metabólicos das ratas diabéticas 15

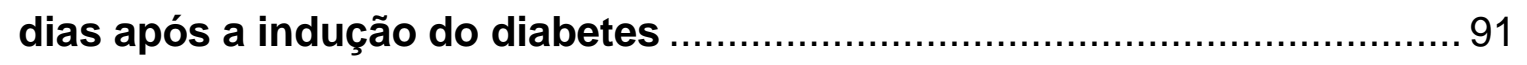

APÊNDICES B- Expressão do RNAm para a iNOS .................................... 92

APÊNDICES C- Expressão do RNAm para os receptores de estrógeno, ESR2 e GPER 


\section{INTRODUÇÃO}

\subsection{Diabetes mellitus e complicações vasculares}

O diabetes mellitus é um conjunto de alterações metabólicas de etiologia múltipla, caracterizada por hiperglicemia crônica e alterações do metabolismo de carboidratos, gorduras e proteínas, como resultado de um defeito da secreção e/ou da ação da insulina nos tecidos-alvo. O diabetes tipo 1 é caracterizado pela ausência completa da produção endógena de insulina. Já no diabetes tipo 2, o aumento da glicose sanguínea resulta da resistência à insulina e deficiência relativa da produção de insulina (RYDÉN et al., 2007).

A Federação Internacional do Diabetes estima que atualmente 382 milhões de pessoas no mundo tenham diabetes e a estimativa é de que no ano 2035 esse número chegue a 592 milhões (INTERNACIONAL DIABETES FEDERATION, 2013). Doenças microvasculares (retinopatia, nefropatia e neuropatia) e macrovasculares (cardíacas, cerebrovasculares e vasculares periféricas) são frequentemente as principais causas de morbidade e mortalidade em pacientes com diabetes tipo 1 e 2 . A disfunção endotelial frequentemente está associada a estas complicações (De VRIESE et al., 2000).

A disfunção endotelial é um desequilíbrio na produção endotelial de mediadores que regulam o tônus vascular, agregação plaquetária, coagulação e fibrinólise. Também é frequentemente referida como redução no relaxamento dependente do endotélio, causada pela redução da biodisponibilidade do óxido nítrico (NO), muito embora a produção de outras substâncias vasoativas derivadas do endotélio, como a prostaciclina, fator hiperpolarizante derivado do endotélio, endotelina, angiotensina II e tromboxano, também possa estar alterada (MOMBOULI; VANHOUTE, 1999).

Redução da vasodilatação dependente do endotélio foi descrita na aorta (CAMERON; COTTER, 1992; HATTORI et al., 1991; NASSAR et al., 2002; PIEPER; PELTIER, 1995; SCHÄFER et al., 2008; TESFAMARIAM et al., 1989; TESFAMARIAM et al., 1993), no leito vascular mesentérico estudado in vitro (HEYGATE et al., 1995; KEEGAN et al., 2000; LINDSAY et al., 1997; PANNIRSELVAM et al., 2002) e na microcirculação mesentérica estudada in vivo (AKAMINE et al., 2003; FORTES et al., 1983a, b, 1984, 1989) de animais diabéticos 
induzidos experimentalmente. Esta alteração também foi demonstrada no corpo cavernoso de homens (SAENZ DE TEJADA et al., 1989) e de ratos (KEEGAN et al., 2000) diabéticos e na artéria braquial de homens diabéticos (KIM et al., 2003). Além disso, aumento da resposta contrátil foi descrita em aorta e artérias mesentéricas (CHANG et al., 1993; HARRIS; MACLEOD, 1988; MACLEOD, 1985; OKON et al., 2003; XAVIER et al., 2003) de ratos diabéticos estudadas in vitro.

Embora redução da resposta vasodilatadora e aumento da contração vascular e da pressão arterial sejam as alterações do diabetes mais observadas (EPENS et al., 2006; KHAMAISI et al., 2003), redução da pressão arterial e da contração vascular foram observadas em pacientes e em modelos experimentais de diabetes tipo 1 do gênero masculino (CHENG; PANG, 2004; GANDO et al., 1997; MAEDA et al., 1995; NAGAREDDY et al., 2006, 2009; REBOLLEDO et al., 2001; RINALDI et al., 2005). Recentemente em nosso laboratório, observamos que a contração do músculo liso em resposta ao cloreto de potássio e à noradrenalina está reduzida em aorta sem endotélio de ratas diabéticas (SARTORETTO et al., 2012).

O aumento da concentração de cálcio intracelular, proveniente do retículo sarcoplasmático é um dos principais processos que inicia a contração vascular induzida por agentes vasoconstritores, sendo que o influxo de cálcio é crítica para manter elevada a concentração do íon e a contração (HIMPENS et al., 1995). Tanto a mobilização do cálcio do estoque intracelular, quanto o influxo de cálcio, em resposta à noradrenalina estão reduzidos em aorta de ratas diabéticas (SARTORETTO, 2009). A expressão e a função do receptor para o inositol 1,4,5trifosfato (IP3) (MA et al., 2008; SHARMA et al., 2003) e dos canais para cálcio dependentes de voltagem tipo L (CARMINES et al., 1996; WANG et al., 2000) estão reduzidas em células do músculo liso de ratos diabéticos.

A fosforilação da cadeia leve da miosina em plaquetas de mulheres diabéticas (GUZMÁN et al., 2001), o conteúdo e a fosforilação da cadeia leve da miosina e o conteúdo da cinase da cadeia leve da miosina nos cardiomiócitos de ratos diabéticos (LIU et al., 1997) estão reduzidos. A exemplo do que ocorre em outros tipos celulares, o conteúdo das proteínas contráteis de células do músculo liso vascular e a sensibilidade dessas proteínas ao cálcio também poderiam sofrer alterações induzidas pelo diabetes e contribuir para a redução da contração vascular. 


\section{2 iNOS/geração de NO e alterações vasculares}

O NO é produzido pela enzima óxido nítrico sintase (NOS). Existem três isoformas da NOS: a NOS neuronal (NOS I ou nNOS), a NOS induzível (NOS II ou iNOS) e a NOS endotelial (NOS III ou eNOS), as quais foram originalmente encontradas no cérebro, macrófagos e endotélio, respectivamente. A eNOS e nNOS são isoformas constitutivas (cNOS), já a expressão da iNOS é induzida por citocinas pró-inflamatórias e por alta concentração de glicose (CUNHA et al., 1994; PACHECO et al., 2006; TER STEEGE et al., 1998). As cNOS são reguladas pelo complexo cálcio $\left(\mathrm{Ca}^{2+}\right)$-calmodulina e produzem $\mathrm{NO}$ de maneira controlada, por curto período (segundos até minutos) e em pequena quantidade (nanomolares). Diferentemente das cNOS, a ativação da iNOS é independente de cálcio e produz NO por longo tempo (horas e dias) e em maior quantidade (micromolares) (BIAN; MURAD, 2003). O NO derivado da eNOS é importante mediador da vasodilatação, regulando o fluxo sanguíneo regional aos tecidos (FURCHGOTT, 1999). Por outro lado, a ativação da iNOS, é danosa para o sistema cardiovascular, pois essa enzima produz alta concentração de NO, promovendo redução da contração do músculo liso vascular, como resultado do aumento da produção de GMPc e da diminuição da concentração do cálcio intracelular (MACMICKING et al., 1995; MONCADA et al., 1991; THIEMERMANN, 1994), e intensa vasodilatação (PARRILLO et al., 1993).

A elevada concentração de NO pode promover modificações pós-tradução de proteínas, como nitração e s-nitrosilação (MARTíNEZ-RUIZ et al., 2011). NO e ânion superóxido são altamente reativos e rapidamente formam peroxinitrito (ISCHIROPOULOS, 1998). A nitração de proteínas é mediada principalmente pelo peroxinitrito, que promove nitração dos resíduos de tirosina (TURKO; MURAD, 2002). Esta reação envolve a incorporação de um grupo nitro (-NO2) no anel fenólico de resíduos de tirosina, para formar o resíduo 3-nitrotirosina (MARTINEZ-RUIZ et al., 2011). O peroxinitrito não é o único a promover a nitração de proteínas, entretanto, este é o principal mecanismo in vivo (VAN DER VLIET et al., 1995), fazendo com que a presença de nitrotirosina seja considerada uma evidência indireta da produção de peroxinitrito (CERIELLO, 2002). Já a s-nitrosilação ocorre pela adição de NO ao grupo tiol de uma cisteína para gerar um s-nitrosotiol (STAMLER et al. 1992). Além do NO, a nitroxila e o peroxinitrito também podem s-nitrosilar proteínas (FOSTER et 
al., 2003; FOSTER et al., 2009). Diferentemente da nitração, que é uma modificação irreversível, a s-nitrosilação é reversível (MARTíNEZ-RUIZ et al., 2011).

Uma vez que as proteínas são nitradas ou s-nitrosiladas, suas funções podem ser alteradas (WU; WILSON, 2009; ZOU, 2007). Por exemplo, a nitração de um único resíduo de tirosina da superóxido dismutase mitocondrial (Mn-SOD) inibiu completamente a sua atividade (MACMILLAN-CROW; THOMPSON, 1999). Em outro trabalho, observou-se que quando a PKC foi s-nitrosilada, sua atividade foi reduzida ( $\mathrm{CHOl}$ et al., 2011). Nestes trabalhos observou-se o efeito da nitração ou snitrosilação induzidas in vitro. No entanto, patologias como o diabetes, também podem induzir nitração ou s-nitrosilação in vivo de diferentes proteínas e que podem acarretar em prejuízo de suas funções (CARVALHO-FILHO et al., 2005; KELLYCOBBS et al., 2012; Ll et al., 2010; XU et al., 2012).

Aumento na expressão da iNOS foi observado no coração e nas camadas média e adventícia de aorta e artérias mesentéricas de ratos diabéticos (NAGAREDDY et al., 2005, 2009). A inibição aguda da iNOS corrigiu a redução da resposta pressórica (CHENG; PANG, 2004; NAGAREDDY et al., 2005) e da contração da artéria mesentérica (BARDELL; MACLEOD, 2001) à noradrenalina em ratos diabéticos. Esses dados sugerem que o NO proveniente da iNOS é diretamente responsável pela redução dessas respostas nos ratos diabéticos. Além disso, formação de peroxinitrito também parece estar envolvida na redução da pressão arterial média, frequência cardíaca e resposta pressórica à metoxamina, pois inibição da iNOS corrigiu esses parâmetros e reduziu a expressão de nitrotirosina no coração e na parede de artéria mesentérica superior em ratos diabéticos (NAGAREDDY et al., 2009).

\subsection{Diabetes, gênero feminino e estrógeno}

As alterações vasculares e os mecanismos pelos quais o diabetes leva a essas alterações são estudados principalmente em machos, porém esses mecanismos podem não ser os mesmos em fêmeas.

Mulheres na pré-menopausa têm menor risco de desenvolver doença cardiovascular quando comparadas com homens da mesma idade e mulheres na pós-menopausa (BARRETT-CONNOR; KNEPPER et al., 1995; SOWERS et al., 1998; WINGARD, 1983). Estes estudos mostram que mulheres parecem ter uma 
proteção vascular durante a pré-menopausa e um efeito benéfico do estrógeno sobre o sistema vascular pode estar relacionado. Entretanto, quando comparamos mulheres e homens com diabetes, mulheres diabéticas mostram maior chance de morte por doença cardiovascular do que homens diabéticos (LEGATO et al., 2006). Além disso, aorta de fêmeas incubadas em meio contendo alta concentração de glicose (GOEL et al., 2007, 2008) e artéria basilar (MAYHAN et al., 2002) e arteríolas mesentéricas (TOLEDO et al., 2003) de fêmeas diabéticas apresentam menor vasodilatação à acetilcolina do que em machos. Esses dados mostram que no diabetes e em estado de alta concentração de glicose, as fêmeas perdem a proteção dos hormônios sexuais femininos. De fato, a redução da função endotelial em aorta de ratas diabéticas ovariectomizadas não é corrigida pela reposição com estrógeno (BOLEGO et al., 1999). Dessa maneira, abolindo o efeito protetor do estrógeno, o diabetes poderia comprometer mais e diferentemente os leitos vasculares de indivíduos do sexo feminino do que do masculino (HU, 2003).

As ações biológicas do estrógeno são mediadas pela combinação da ativação dos receptores clássicos para estrógeno, ESR1(ERa) e ESR2 (ERß), e do receptor para estrógeno acoplado à proteína G, GPER (REVANKAR et al., 2005), que são capazes de mediar os eventos de sinalização rápidos e os de transcrição. Os receptores clássicos para estrógeno pertencem à superfamília dos fatores de transcrição ativados por ligantes. Os ESR1 e ESR2 são amplamente distribuídos nos tecidos cardiovasculares, incluindo células endoteliais, do músculo liso e miocárdicas (BOLEGO et al., 2006). A geração de camundongos com deleção do ESR1 e ESR2 tem contribuído para o conhecimento do papel específico destes subtipos no sistema cardiovascular (HEWITT et al., 2005). O ESR1 parece mediar as principais ações cardioprotetoras do estrógeno, incluindo uma ação não-genômica sobre a vasodilatação (BOLEGO et al., 2005). Tratamento com estrógeno aumenta a produção basal de NO somente em aorta de camundongos que expressam funcionalmente o ESR1 (DARBLADE et al., 2002). Além disso, a ativação do ESR1 promove inibição da expressão de fatores inflamatórios, como a iNOS (VEGETO et al., 2001). Já a ativação do ESR2 induz a expressão da iNOS no músculo liso vascular de ratos (CIGNARELLA et al., 2006). Assim, tem sido sugerido que o efeito cardioprotetor induzido pelo estrógeno é mediado pelo subtipo ESR1, enquanto que a expressão do subtipo ESR2 pode ser induzida por injúrias. O GPER também parece ter uma ação cardioprotetora. Foi demonstrado que um agonista específico 
para GPER promoveu vasodilatação em artérias mesentéricas de ratos e carótidas de camundongos (HAAS et al., 2009).

Maggi e colaboradores (2003) mostraram que o diabetes aumenta a expressão dos receptores de estrógeno nas células do músculo liso vascular, sendo que o aumento do ESR2 é muito mais pronunciado do que o de ESR1, e que o estrógeno aumenta a expressão da iNOS nessas células. Considerando que a alta concentração de NO produzida pela iNOS e o seu produto da reação com ânion superóxido são citotóxicos (MARSHALL et al., 2000), aumento da expressão do ESR2 poderia explicar a perda da proteção cardiovascular do estrógeno na fêmea diabética.

A reposição de insulina restaurou a resposta vasoconstritora reduzida ao cloreto de potássio e à noradrenalina em aorta de ratos diabéticos (KOBAYASHI; KAMATA, 1999). O tratamento com insulina também restaurou a redução da contratilidade cardíaca, da expressão do conteúdo e fosforilação da cadeia leve da miosina e da cinase da cadeia leve da miosina nos cardiomiócitos de ratos diabéticos (LIU et al., 1997). Nos dois estudos só foi possível observar um efeito da insulina em aumentar a contratilidade vascular e cardíaca, quando a glicemia foi normalizada. As ações da insulina não são restritas apenas ao metabolismo de carboidratos, proteínas e lipídeos. A insulina possui ações importantes no eixo hipotálamo-hipófise-gônadas, interferindo com a concentração dos hormônios sexuais e a função do sistema reprodutor. Isso explica o fato de mulheres diabéticas apresentarem alterações no sistema reprodutor, incluindo redução da concentração de hormônio folículo estimulante (FSH), hormônio luteinizante (LH), estrógeno, progesterona, ausência de ovulação, dificuldade de engravidar e de manter a gravidez (ZARZYCKI; ZIENIEWICZ, 2005). Portanto, em fêmeas diabéticas, tanto os efeitos metabólicos quanto os efeitos da insulina sobre a regulação dos esteroides sexuais podem ter influência nas alterações vasculares. 


\section{OBJETIVO}

Redução da contração vascular é observada em ratos diabéticos e tratamento de ratos diabéticos com insulina corrige a contratilidade vascular. Aumento da expressão da iNOS/geração de NO contribui para a redução da resposta pressórica induzida por infusão de agonistas adrenérgicos. Em nosso laboratório, observamos redução da capacidade contrátil em aorta de ratas diabéticas, mas os mecanismos que levam a essa alteração não foram estudos. Os mecanismos pelos quais o diabetes leva a alterações vasculares e os efeitos vasculares da reposição de insulina podem ser diferentes em machos e fêmeas, isso porque o diabetes altera 0 padrão de expressão vascular dos receptores de estrógeno, que possuem ações vasculares diferenciadas. Além disso, insulina regula a concentração de esteroides sexuais, mas o efeito da insulina sobre a expressão dos receptores de estrógeno não é conhecido. Assim, o objetivo deste trabalho foi investigar se em ratas diabéticas o aumento da expressão da iNOS/geração de NO pode ser responsável pela redução da contração vascular, assim como, o efeito do tratamento com insulina sobre a contratilidade vascular e a expressão de receptores de estrógeno em aorta de ratas diabéticas. 


\section{MATERIAIS E MÉTODOS}

\subsection{Animais}

Ratas Wistar, de 8-10 semanas, pesando de 180 a $200 \mathrm{~g}$ no início dos experimentos foram provenientes do Biotério do Departamento de Farmacologia do Instituto de Ciências Biomédicas (ICB) da Universidade de São Paulo (USP). As ratas tiveram livre acesso à água e ração e foram mantidas em sala com temperatura e umidade constantes $\left(24^{\circ} \mathrm{C} / 60 \%\right)$, com ciclos claro/escuro de 12/12 horas. Os procedimentos foram aprovados pela Comissão de Ética no Uso de Animais (CEUA) do ICB-USP sob o número 007/04/CEUA e estão de acordo com os Princípios Éticos na Experimentação Animal, do Conselho Nacional de Controle de Experimentação Animal (CONCEA).

Grupos experimentais:

Grupo 1 - Controle

Grupo 2 - Diabética

Grupo 3 - Diabética tratada com insulina

Grupo 4 - Diabética tratada com L-NIL

\subsection{Indução do diabetes tipo 1}

Após restrição alimentar de 15 horas, o diabetes mellitus foi induzido por injeção intravenosa (veia caudal) de aloxana (40 mg/kg) (Sigma Aldrich, St. Louis, MO, EUA) dissolvida em solução salina (cloreto de sódio 0,9\%). Este período de restrição alimentar é essencial para que o diabetes seja induzido, pois a aloxana compete pelo mesmo transportador da glicose, GLUT 2, para entrar nas células $\beta$ pancreáticas (JORNS et al., 1997). Ratas do grupo controle receberam igual volume de solução salina. Ratas que apresentaram glicemia $\geq 200 \mathrm{mg} / \mathrm{dL}$ foram utilizadas no presente estudo.

\subsection{Tratamento com insulina}

O tratamento com insulina NPH (Novo Nordisk A/S, Bagsvaerd, Dinamarca) 
(insulina de ação intermediária) foi iniciado 15 dias após a indução do diabetes. Ratas diabéticas receberam, durante 15 dias, 6 UI de insulina NPH divididas em duas doses diárias: 2 UI entre as 8:00 e 10:00 horas e $4 \mathrm{UI}$ entre as 16:00 e 18:00 horas.

Este esquema de tratamento foi escolhido em ensaios prévios (dados não mostrados). O tipo e a dose de insulina foram aqueles que, embora não normalizasse completamente a glicemia, tivesse efeito sobre a contração vascular.

\subsection{Tratamento com L-NIL}

Após 72 horas da indução do diabetes, período necessário para que ocorra aumento da glicemia (FORTES et al., 1983), ratas diabéticas foram tratadas com um inibidor da iNOS, L-NIL (N6-(1-iminoethyl)-L-lysine dihydrochoride, Cayman Chemical Company, Ann Arbor, MI, EUA), na dose de $3 \mathrm{mg} / \mathrm{kg} / \mathrm{dia}$ (SOLIMAN et al., 2008; NAGARREDY et al., 2009), por gavagem, durante 4 semanas. O L-NIL é um potente e relativamente seletivo inibidor da iNOS, com $\mathrm{CE}_{50}$ (concentração necessária para produzir $50 \%$ do efeito máximo) de $5,9 \mu \mathrm{M}$ para iNOS comparado a CE50 de $138 \mu \mathrm{M}$ para eNOS e $35 \mu \mathrm{M}$ para nNOS (HALLINAN et al., 2002).

\subsection{Obtenção de amostras de sangue e tecidos}

No $30^{\circ}$ dia da indução do diabetes, 15 horas após a última dose de insulina e 4 horas de restrição alimentar, ratas dos 4 grupos experimentais foram anestesiadas com tiopental $(50 \mathrm{mg} / \mathrm{kg}$ ), por via intraperitoneal, e sofreram laparatomia. Amostra de sangue foi retirada pela aorta abdominal e o útero foi removido. O sangue foi centrifugado a $3000 \mathrm{rpm}$ por 15 minutos para separação do soro, que foi armazenado em freezer $-80^{\circ} \mathrm{C}$. Para um lote de animais, o sangue foi coletado em tubos contendo EDTA para obtenção do plasma, que foi armazenado em freezer - 80 ${ }^{\circ} \mathrm{C}$.

Para obtenção da aorta torácica, os mesmos procedimentos acima foram adotados, com exceção da restrição alimentar, e, após anestesia, toracotomia foi realizada e o segmento torácico da aorta foi removido. Este segmento foi imediatamente colocado em solução de Krebs-Henseleit modificada (composição em mM: glicose 5; cloreto de sódio 130; sulfato de magnésio 1,17 ; fosfato de potássio 
1,18; bicarbonato de sódio 14,9; cloreto de potássio 4,7; cloreto de cálcio 1,56 e EDTA 0,026) e dissecado, removendo-se o tecido adiposo e conectivo. Aorta torácica foi manipulada de acordo com as técnicas descritas abaixo.

\subsection{Caracterização das ratas após 30 dias da indução do diabetes}

\subsubsection{Glicemia}

A glicemia foi avaliada após restrição alimentar de 4 horas e após 15 horas da última injeção de insulina, utilizando-se glicosímetro Advantage ${ }^{\circledR}$ (Roche, Mannheim, Alemanha), em amostras de sangue obtidas por punção da extremidade da cauda. Em um lote de ratas diabéticas tratadas com insulina, a glicemia foi avaliada em diferentes tempos após a injeção de 2 e 4 UI de insulina NPH. A glicemia foi determinada imediatamente antes (inicial) e 1, 2, 4, 5, 6 e 8 horas após a injeção de $2 \mathrm{UI}$ de insulina NPH. Após a determinação da glicemia na $8^{\circ}$ hora, $4 \mathrm{UI}$ de insulina $\mathrm{NPH}$ foi administrada e a glicemia foi determinada 1, 2, 4 e 6 horas após essa injeção.

\subsubsection{Dosagem de insulina}

A concentração de insulina foi determinada por radioimunoensaio (Rat Insulin RIA Kit, Linco, St Charles, MO, EUA). O limite de detecção do kit é de 1,2 $\mu \mathrm{UI} / \mathrm{mL}$.

\subsubsection{Ganho de massa corpórea}

As ratas foram pesadas no dia e 30 dias após a indução do diabetes. O ganho de massa foi calculado pela diferença entre a massa inicial (no dia da indução) e final (30 dias após a indução). 


\subsubsection{Consumo de água e ração}

Ratas dos 4 grupos experimentais foram colocadas em gaiolas metabólicas individuais e receberam volume de água e quantidade de ração determinados. $\mathrm{O}$ consumo de água e ração foram determinados pela diferença do volume e da quantidade iniciais pelos remanescentes após 24 horas.

\subsubsection{Volume urinário e uroanálise}

A urina de ratas mantidas em gaiolas metabólicas durante 24 horas foi coletada em Becker e o volume foi determinado em proveta graduada. Foram utilizadas tiras reativas para uroanálise Keto-Diastix® (Bayer Diagnóstica, São Paulo, Brasil) na determinação da glicosúria e cetonúria em urina de 24 horas.

\subsection{Massa do útero, estudo do ciclo estral e dosagem de hormônios sexuais femininos}

Após remoção dos ovários e gordura, a massa total (no momento da retirada do tecido) e a massa seca (após 24 horas de secagem em estufa a $37^{\circ} \mathrm{C}$ ) dos úteros foram determinadas. $O$ ciclo estral foi avaliado por meio do esfregaço vaginal. As células do esfregaço vaginal foram observadas em microscópio óptico. As alterações celulares cíclicas no aparelho reprodutor feminino são refletidas na secreção vaginal e, assim, o exame celular dessa secreção permite diferenciar as diversas fases do ciclo estral (MARCONDES et al.; 2002).

As concentrações dos hormônios estradiol e progesterona foram determinadas no soro utilizando-se kit de radioimunoensaio (Siemens Healthcare Diagnostic, Los Angeles, CA, EUA). Os limites de detecção dos kits de estradiol e progesterona são $8 \mathrm{pg} / \mathrm{mL}$ e $0,02 \mathrm{ng} / \mathrm{mL}$, respectivamente.

Uma vez que as ratas diabéticas param de ciclar e permanecem constantemente em diestro, as ratas de todos os grupos estavam na fase diestro para a avaliação destes parâmetros. 


\subsection{Pressão arterial direta}

Dezoito horas após a última dose de insulina, ratas controles, diabéticas, diabéticas tratadas com insulina e diabéticas tratadas com L-NIL foram anestesiadas com uma mistura de cetamina e xilasina (90 e $5 \mathrm{mg} / \mathrm{kg}$, respectivamente, i.p.) e um cateter de polietileno (PE-10), preenchido com uma solução de salina e heparina (1:10), foi introduzido na carótida direita e exteriorizado no dorso do animal. Vinte e quatro horas após a inserção do cateter, o mesmo foi conectado ao transdutor de pressão (Deltran DPT-100, Utah medical products, Midvale, EUA), que estava ligado a um amplificador (ML224 Quad Bridge Amp, ADInstruments, NWS, Austrália), que por sua vez, estava acoplado a um sistema digital de aquisição de dados (PowerLab, ADInstruments, NWS, Austrália) para aquisição dos registros de pressão arterial e frequência cardíaca.

\subsection{Dosagem plasmática de óxido nítrico}

A concentração plasmática de $\mathrm{NO}$ foi determinada pela dosagem de nitrito e nitrato, utilizando o aparelho de Sievers Nitric Oxide Analyzer (NOA 280, GE Analytical Instruments, Boulder, Colorado, EUA). Para medir o nitrito e nitrato, o vaso de purga continha um agente redutor ( $1 \%$ de iodeto de potássio em ácido acético glacial) para converter nitrito e nitrato a NO. O NO produzido foi carregado para o NOA, onde este reagiu com o ozônio, formando dióxido de nitrogênio, a emissão associado é proporcional à quantidade de NO presente na amostra.

\subsection{Reatividade da aorta torácica isolada}

Aorta torácica, que foi obtida como descrito anteriormente, foi seccionada em anéis transversais de $4 \mathrm{~mm}$. O endotélio foi removido mecanicamente com uma haste metálica fina envolta em algodão. Os anéis de aorta foram suspensos por um par de ganchos de aço inoxidável, sendo que um gancho era fixado à base da cuba de vidro, para estudo de órgão isolado, e o outro conectado a um transdutor de força (TRI201-PAD; Panlab, Barcelona, Espanha). O transdutor foi conectado a um sistema de aquisição de dados (Power Lab, ADInstruments). As cubas de vidro 
foram preenchidas com $10 \mathrm{~mL}$ de solução de Krebs-Henseleit gaseificada com mistura de $95 \%$ de $\mathrm{O}_{2}$ e $5 \%$ de $\mathrm{CO}_{2}$ e mantida aquecida a $37 \pm 0,5{ }^{\circ} \mathrm{C}$ durante todo o protocolo experimental. As preparações permaneceram sob tensão de $1,5 \mathrm{~g}$ por um período de 60 minutos para estabilização, com trocas de solução nutriente e ajuste de tensão a cada 20 minutos.

\subsubsection{Avaliação da resposta vasoconstritora à noradrenalina}

Após o período de estabilização de 60 minutos, curvas concentração resposta foram realizadas com solução de noradrenalina (Sigma Aldrich) em concentrações crescentes (10 nM a $30 \mu \mathrm{M})$ de maneira cumulativa, com intervalos de 3 minutos entre cada concentração, tempo necessário para a estabilização da resposta contrátil.

\subsubsection{Avaliação da resposta vasoconstritora à fenilefrina}

Após o período de estabilização de 60 minutos, curvas concentração resposta foram realizadas com solução de fenilefrina (Sigma Aldrich) em concentrações crescentes (100 nM a $30 \mu \mathrm{M})$ de maneira cumulativa, com intervalos de 3 minutos entre cada concentração, tempo necessário para a estabilização da resposta contrátil.

\subsubsection{Avaliação da resposta vasoconstritora ao cloreto de potássio (KCl)}

Após o período de estabilização de 60 minutos, curvas concentração resposta foram realizadas com solução de $\mathrm{KCl}$ em concentrações crescentes (1 a $108 \mathrm{mM}$ ) de maneira cumulativa, com intervalos de 5-8 minutos entre cada concentração, tempo necessário para a estabilização da resposta contrátil. 


\subsubsection{Avaliação da resposta vasoconstritora à noradrenalina na presença de inibidores da atividade da iNOS}

Após o período de estabilização de 60 minutos, os inibidores da atividade da iNOS L-NIL $(10 \mu \mathrm{M}) \quad$ (ZOCRATO et al., 2010) ou $1400 \mathrm{~W}$ (N-[[3(aminomethyl)phenyl]methyl]-ethanimidamide, dihydrochloride; Cayman Chemical) $(10 \mu \mathrm{M})$ (ALVAREZ et al., 2008) foram adicionados ao banho, 30 minutos antes do início da curva concentração resposta à noradrenalina.

\subsubsection{Avaliação da resposta vasoconstritora à noradrenalina na presença do antagonista do receptor para estrógeno ESR2}

Após o período de estabilização de 60 minutos, o antagonista do receptor para estrógeno ESR2 PHTPP (4-[2-Phenyl-5,7-bis(trifluoromethyl-)pyrazolo[1,5a]pyrimidin-3-yl]phenol; Tocris Bioscience Joins R\&D Systems, Minneapolis, MN, EUA), nas concentrações $0,1,1$ e $10 \mu \mathrm{M}$, foi adicionado ao banho, 30 minutos antes do início da curva concentração resposta para noradrenalina.

\subsection{Imuno-histoquímica}

\subsubsection{Obtenção do material}

Um segmento de aorta $(5 \mathrm{~mm})$ foi imerso na solução fixadora paraformaldeído $4 \%$ por 6 horas. Após a fixação, os segmentos de aorta foram desidratados com concentrações crescentes de álcool (70, 85, 95 e 100\%, banhos de 15 minutos), diafinizados em banhos de xilol (2-3 minutos cada) e emblocados em parafina. Cortes transversais $(8 \mu \mathrm{M})$ não seriados foram obtidos em micrótomo (Leica, Berlin, Alemanha) e colocados em lâminas tratadas com poli-L-lisina (Sigma-Aldrich). Em seguida, os cortes foram desparafinizados em banhos de xilol e hidratados em banhos de álcool em concentrações decrescentes (100, 95, 85 e 70\%). A recuperação antigênica foi realizada com tampão citrato $(0,01 \mathrm{M}, \mathrm{pH}$ 6) para 0 ESR2, GPER e iNOS. 


\subsubsection{Reação de imunorreatividade}

Os anticorpos primários anti-ESR2 (Millipore, Billerica, MA, EUA) (1:100), antiGPER (Thermo Fisher Scientific, Waltham, MA, EUA) (1:100) e anti-iNOS (Abcam, Cambridge, Reino Unido) (1:100) foram diluídos em tampão fosfato (PB 0,1 M) contendo $0,3 \%$ de Tween 20 e $5 \%$ de soro normal de cabra (anti-ESR2, GPER e iNOS) e colocados sobre os cortes de aorta para incubação por um período de aproximadamente 18 horas a $4{ }^{\circ} \mathrm{C}$. Paralelamente, foram realizadas reações controles substituindo-se o anticorpo primário por PB 0,1 M contendo 0,3\% de Tween 20 e $5 \%$ de soro normal de cabra (anti-ESR2, GPER e iNOS).

Após 18 horas, os cortes foram lavados com PB e incubados por uma hora com anticorpo secundário, anti-rabbit (ESR2, GPER e iNOS), conjugados com biotina (Vector Laboratories, Burlingame, CA, EUA), na diluição 1:1000, em câmara úmida, à temperatura ambiente. Após a incubação, os cortes de aorta foram lavados novamente em PB e incubados em câmara úmida com solução do kit $A B C$ Vectastain (Vector Laboratories, Burlingame, CA, EUA) por uma hora, à temperatura ambiente. A revelação da imunorreatividade foi realizada com DAB (diaminobenzina, $0,5 \mathrm{mg} / \mathrm{mL}$-Sigma Aldrich) e $\mathrm{H}_{2} \mathrm{O}_{2}$ 0,06\%.

Cinco campos de cada corte foram fotografados, sendo que para cada animal analisou-se 3 cortes. A densidade óptica da imunorreatividade foi determinada na camada média dos cortes de aorta utilizando-se o programa Image J (NIH, EUA).

\subsection{Western blot para receptor de estrógeno GPER e IL-1 $\beta$}

Segmentos de aorta foram congelados e triturados em nitrogênio líquido e homogeneizados em tampão contendo Triton-X-100 (1\%), Tris (100 mM, pH 7,4), pirofosfato de sódio $(100 \mathrm{mM})$, fluoreto de sódio $(100 \mathrm{mM})$, EDTA $(10 \mathrm{mM})$, ortovanadato de sódio (10 mM), PMSF $(2 \mathrm{mM})$ e aprotinina $(0,01 \mathrm{mg} / \mathrm{mL})$.

Os extratos teciduais foram centrifugados a $10000 \mathrm{~g}$ a $4{ }^{\circ} \mathrm{C}$ por 30 minutos para a remoção do material insolúvel. Após a centrifugação, o conteúdo proteico total foi quantificado pelo método de BCA (Thermo Fischer). O sobrenadante foi tratado com tampão de Laemmli (BioRad, Hercules, CA, EUA) contendo ditiotreitol (DTT) $(100 \mathrm{mM})$, aquecido em banho seco a $100{ }^{\circ} \mathrm{C}$ por 5 minutos, e $50 \mu \mathrm{g}$ de 
proteínas totais foram submetidas à eletroforese em gel de poliacrilamida (SDSPAGE, 12\%).

A transferência das proteínas separadas no gel foi feita eletricamente para uma membrana de PVDF (GE-Armshan), por 1 hora e 30 minutos a 100 V. Após a transferência, verificou-se a eficiência da transferência e, para tal, a membrana foi incubada em ácido acético (1\%) por 5 minutos, seguida de incubação com o corante Ponceau por 20 minutos e nova incubação com ácido acético (1\%) por 5 minutos. Após lavagem com água destilada e TBS-T (Tris 10 mM, NaCl 150 mM e Tween 20 0,02\%), a membrana foi incubada com solução bloqueadora constituída de albumina (5\%) (Sigma Aldrich) em TBS-T por 2 horas em temperatura ambiente, para reduzir a ligação inespecífica dos anticorpos. Em seguida, a membrana foi lavada com TBST por 30 minutos e, então, incubada com anticorpo anti-GPER (Thermo Fisher Scientific) (1:1000) ou anti-IL-1 $\beta$ (BioLegend, San Diego, CA, EUA) (1:750) por 12 horas a $4{ }^{\circ} \mathrm{C}$. O anticorpo secundário conjugado com peroxidase, anti-rabbit (1:2000) para o GPER e anti-hamster (1:2000) para a IL-1 $\beta$, foi incubado por 1 hora e 30 minutos em temperatura ambiente e, logo após, com a solução de quimioluminescência, como descrito no protocolo do kit (Thermo Fisher Scientific). A emissão de luz foi detectada e visualizada em filmes radiográficos. A intensidade das bandas foi quantificada por densitometria óptica utilizando-se programa de análise de imagens (Image J). Essa intensidade foi normalizada pela intensidade de bandas coradas com o corante Ponceau conforme descrito por Romero-Calvo e colaboradores (2010).

\subsection{Western blot para proteínas S-nitrosiladas}

O endotélio de segmentos de aorta torácica foi removido mecanicamente com uma haste metálica fina envolta em algodão e imediatamente congelados em nitrogênio líquido e mantidos a $-80^{\circ} \mathrm{C}$ até o processamento. $\mathrm{O}$ método biotina-switch para detectar proteínas s-nitrosiladas foi feito com um kit comercial (Cayman Chemical) modificado a partir do método de Jaffrey e Snyder (2001). Esta técnica consiste em substituir grupo nitrosotiol ligado a resíduos de cisteína com biotina. Para tanto, grupos tióis livres foram bloqueados e, em seguida, promove-se clivagem dos grupos nitrosotióis em tiol livre e marcação dos tióis livres recémformados com biotina. 
Após a extração, foi realizado Western blot, como descrito anteriormente no item anterior, com a diferença que $30 \mu \mathrm{g}$ de proteínas foram aplicadas no gel SDSPAGE e a membrana utilizada foi de nitrocelulose (Millipore). Após bloqueio, a membrana foi lavada e, então, incubada com reagente de detecção de proteínas snitrosiladas, diluído em $2 \%$ de albumina bovina (1:150) durante 12 horas. Após a incubação, a membrana foi lavada $e$ incubada com a solução de quimioluminescência, como descrito no protocolo do kit (Thermo Fisher Scientific). A emissão de luz foi detectada e visualizada em filmes radiográficos. A intensidade das bandas foi quantificada por densitometria óptica utilizando-se programa de análise de intensidade de bandas (Image J). As mesmas membranas foram utilizadas para verificar a expressão da $\alpha$-actina (1:10000, Sigma Aldrich), que foi usada para normalizar a expressão de proteínas nitrosiladas.

\subsection{Análise estatística}

A resposta máxima ( $\mathrm{R}_{\mathrm{Max}}$ ), em gramas de tensão, e a concentração do agonista que induz metade da resposta máxima ( $\left.C E_{50}\right)$, expressa como -log $\mathrm{CE}_{50}$ $\left(\mathrm{pD}_{2}\right)$, foram calculadas a partir das curvas concentração resposta. Os resultados foram expressos como média \pm erro padrão da média (epm). As análises estatísticas foram realizadas utilizando-se análise de variância de uma via (ANOVA) seguida do teste de Bartlett para a homogeneidade das variâncias e do teste de múltiplas comparações Tukey-Kramer. O nível de significância mínima aceitável foi $p<0,05$. 


\section{RESULTADOS}

\subsection{Parâmetros biológicos}

Ratas que receberam aloxana apresentaram, após 30 dias, aumento da glicemia e redução da insulinemia em comparação com as que receberam veículo, caracterizando o diabetes (Tabela 1). Ratas diabéticas apresentaram menor ganho de massa corpórea em 30 dias do que ratas controles (Tabela 1). O consumo de ração e de água e volume de urina em 24 horas foram maiores no grupo diabética do que no grupo controle (Tabela 1). A glicosúria foi detectada somente na urina de 24 horas de ratas diabéticas (Tabela 1). $O$ tratamento com $6 \mathrm{UI} /$ dia de insulina NPH durante 15 dias não corrigiu a glicemia, que foi determinada 18 horas após a última dose de insulina, e aumentou a concentração sérica de insulina em ratas diabéticas, mas não para os níveis de ratas controles (Tabela 1). O ganho de massa corpórea, o consumo de água e a produção de urina, mas não o consumo de ração, foram corrigidos pelo tratamento com insulina (Tabela 1). O tratamento com L-NIL não preveniu as alterações observadas em ratas diabéticas (Tabela 1). Cetonúria não foi detectada em nenhuma rata dos diferentes grupos experimentais.

Em anexo parâmetros metabólicos das ratas diabéticas 15 dias após a indução do diabetes. 
Tabela 1 - Parâmetros biológicos de ratas controles, diabéticas, diabéticas tratadas com insulina e diabéticas tratadas com L-NIL 30 dias após a indução do diabetes

\begin{tabular}{|c|c|c|c|c|}
\hline & Controle & Diabética & $\begin{array}{c}\text { Diabética-Insulina } \\
\text { (6 UI/dia) }\end{array}$ & $\begin{array}{c}\text { Diabética-LNIL } \\
(3 \mathrm{mg} / \mathrm{kg})\end{array}$ \\
\hline $\begin{array}{l}\text { Glicemia } \\
(\mathrm{mg} / \mathrm{dL})\end{array}$ & $\begin{array}{c}115,6 \pm 2,3 \\
(3)\end{array}$ & $\begin{array}{c}557,5 \pm 5,9^{*} \\
(3)\end{array}$ & $\begin{array}{c}545,7 \pm 7,6^{*} \\
(3)\end{array}$ & $\begin{array}{c}565,7 \pm 8,7^{*} \\
(3)\end{array}$ \\
\hline $\begin{array}{l}\text { Insulina } \\
(\mu \mathrm{U} / \mathrm{mL})\end{array}$ & $\begin{array}{l}11,4 \pm 0,4 \\
(6)\end{array}$ & $\begin{array}{l}6,6 \pm 0,5^{*} \\
(5)\end{array}$ & $\begin{array}{c}9,3 \pm 0,7^{\star \# \#} \\
(5)\end{array}$ & $\begin{array}{c}6,2 \pm 0,43^{*} \\
(6)\end{array}$ \\
\hline $\begin{array}{c}\text { Ganho de peso } \\
\text { (g) }\end{array}$ & $\begin{array}{l}38,8 \pm 3,2 \\
\quad(6)\end{array}$ & $\begin{array}{c}-2,1 \pm 8,5^{\star} \\
(7)\end{array}$ & $\begin{array}{l}32,5 \pm 4,0^{\#} \\
\quad(4)\end{array}$ & $\begin{array}{c}2,6 \pm 3,5^{\star} \\
(9)\end{array}$ \\
\hline $\begin{array}{l}\text { Ração } \\
\text { (g/24h) }\end{array}$ & $\begin{array}{c}6,7 \pm 0,3 \\
(6)\end{array}$ & $\begin{array}{c}18,8 \pm 1,1^{*} \\
(5)\end{array}$ & $\begin{array}{c}13,2 \pm 0,6^{\star \#} \\
(4)\end{array}$ & $\begin{array}{c}17,5 \pm 0,6^{*} \\
(8)\end{array}$ \\
\hline $\begin{array}{c}\text { Água } \\
(\mathrm{mL} / 24 \mathrm{~h})\end{array}$ & $\begin{array}{l}11,7 \pm 0,8 \\
(6)\end{array}$ & $\begin{array}{c}79,7 \pm 3,8^{*} \\
(5)\end{array}$ & $\begin{array}{c}23,2 \pm 1,4^{\#} \\
(4)\end{array}$ & $\begin{array}{c}70,2 \pm 4,1^{*} \\
(8)\end{array}$ \\
\hline $\begin{array}{l}\text { Urina } \\
(\mathrm{mL} / 24 \mathrm{~h})\end{array}$ & $\begin{array}{c}4,1 \pm 0,4 \\
(6)\end{array}$ & $\begin{array}{c}65,1 \pm 4,2^{*} \\
(5)\end{array}$ & $\begin{array}{c}13,2 \pm 1,3^{\#} \\
(4)\end{array}$ & $\begin{array}{c}51,2 \pm 3,3^{* \#} \\
(9)\end{array}$ \\
\hline $\begin{array}{l}\text { Glicosúria } \\
\text { (g/dL) }\end{array}$ & $\begin{array}{l}\text { Negativo } \\
\text { (5) }\end{array}$ & $\begin{array}{c}5,0 \pm 0,0 \\
(3)\end{array}$ & $\begin{array}{c}5,0 \pm 0,0 \\
(4)\end{array}$ & $\begin{array}{l}5,0 \pm 0,0 \\
(10)\end{array}$ \\
\hline
\end{tabular}

Os resultados estão expressos como média \pm epm. O número de ratas utilizadas em cada grupo encontra-se entre parênteses. ${ }^{*} p<0,05$ vs Controle. ${ }^{\#} p<0,05$ vs Diabética.

Fonte: Sartoretto (2013) 


\subsection{Glicemia em diferente tempos após a injeção de 2 e 4 UI de insulina NPH}

Após 1 hora da injeção de 2 UI de insulina NPH, a glicemia de ratas diabéticas foi menor que $120 \mathrm{mg} / \mathrm{dL}$ e permaneceu menor que $100 \mathrm{mg} / \mathrm{dL}$ por aproximadamente 4 horas (Tabela 2). Na quinta hora após a injeção de 2 UI de insulina, ratas diabéticas já apresentavam glicemia maior de $200 \mathrm{mg} / \mathrm{dL}$, que gradativamente foi se elevando, mas que não ultrapassou $300 \mathrm{mg} / \mathrm{dL}$ até o momento da administração de 4 UI de insulina NPH. Na primeira hora após a injeção de 4 UI de insulina $\mathrm{NPH}$, ratas diabéticas apresentaram glicemia abaixo de $70 \mathrm{mg} / \mathrm{dL}$ e na quarta hora a glicemia ainda estava abaixo de $150 \mathrm{mg} / \mathrm{dL}$. Contudo, na sexta hora a glicemia já havia ultrapassado $300 \mathrm{mg} / \mathrm{dL}$. 
Tabela 2 - Glicemia de ratas diabéticas em diferentes tempos após a injeção de 2 e 4 UI de insulina NPH

\begin{tabular}{|c|c|}
\hline & Glicemia (mg/dL) \\
\hline Inicial & $499,0 \pm 36,4$ \\
\hline \multicolumn{2}{|c|}{ Injeção de 2UI de insulina NPH } \\
\hline 1 hora & $112,8 \pm 17,9$ \\
\hline 2 horas & $57,2 \pm 5,9$ \\
\hline 4 horas & $94,0 \pm 12,0$ \\
\hline 5 horas & $202,6 \pm 67,8$ \\
\hline 6 horas & $245,8 \pm 77,2$ \\
\hline 8 horas & $286,8 \pm 38,8$ \\
\hline \multicolumn{2}{|c|}{ Injeção de 4UI de insulina NPH } \\
\hline 1 hora & $67,4 \pm 11,6$ \\
\hline 2 horas & $68,2 \pm 4,8$ \\
\hline 4 horas & $146,4 \pm 19,1$ \\
\hline 6 horas & $331,0 \pm 57,9$ \\
\hline
\end{tabular}

Os valores estão expressos como média \pm epm. Cinco animais de cada grupo experimental foram utilizados neste experimento.

Fonte: Sartoretto (2013) 


\subsection{Parâmetros do ciclo estral e de hormônios sexuais}

Ratas diabéticas apresentam parada do ciclo estral, que fica estacionado na fase diestro. O tratamento com insulina, mas não o tratamento com L-NIL, normaliza o ciclo estral de ratas diabéticas. $\mathrm{Na}$ fase diestro, a massa total e seca do útero de ratas diabéticas estavam diminuídas em relação aos de ratas controles (Tabela 3). 0 tratamento das ratas diabéticas com insulina restaurou a massa total e seca do útero (Tabela 3). Já o tratamento com L-NIL não preveniu essas alterações (Tabela 3).

$\mathrm{Na}$ fase diestro, a concentração sérica de estradiol foi semelhante entre todos os grupos experimentais (Tabela 3). Por outro lado, a concentração de progesterona na fase diestro foi reduzida em ratas diabéticas, que foi corrigida pelo tratamento com insulina, mas não pelo tratamento com L-NIL (Tabela 3).

Tabela 3 - Massa uterina e concentração de estradiol e progesterona em ratas controles, diabéticas, diabéticas tratadas com insulina e diabéticas tratadas com L-NIL na fase diestro 30 dias após a indução do diabetes

\begin{tabular}{|c|c|c|c|c|}
\hline & Controle & Diabética & $\begin{array}{c}\text { Diabética-Insulina } \\
\text { (6 Ul/dia) }\end{array}$ & $\begin{array}{c}\text { Diabética-LNIL } \\
(3 \mathrm{mg} / \mathrm{kg})\end{array}$ \\
\hline $\begin{array}{l}\text { Massa total } \\
(\mathrm{mg} / 100 \mathrm{~g})\end{array}$ & $\begin{array}{c}180,8 \pm 30,6 \\
(5)\end{array}$ & $\begin{array}{c}69,9 \pm 17,7^{*} \\
(4)\end{array}$ & $\begin{array}{c}111,2 \pm 10,4 \\
(9)\end{array}$ & $\begin{array}{c}78,4 \pm 3,6^{*} \\
(7)\end{array}$ \\
\hline $\begin{array}{c}\text { Massa seca } \\
(\mathrm{mg} / 100 \mathrm{~g})\end{array}$ & $\begin{array}{l}33,2 \pm 2,8 \\
(4)\end{array}$ & $\begin{array}{c}17,0 \pm 2,3^{*} \\
(5)\end{array}$ & $\begin{array}{c}29,5 \pm 2,6 \\
(4)\end{array}$ & $\begin{array}{c}19,7 \pm 0,5^{*} \\
(7)\end{array}$ \\
\hline $\begin{array}{l}\text { Estradiol } \\
(\mathrm{pg} / \mathrm{mL})\end{array}$ & $\begin{array}{l}21,5 \pm 1,7 \\
(10)\end{array}$ & $\begin{array}{l}26,5 \pm 4,3 \\
\quad(12)\end{array}$ & $\begin{array}{c}21,8 \pm 1,6 \\
(6)\end{array}$ & $\begin{array}{l}23,3 \pm 2,4 \\
\quad(11)\end{array}$ \\
\hline $\begin{array}{l}\text { Progesterona } \\
\text { (ng/mL) }\end{array}$ & $\begin{array}{l}14,9 \pm 1,6 \\
(10)\end{array}$ & $\begin{array}{c}4,5 \pm 1,0^{*} \\
(12)\end{array}$ & $\begin{array}{l}14,8 \pm 2,1 \\
(6)\end{array}$ & $\begin{array}{c}5,4 \pm 1,1^{*} \\
(11)\end{array}$ \\
\hline
\end{tabular}

Os resultados estão expressos como média \pm epm. A massa uterina foi corrigida pela massa corpórea das ratas e foi expressa como $\mathrm{mg}$ de útero/100 g de massa corpórea. O número de ratas utilizadas em cada grupo encontra-se entre parênteses. ${ }^{*} p<0,05$ vs Controle.

Fonte: Sartoretto (2013) 


\subsection{Pressão arterial e frequência cardíaca}

Ratas diabéticas apresentaram redução na pressão arterial sistólica e diastólica (Tabela 4). O tratamento com insulina aumentou apenas a pressão arterial sistólica. O tratamento de ratas diabéticas com L-NIL aumentou a pressão arterial sistólica e diastólica. A frequência cardíaca não diferiu entre os grupos estudados (Tabela 4).

Tabela 4 - Pressão arterial (PA) sistólica e diastólica e frequência cardíaca (FC) de ratas controles, diabéticas, diabéticas tratadas com insulina e diabéticas tratadas com L-NIL 30 dias após a indução do diabetes

\begin{tabular}{|c|c|c|c|c|}
\hline & $\begin{array}{c}\text { Controle } \\
\text { (6) }\end{array}$ & $\begin{array}{c}\text { Diabética } \\
\text { (4) }\end{array}$ & $\begin{array}{c}\text { Diabética-Insulina } \\
\text { (6 Ul/dia) } \\
\text { (4) }\end{array}$ & $\begin{array}{c}\text { Diabética-LNIL } \\
\text { (3 mg/Kg) } \\
(5)\end{array}$ \\
\hline $\begin{array}{l}\text { PA sistólica } \\
\text { (mmHg) }\end{array}$ & $131,2 \pm 2,6$ & $115,6 \pm 1,7^{*}$ & $123,4 \pm 3,0$ & $121,4 \pm 2,5$ \\
\hline $\begin{array}{l}\text { PA diastólica } \\
(\mathrm{mmHg})\end{array}$ & $98,8 \pm 2,0$ & $84,5 \pm 2,4^{*}$ & $77,7 \pm 4,6^{\star}$ & $92,0 \pm 2,1$ \\
\hline $\begin{array}{c}\text { FC } \\
\text { (BMP) }\end{array}$ & $346,2 \pm 7,7$ & $306,6 \pm 12,9$ & $297,7 \pm 26,1$ & $308,0 \pm 20,8$ \\
\hline
\end{tabular}

Os resultados estão expressos como média \pm epm. O número de ratas utilizadas em cada grupo encontra-se entre parênteses. ${ }^{*} p<0,05$ vs Controle.

Fonte: Sartoretto (2013) 


\subsection{Imunorreatividade para a iNOS em aorta de ratas controles, diabéticas, diabéticas tratadas com insulina e diabéticas tratadas com L-NIL}

Observamos que na camada média de aorta de ratas diabéticas há maior imunorreatividade para a iNOS quando comparadas ao de ratas controles (Figura 1). O tratamento com insulina, mas não com L-NIL, corrigiu esse aumento (Figura 1).

Em anexo expressão do RNAm para a iNOS em aorta de ratas controles e diabéticas.

Figura 1 - Imunorreatividade da iNOS na camada média de aorta de ratas controles (CT), diabéticas (DB), diabéticas tratadas com insulina (DT-Ins) e diabéticas tratadas com L-NIL (DT-LNIL)

CT

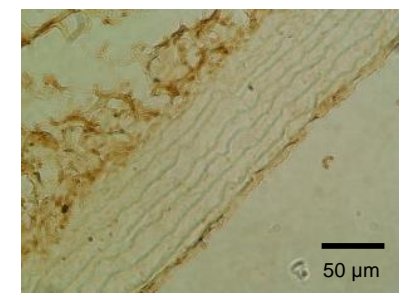

DB

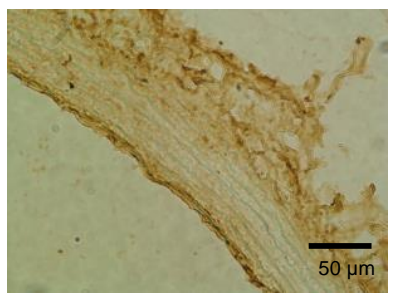

DT-Ins

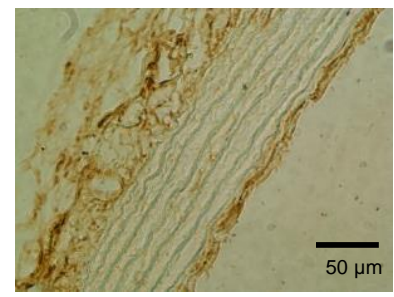

DT-LNIL

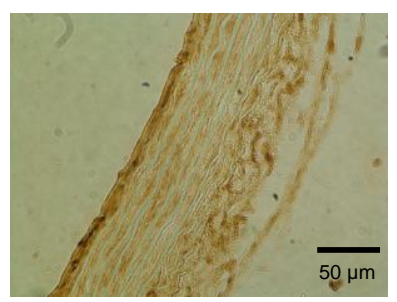

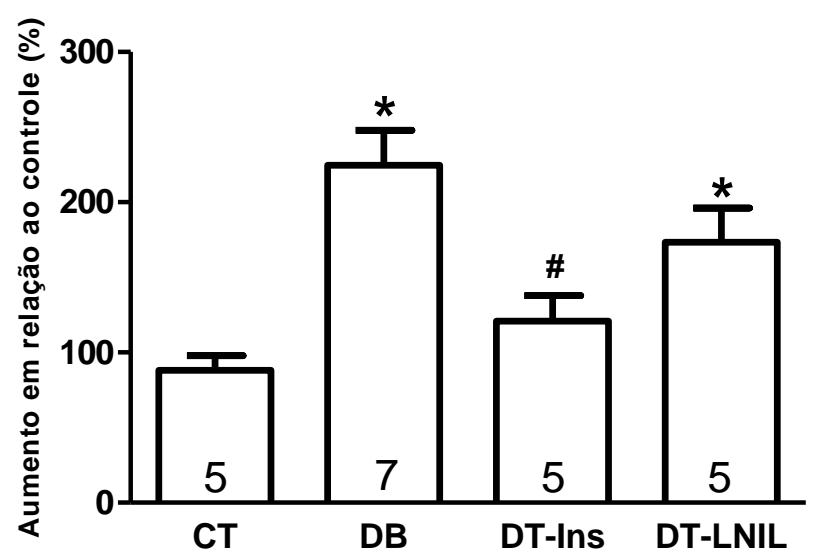

Os valores estão expressos como média \pm epm do aumento em relação ao controle (\%). Os números dentro das barras representam número de ratas utilizadas em cada grupo. ${ }^{*} p<0,05$ vs $C T$. ${ }^{*} p<0,05$ vs DB. Acima do gráfico de histograma estão representadas fotomicrografias (400x) ilustrando a imunorreatividade da iNOS em cortes de aorta de ratas controles, diabéticas, diabéticas tratadas com insulina ou L-NIL.

Fonte: Sartoretto (2013) 
4.6 Concentração plasmática de óxido nítrico de ratas controles, diabéticas, diabéticas tratadas com insulina e diabéticas tratadas com L-NIL

A concentração plasmática de NO foi aumentada em ratas diabéticas (Figura 2). O tratamento tanto com insulina quanto com L-NIL foi eficaz em reduzir a concentração de NO plasmático nas ratas diabéticas (Figura 2).

Figura 2 - Concentração plasmática de NO (óxido nítrico) analisado pelo NOA (Nitric Oxide Analyzer) nas ratas controles (CT), diabéticas (DB), diabéticas tratadas com insulina (DT-Ins) e diabéticas tratadas com LNIL (DT-LNIL)

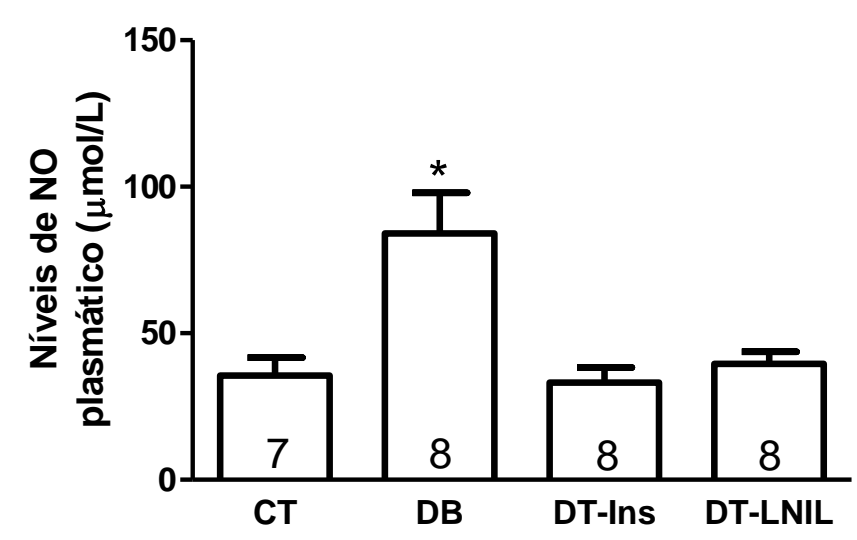

Os valores estão expressos como média \pm epm. Os números dentro das barras representam número de ratas utilizadas em cada grupo. * $\mathrm{p}<0,05$ vs CT.

Fonte: Sartoretto (2013) 


\subsection{Expressão proteica da IL-1 $\beta$ em aorta de ratas controles, diabéticas, diabéticas tratadas com insulina e diabéticas tratadas com L-NIL}

A expressão proteica da IL-1 $1 \beta$ foi aumentada em aorta de ratas diabéticas quando comparadas com aorta de ratas controles. $\mathrm{O}$ tratamento com insulina e LNIL corrigiram a expressão desta proteína inflamatória em aorta de ratas diabéticas (Figura 3).

Figura 3 - Expressão proteica da IL-1 em aorta de ratas controles (CT), diabéticas (DB), diabéticas tratadas com insulina (DT-Ins) e diabéticas tratadas com L-NIL (DT-LNIL)
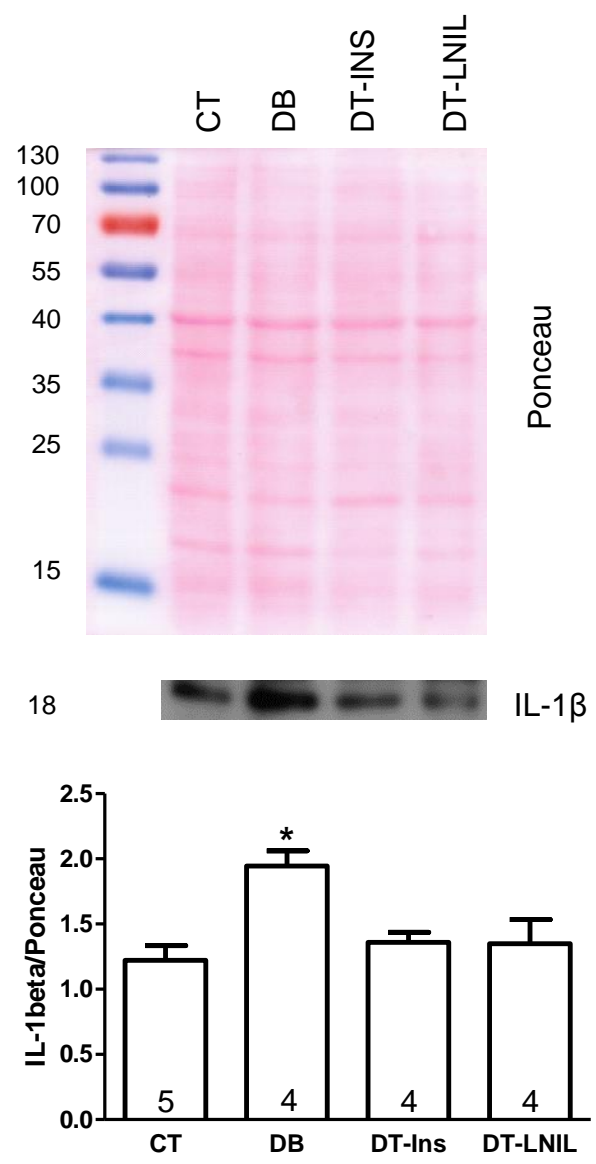

Os valores foram representados como média \pm epm. O número de ratas utilizadas em cada grupo encontra-se no interior das barras. Os valores foram normalizados pela densitometria das bandas coradas por Ponceau. No topo da figura, imagens representativas do Western blot e a membrana corada com Ponceau. ${ }^{*} \mathrm{p}<0,05$ vs CT, DT-Ins e DT-LNIL.

Fonte: Sartoretto (2013) 
4.8 Resposta vasoconstritora em aorta de ratas controles, diabéticas e diabéticas tratadas com insulina

\subsubsection{Resposta vasoconstritora à noradrenalina}

A resposta vasoconstritora induzida pela noradrenalina foi reduzida em anéis de aorta sem endotélio de ratas diabéticas quando comparadas com a de ratas controles (Figura 4). O tratamento com insulina corrigiu esta resposta em aorta de ratas diabéticas (Figura 4). 
Figura 4 - Curva concentração-resposta (A) e resposta máxima (B) para a noradrenalina em anéis de aorta sem endotélio de ratas controles (CT), diabéticas (DB) e diabéticas tratadas com insulina (DT-Ins)

A

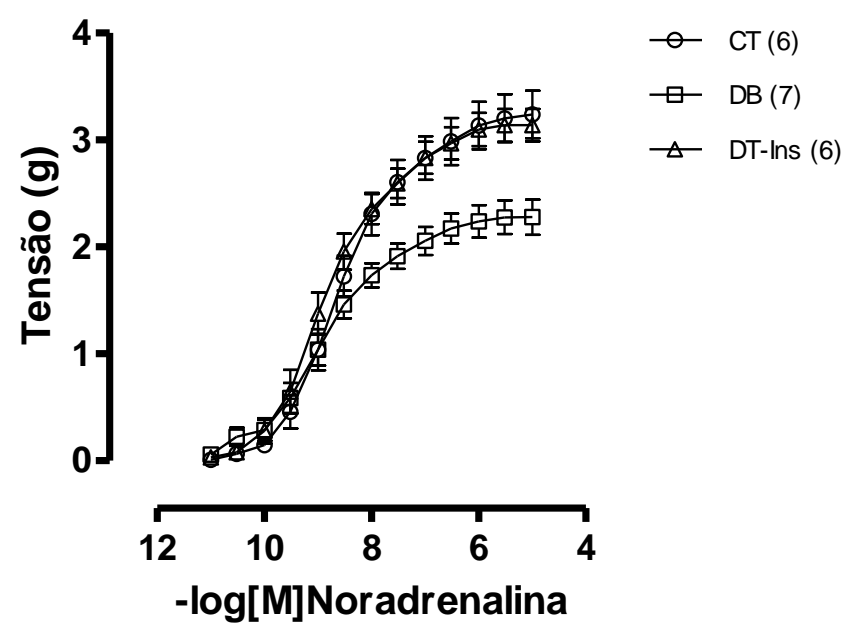

B

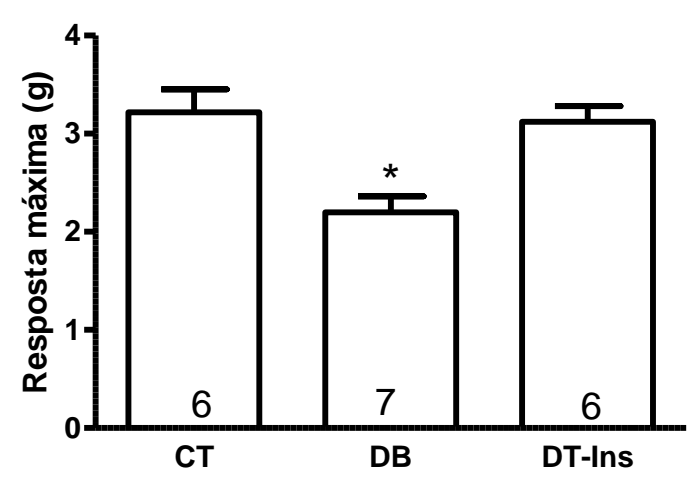

Cada ponto representa a média \pm epm do aumento de tensão $(\mathrm{g})$. O número de ratas utilizadas em cada grupo encontra-se no interior das barras. ${ }^{*} p<0,05$ vs CT e DT-Ins.

Fonte: Sartoretto (2013) 


\subsubsection{Resposta vasoconstritora à fenilefrina}

A resposta vasoconstritora induzida pela fenilefrina foi reduzida em anéis de aortas sem endotélio de ratas diabéticas quando comparadas com de ratas controles (Figura 5). O tratamento com insulina corrigiu esta resposta em aorta de ratas diabéticas (Figura 5).

Figura 5 - Curva concentração-resposta (A) e resposta máxima (B) para a noradrenalina em anéis de aorta sem endotélio de ratas controles (CT), diabéticas (DB) e diabéticas tratadas com insulina (DT-Ins)

A

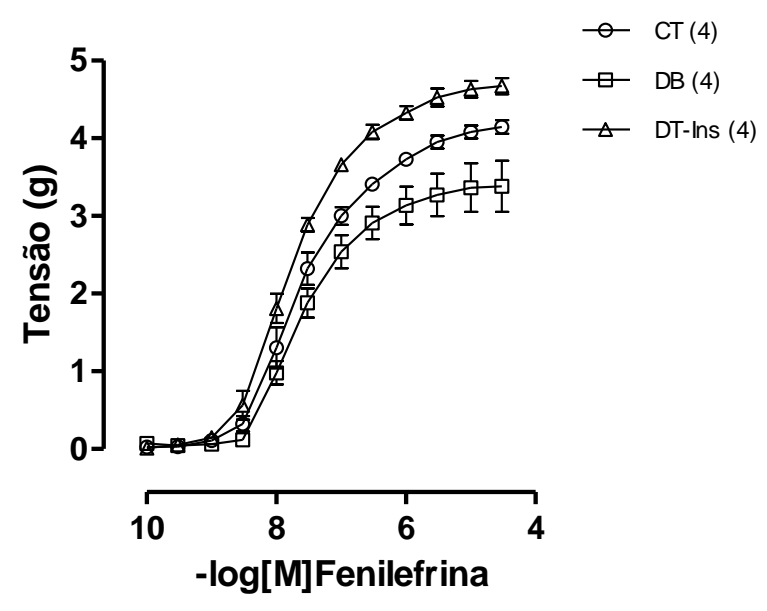

B

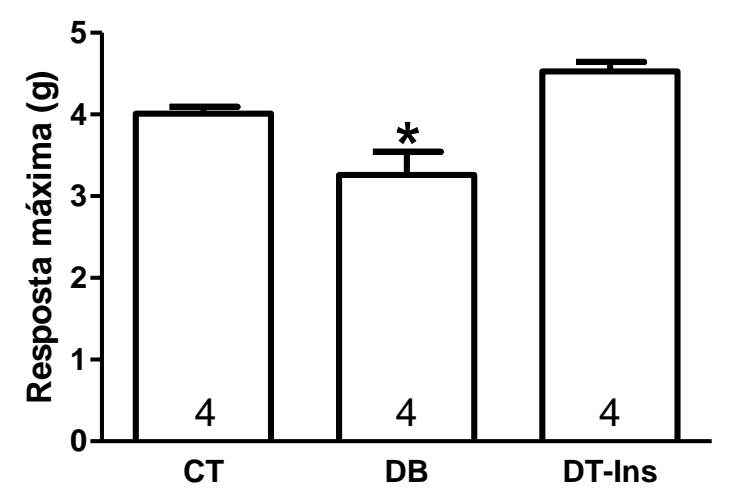

Cada ponto representa a média \pm epm do aumento de tensão $(\mathrm{g})$. O número de ratas utilizadas em cada grupo encontra-se no interior das barras. ${ }^{*} p<0,05$ vs CT e DT-Ins.

Fonte: Sartoretto (2013) 


\subsubsection{Resposta vasoconstritora ao cloreto de potássio}

A resposta vasoconstritora induzida pela alta concentração de potássio foi reduzida em anéis de aorta sem endotélio de ratas diabéticas quando comparadas com a de ratas controles (Figura 6 ). $O$ tratamento com insulina não corrigiu esta resposta em aorta de ratas diabéticas (Figura 6).

Figura 6 - Curva concentração-resposta (A) e resposta máxima (B) para o cloreto de potássio $(\mathrm{KCl})$ em anéis de aorta sem endotélio de ratas controles (CT), diabéticas (DB) e diabéticas tratadas com insulina (DT-Ins)

A

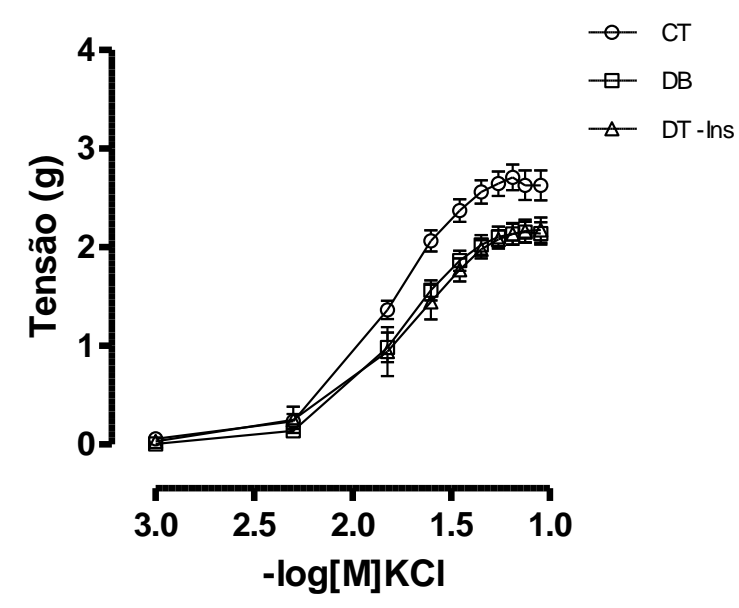

B

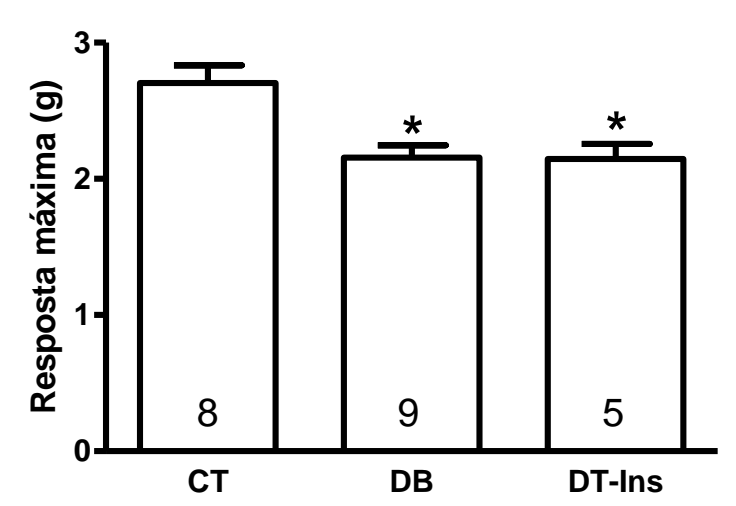

Cada ponto representa a média \pm epm do aumento de tensão $(\mathrm{g})$. O número de ratas utilizadas em cada grupo encontra-se no interior das barras. ${ }^{*} p<0,05$ vs $C T$.

Fonte: Sartoretto (2013) 


\subsection{Resposta vasoconstritora à noradrenalina em aorta de ratas controles e diabéticas após a inibição aguda da iNOS}

A inibição aguda da iNOS, com diferentes inibidores específicos da iNOS LNIL $(10 \mu \mathrm{M})$ e 1400W $(10 \mu \mathrm{M})$, não teve efeito na resposta máxima ou na sensibilidade à noradrenalina de anéis sem endotélio de aorta de ratas controles (Figura 7A, Tabela 5). Já em aorta de ratas diabéticas, a inibição aguda da iNOS, tanto pelo L-NIL quanto com 1400W, aumentou a resposta vasoconstritora à noradrenalina (Figura 7B). No entanto, a resposta máxima à noradrenalina após inibição aguda da iNOS ainda foi diferente daquela de ratas controles (Tabela 5). 
Figura 7 - Curva concentração-resposta para a noradrenalina em anéis de aorta sem endotélio de ratas controles $(\mathbf{A})$ e diabéticas $(\mathbf{B})$ na ausência $(-)$ e presença dos inibidores específicos da iNOS L-NIL $(10 \mu \mathrm{M})$ ou 1400W $(10 \mu \mathrm{M})$

A

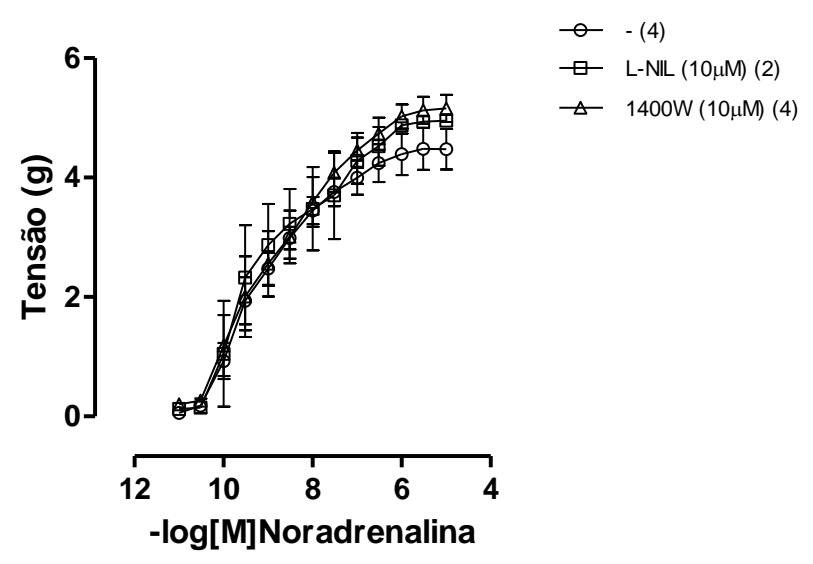

B

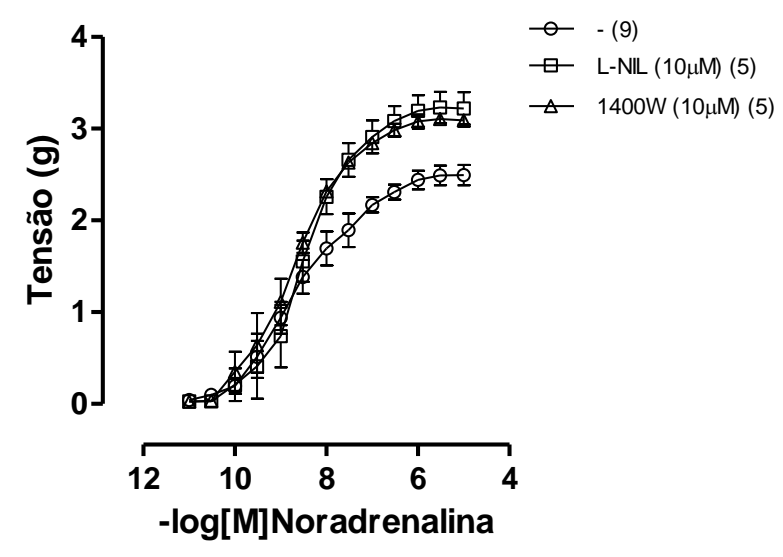

Cada ponto representa a média \pm epm do aumento de tensão $(\mathrm{g})$. O número de ratas utilizadas em cada grupo encontra-se no entre parênteses.

Fonte: Sartoretto (2013) 
Tabela 5 - Resposta máxima e sensibilidade à noradrenalina na ausência (-) e presença dos inibidores da iNOS L-NIL $(10 \mu \mathrm{M})$ ou 1400W $(10 \mu \mathrm{M})$ em anéis de aorta sem endotélio de ratas controles (CT) e diabéticas (DB)

\begin{tabular}{ccc}
\hline Grupo & Resposta máxima (g) & $\mathrm{pD}_{2}$ \\
\hline CT - (4) & $4,42 \pm 0,31$ & $9,93 \pm 0,59$ \\
CT L-NIL (2) & $4,81 \pm 0,02$ & $9,36 \pm 0,68$ \\
CT 1400W (4) & $5,02 \pm 0,20$ & $9,51 \pm 0,67$ \\
DB - (9) & $2,45 \pm 0,10^{\star}$ & $\mathrm{ND}$ \\
DB L-NIL (5) & $3,12 \pm 0,17^{\star \#}$ & $\mathrm{ND}$ \\
DB 1400W (5) & $3,03 \pm 0,07^{\star \#}$ & $\mathrm{ND}$
\end{tabular}

Os valores de resposta máxima representam a média \pm epm. O número de ratas utilizadas em cada grupo encontra-se entre parênteses. $\mathrm{ND}=0$ pD2 não foi determinado, pois houve diferença significativa na resposta máxima. ${ }^{*} p<0,05$ vs CT na ausência dos inibidores. ${ }^{*} p<0,05$ vs DB na ausência dos inibidores.

Fonte: Sartoretto (2013) 
4.10 Resposta vasoconstritora em aorta de ratas controles, diabéticas e diabéticas tratadas cronicamente com L-NIL

\subsubsection{Resposta vasoconstritora à noradrenalina}

A resposta vasoconstritora induzida pelo agonista adrenérgico noradrenalina, em anéis de aorta sem endotélio, foi menor em ratas diabéticas quando comparadas às ratas controles (Figura 8 ). $O$ tratamento com L-NIL preveniu a redução da resposta vasoconstritora à noradrenalina em aorta de ratas diabéticas (Figura 8). 
Figura 8 - Curva concentração-resposta (A) e resposta máxima (B) para noradrenalina em anéis de aorta sem endotélio de ratas controles (CT), diabéticas (DB) e diabéticas tratadas cronicamente com L-NIL (DT-LNIL)

A

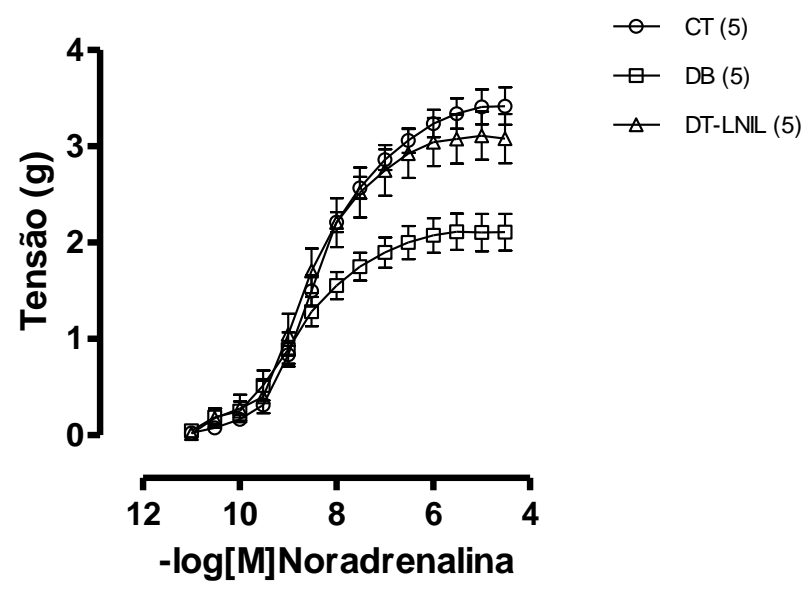

B

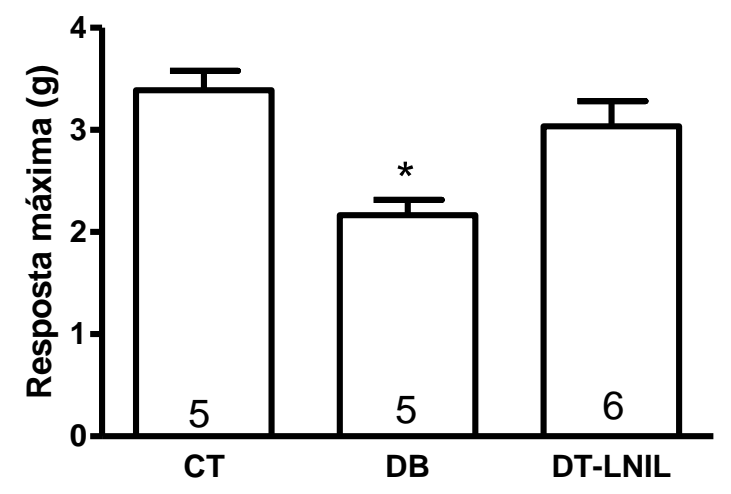

Cada ponto representa a média \pm epm do aumento de tensão $(\mathrm{g})$. O número de ratas utilizadas em cada grupo encontra-se no interior das barras. * $p<0,05$ vs CT.

Fonte: Sartoretto (2013) 


\subsubsection{Resposta vasoconstritora à fenilefrina}

A resposta vasoconstritora induzida pela fenilefrina foi reduzida em anéis de aorta sem endotélio de ratas diabéticas quando comparadas com de ratas controles (Figura 9). O tratamento com L-NIL preveniu a redução da resposta à fenilefrina em aorta de ratas diabéticas (Figura 9).

Figura 9 - Curva concentração-resposta (A) e resposta máxima (B) para a fenilefrina em anéis de aorta sem endotélio de ratas controles (CT), diabéticas (DB) e diabéticas tratadas com L-NIL (DT-LNIL)

A

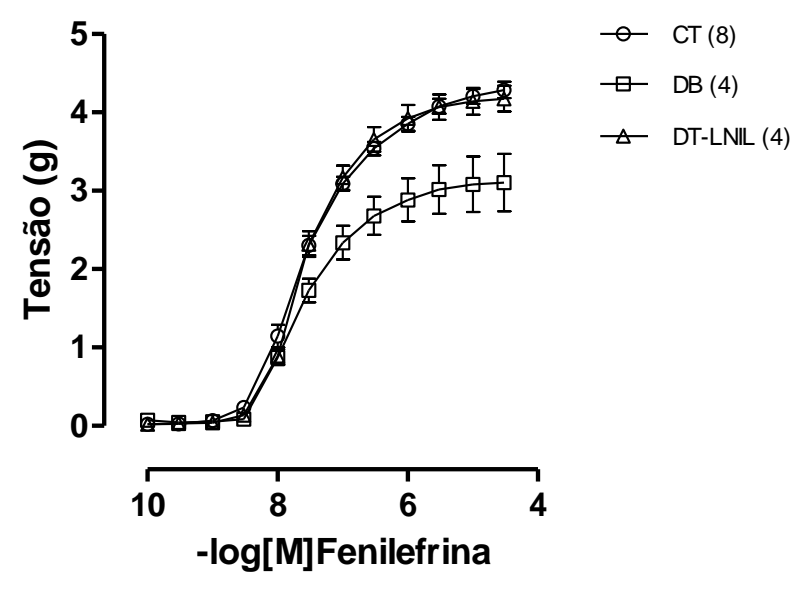

B

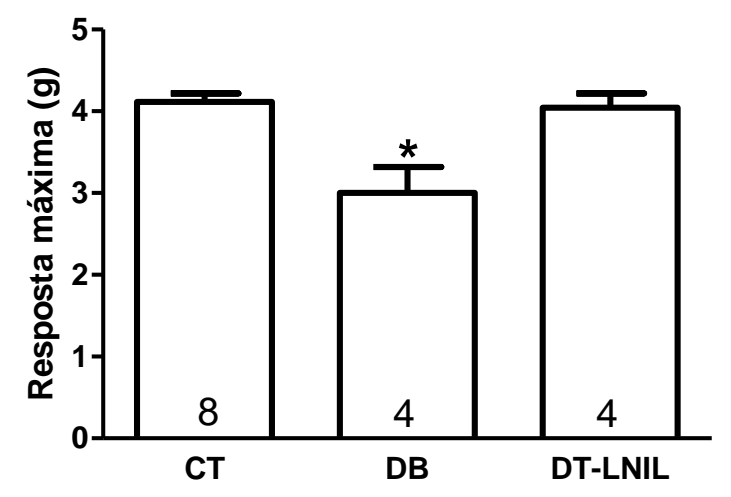

Cada ponto representa a média \pm epm do aumento de tensão $(\mathrm{g})$. O número de ratas utilizadas em cada grupo encontra-se no interior das barras. * $\mathrm{p}<0,05$ vs CT e DT-LNIL.

Fonte: Sartoretto (2013) 


\subsubsection{Resposta vasoconstritora ao cloreto de potássio}

A resposta vasoconstritora induzida pela alta concentração de potássio foi reduzida em anéis de aorta sem endotélio de ratas diabéticas quando comparadas com a de ratas controles (Figura 10). O tratamento com L-NIL não preveniu essa alteração (Figura 10).

Figura 10 - Curva concentração-resposta (A) e resposta máxima (B) para o cloreto de potássio $(\mathrm{KCl})$ em anéis de aorta sem endotélio de ratas controles (CT), diabéticas (DB) e diabéticas tratadas com L-NIL (DT-LNIL)

A

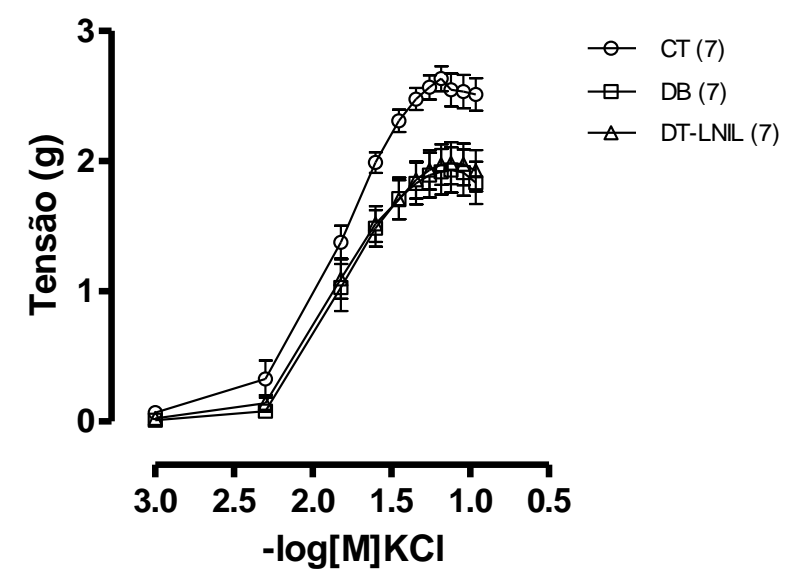

B

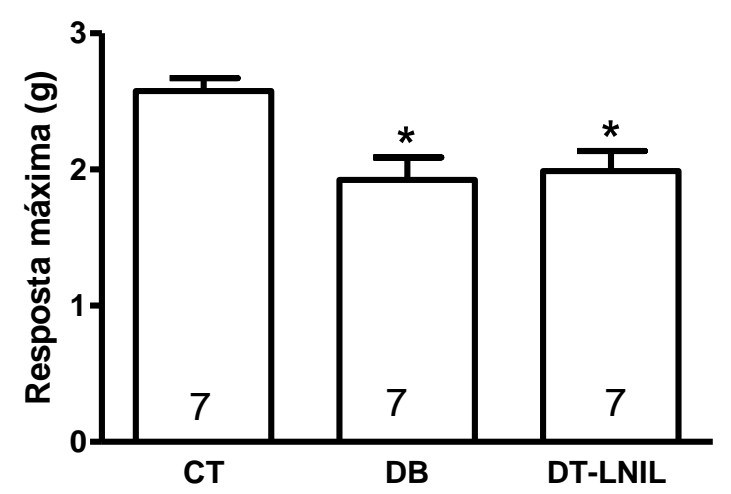

Cada ponto representa a média \pm epm do aumento de tensão $(\mathrm{g})$. O número de ratas utilizadas em cada grupo encontra-se no interior das barras. ${ }^{*} p<0,05$ vs $C T$.

Fonte: Sartoretto (2013) 
4.11 Expressão de proteínas S-nitrosiladas em aorta de ratas controles, diabéticas, diabéticas tratadas com insulina e diabéticas tratadas com LNIL

Ratas diabéticas apresentaram aumento na expressão de proteínas snitrosiladas em aorta quando comparadas com ratas controles, o tratamento com insulina foi eficaz em corrigir esse aumento. Já a quantidade de proteínas snitrosiladas em aorta de ratas diabéticas tratadas com L-NIL não foi diferente de ratas controles e diabéticas (Figura 11). 
Figura 11 - Expressão proteica de proteínas S-nitrosiladas em aorta de ratas controles (CT), diabéticas (DB), diabéticas tratadas com insulina (DTIns) e diabéticas tratadas com L-NIL (DT-LNIL)
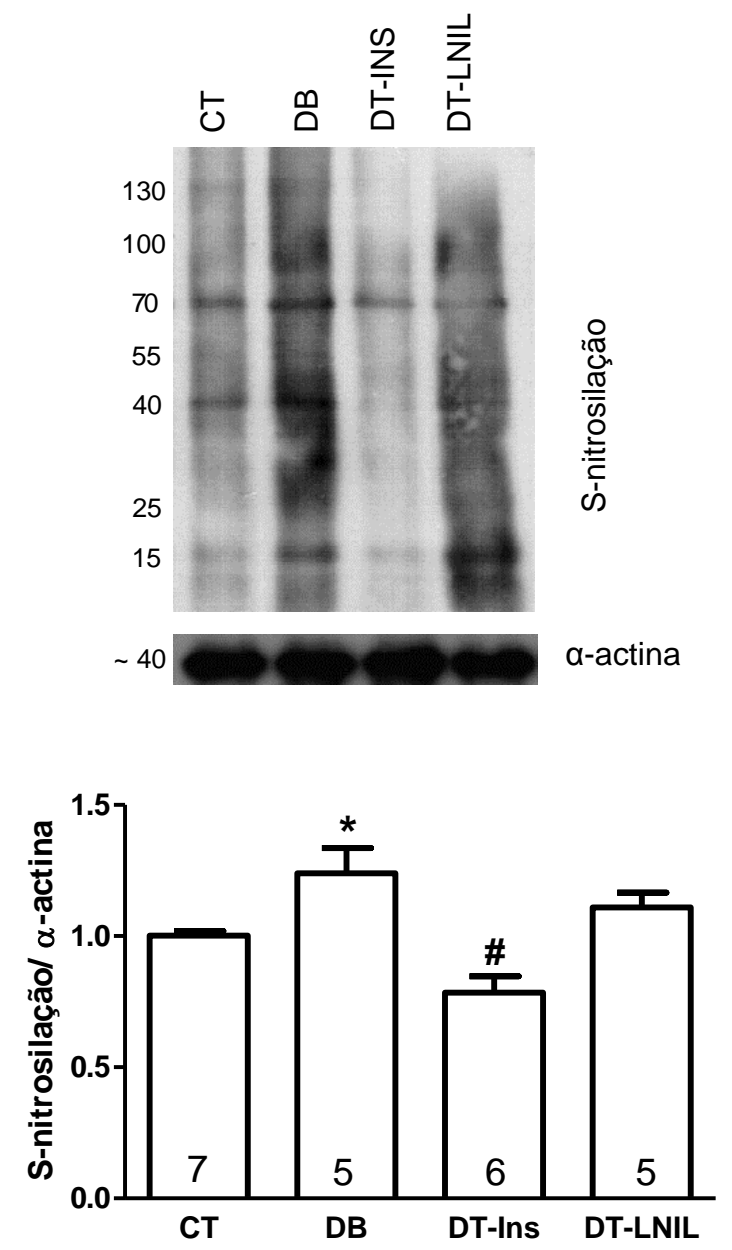

O gráfico em histograma de barras mostra a análise densitométrica da expressão das proteínas Snitrosiladas. Os valores foram normalizados pela expressão da a-actina. Os valores estão representados como a média \pm epm. O número de ratas utilizadas em cada grupo encontra-se no interior das barras. No topo da figura, imagens representativas do Western blot. " $p<0,05$ vs CT. $\# p<0,05$ vs DB.

Fonte: Sartoretto (2013) 


\subsection{Expressão proteica e imunorreatividade do receptor de estrógeno GPER}

Aorta de ratas diabéticas apresenta aumento na expressão proteica (Figura 12) e na imunorreatividade (Figura 13) do receptor para estrógeno GPER (Figura 12). O tratamento de ratas diabéticas com insulina reduziu a expressão deste receptor. O tratamento com L-NIL das ratas diabéticas não foi eficaz em prevenir o aumento da expressão deste receptor em aorta de ratas diabéticas (Figura 12).

Em anexo expressão do RNAm para o GPER em aorta de ratas controles e diabéticas.

Figura 12 - Expressão do receptor de estrógeno GPER em aorta de ratas controles (CT), diabéticas (DB), diabéticas tratadas com insulina (DT-Ins) e diabéticas tratadas com L-NIL (DT-LNIL)
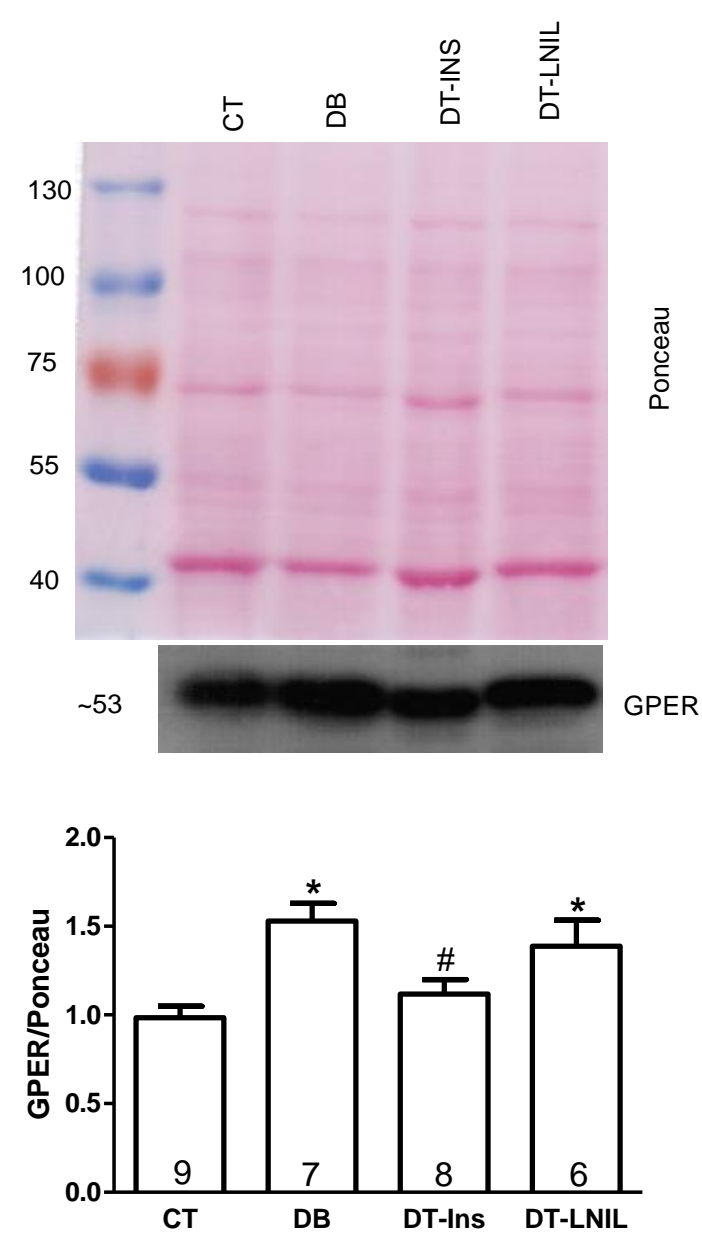

O gráfico em histograma de barras mostra a análise densitométrica da expressão proteica do GPER. Os valores foram normalizados pela densitometria das bandas coradas por Ponceau. Os valores estão representados como a média $\pm \mathrm{epm}$. O número de ratas utilizadas em cada grupo encontra-se no interior das barras. No topo da figura, imagens representativas do Western blot. ${ }^{*} p<0,05$ vs CT. $\# \mathrm{p}<0,05$ vs $D B$.

Fonte: Sartoretto (2013) 
Figura 13 - Expressão dos receptores de estrógeno GPER em aortas de ratas controles (CT), diabéticas (DB), diabéticas tratadas com insulina (DTIns) e diabéticas tratadas com L-NIL (DT-LNIL)

CT

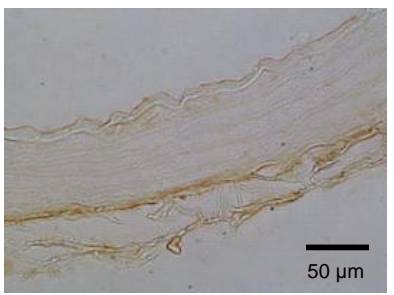

DB

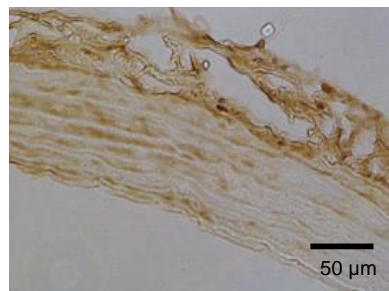

DT-Ins

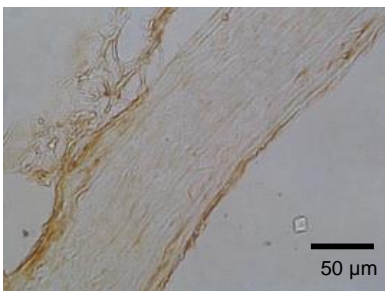

DT-LNIL

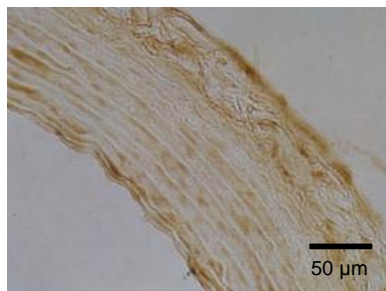

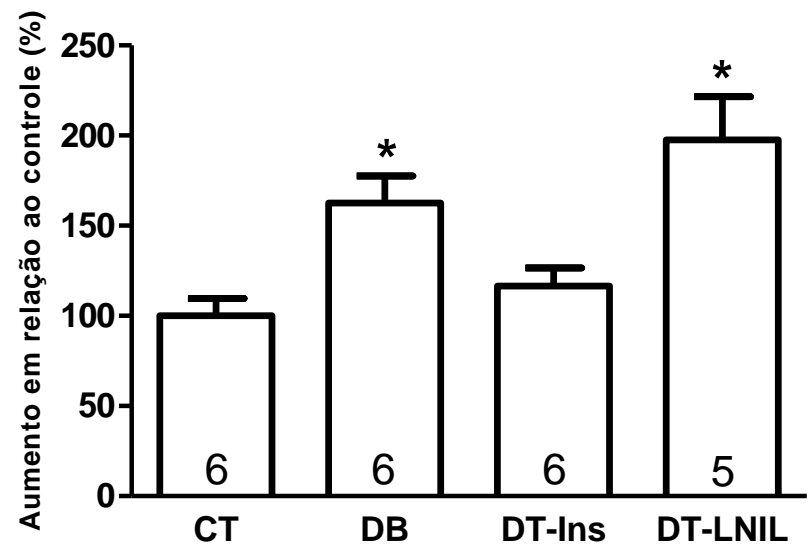

Os valores estão expressos como média \pm epm do aumento em relação ao controle (\%). Os números dentro das barras representam número de ratas utilizadas em cada grupo. ${ }^{*} p<0,05$ vs $C T$. Acima do gráfico de histograma estão representadas fotomicrografias (400x) ilustrando a imunomarcação do GPER em cortes de aorta de ratas controle, diabéticas, diabéticas tratadas com insulina ou L-NIL.

Fonte: Sartoretto (2013) 


\subsection{Imunorreatividade para o receptor de estrógeno, ESR2, em aorta de ratas} controles, diabéticas e diabéticas tratadas com insulina e diabéticas tratadas com L-NIL

A camada média de aorta de ratas diabéticas apresentaram maior imunorreatividade para o receptor ESR2 do que de ratas controles (Figura 14). O tratamento com insulina, mas não o tratamento com L-NIL, corrigiu o aumento dessa imunorreatividade em cortes de aorta de ratas diabéticas (Figura 14).

Em anexo expressão do RNAm do ESR2 em aorta de ratas controle e diabética.

Figura 14 - Expressão do receptor de estrógeno ESR2 em aorta de ratas controles (CT), diabéticas (DB), diabéticas tratadas com insulina (DT-Ins) e diabéticas tratadas com L-NIL (DT-LNIL)

CT

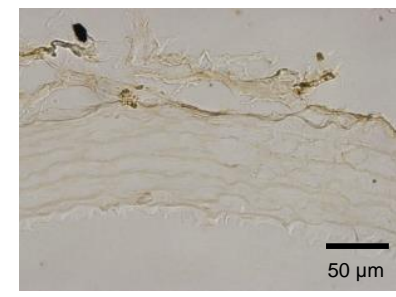

DB

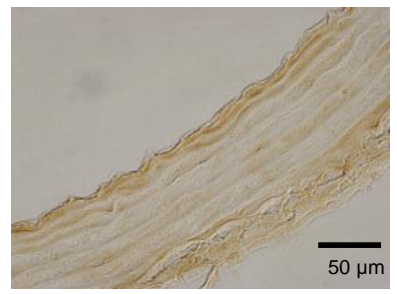

DT-Ins

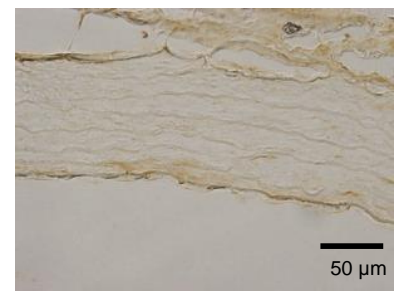

DT-LNIL

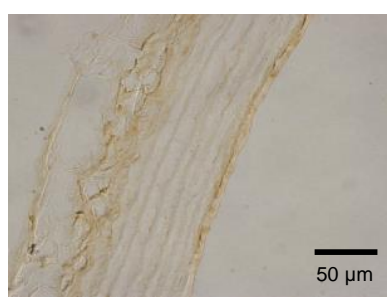

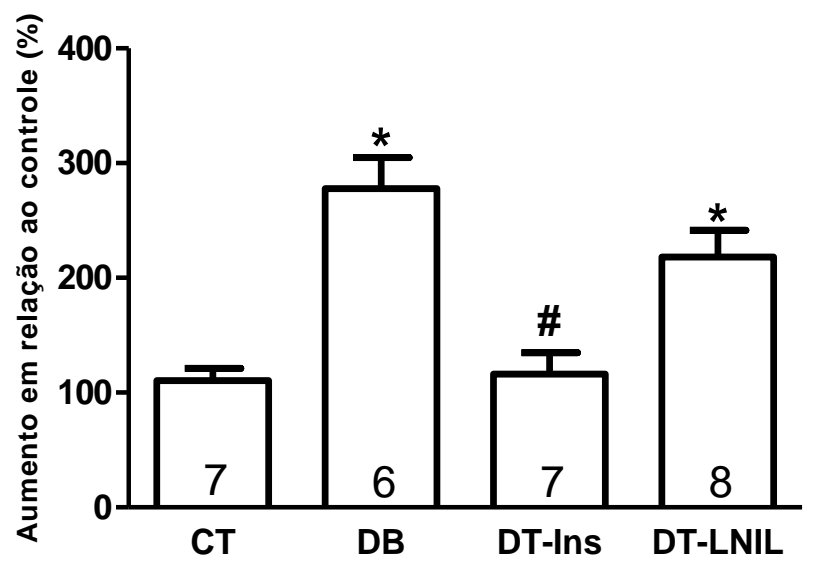

Os valores estão expressos como média \pm epm do aumento em relação ao controle (\%). Os números dentro das barras representam número de ratas utilizadas em cada grupo. ${ }^{*} \mathrm{p}<0,05$ vs $\mathrm{CT}$. ${ }^{\#} \mathrm{p}<0,05$ vs DB. Acima do gráfico de histograma estão representadas fotomicrografias (400x) ilustrando a imunomarcação do ESR2 em cortes de aortas de ratas controle, diabéticas, diabéticas tratadas com insulina ou L-NIL.

Fonte: Sartoretto (2013) 
4.14 Resposta vasoconstritora à noradrenalina em aorta de ratas controles e diabéticas após bloqueio agudo do receptor de estrógeno ESR2

O antagonismo agudo do receptor de estrógeno ESR2 com diferentes concentrações do antagonista PHTPP não modificou a resposta máxima e a sensibilidade à noradrenalina em aorta sem endotélio de ratas controles (Figura 15, Tabela 6) e diabéticas (Figura 16, Tabela 7). 
Figura 15 - Curva concentração-resposta para a noradrenalina em anéis de aorta sem endotélio de ratas controles na presença de diferentes concentrações do antagonista do receptor ESR2 (PHTPP)

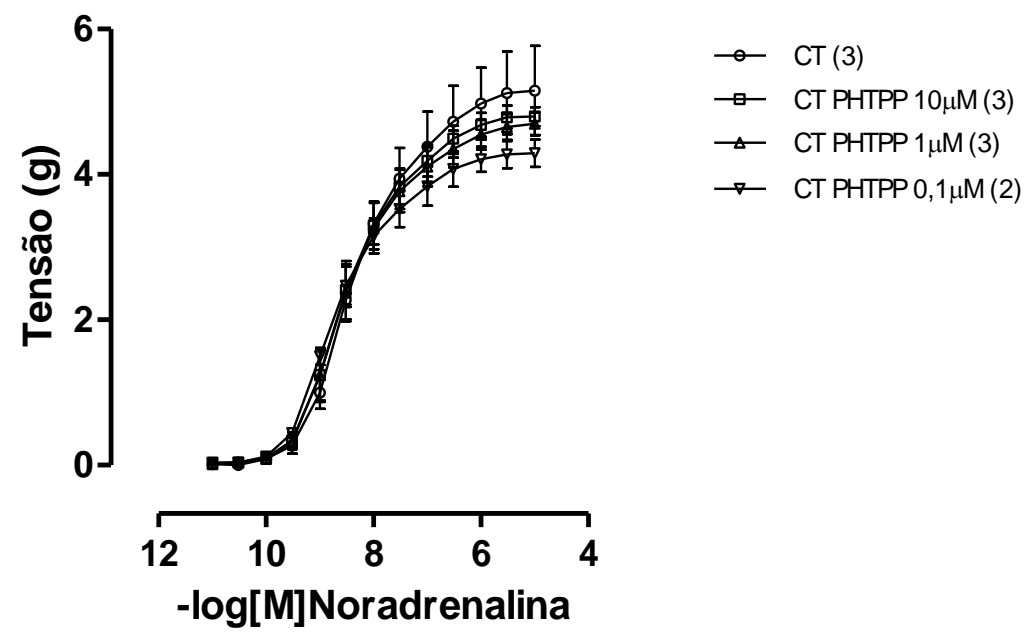

Cada ponto representa a média \pm epm do aumento de tensão $(\mathrm{g})$. O número de ratas utilizadas em cada grupo encontra-se entre parênteses.

Fonte: Sartoretto (2013)

Tabela 6 - Resposta máxima e sensibilidade à noradrenalina em anéis de aorta sem endotélio de ratas controles na presença de diferentes concentrações do antagonista do receptor ESR2 (PHTPP)

$\begin{array}{lll}\text { Grupo } & \text { Resposta máxima }(\mathrm{g}) & \mathrm{pD}_{2}\end{array}$

CT (3) $\quad 4,98 \pm 0,40 \quad 8,40 \pm 0,08$

$\begin{array}{lll}\text { CT PHTPP } 10 \mu \mathrm{M}(3) & 4,68 \pm 0,17 & 8,52 \pm 0,15 \\ \text { CT PHTPP } 1 \mu \mathrm{M}(3) & 4,56 \pm 0,15 & 8,54 \pm 0,17 \\ \text { CT PHTPP 0,1 } \boldsymbol{\mu M}(\mathbf{2}) & 4,18 \pm 0,14 & 8,71 \pm 0,06\end{array}$

Os valores de resposta máxima e $\mathrm{pD}_{2}\left(-\log \mathrm{CE}_{50}\right)$ representam a média \pm epm. O número de ratas utilizadas em cada grupo encontra-se entre parênteses.

Fonte: Sartoretto (2013) 
Figura 16 - Curva concentração-resposta para a noradrenalina em anéis de aortas sem endotélio de ratas diabéticas na presença de diferentes concentrações do antagonista do ESR2 (PHTPP)

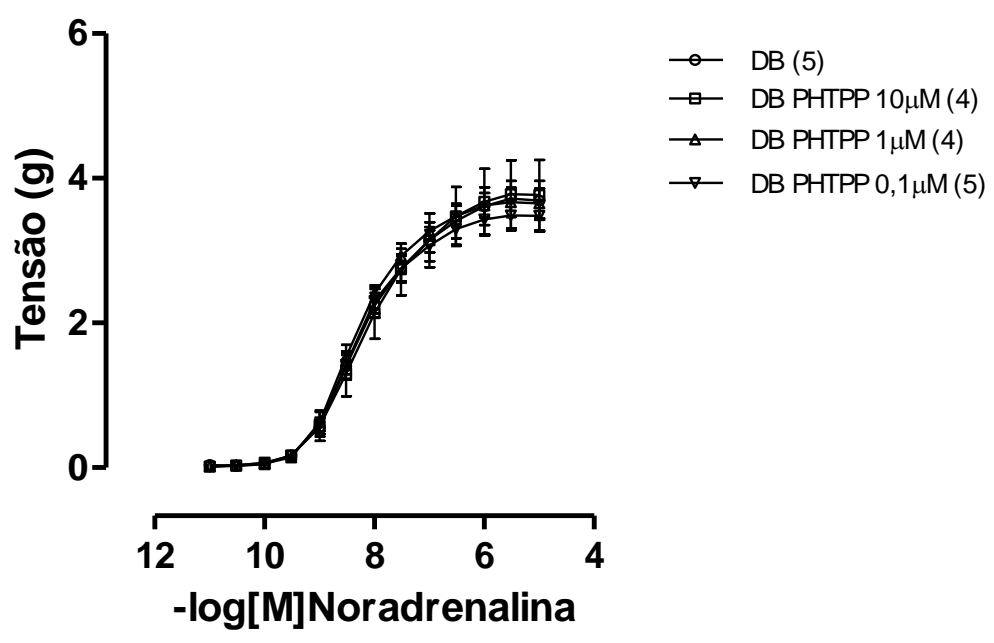

Cada ponto representa a média \pm epm do aumento de tensão $(\mathrm{g})$. O número de ratas utilizadas em cada grupo encontra-se entre parênteses.

Fonte: Sartoretto (2013)

Tabela 7 - Resposta máxima e sensibilidade à noradrenalina em anéis de aorta sem endotélio de ratas diabéticas na presença de diferentes concentrações do antagonista do receptor ESR2 (PHTPP)

\section{Grupo}

Resposta máxima (g)

$\mathrm{pD}_{2}$

DB (5)

$3,63 \pm 0,22$

$8,26 \pm 0,11$

DB PHTPP $10 \mu \mathrm{M}$ (4)

$3,70 \pm 0,44$

$8,16 \pm 0,11$

DB PHTPP $1 \mu M$ (4)

$3,57 \pm 0,19$

$8,38 \pm 0,10$

DB PHTPP 0,1 $\mu \mathrm{M}(5)$

$3,38 \pm 0,20$

$8,37 \pm 0,06$

Os valores de resposta máxima e $\mathrm{pD}_{2}\left(-\log \mathrm{CE}_{50}\right)$ representam a média \pm epm. O número de ratas utilizadas em cada grupo encontra-se entre parênteses.

Fonte: Sartoretto (2013) 


\section{DISCUSSÃO}

Nossos resultados mostram que o aumento da expressão da iNOS/geração de NO é responsável pela redução da resposta contrátil induzida por ativação de receptor adrenérgico, mas não daquela induzida por despolarização de membrana que ocorre por alta concentração de potássio. $O$ aumento da expressão de proteínas s-nitrosiladas e o aumento da expressão dos receptores de estrógeno, ESR2 e GPER, podem contribuir para a redução da capacidade contrátil em aorta de ratas diabéticas, uma vez que o tratamento com insulina foi eficaz em corrigir tanto a contração vascular, quanto a expressão das proteínas s-nitrosiladas e dos receptores de estrógeno. No entanto, o envolvimento do receptor de estrógeno ESR2 depende de mecanismos que não são bloqueados agudamente.

Semelhantemente ao já bem descrito na literatura, administração de aloxana (40 mg/kg) por via intravenosa em ratas de 8-10 semanas provocou, após 30 dias, aumento da glicemia, diminuição dos níveis de insulina, diminuição do ganho de peso, aumento do consumo de ração e água e aumento do volume urinário, caracterizando o modelo de diabetes mellitus tipo 1 . Outra característica presente neste modelo é a alteração do ciclo estral, assim como redução na concentração dos hormônios sexuais femininos. Apesar de neste trabalho não termos observado redução na concentração de estrógeno na fase diestro, é importante ressaltar que o ciclo estral das ratas diabéticas fica estacionado nessa fase e, por não passarem pela fase proestro, na qual se observa pico da concentração de estrógeno, os sistemas biológicos dessas ratas não sofrem influências das variações da concentração do hormônio. Como esperado, o tratamento com insulina melhorou os parâmetros metabólicos, embora não os tenha corrigido completamente, e corrigiu as alterações do ciclo estral e da concentração dos hormônios sexuais. Por outro lado, o tratamento com L-NIL não teve efeito sobre os parâmetros metabólicos e hormonais. Aumento da iNOS/geração de NO pode promover destruição de células $\beta$ pancreáticas $e$, consequentemente, reduzir a secreção de insulina em humanos (ARNUSH et al., 1998; CORBETT et al., 1996). Além disso, foi observado que o aumento da iNOS prejudica a sinalização da insulina, por exemplo, promovendo resistência à insulina no músculo esquelético devido a mudanças pós-tradução nos receptores de insulina e nas proteínas envolvidas na sinalização (ROPELLE et al., 2013). No entanto, no presente estudo, o diabetes foi induzido quimicamente e a 
iNOS parece não participar no mecanismo de destruição das células $\beta$ induzida pela aloxana e interferir na sinalização da insulina.

Outra característica observada nas ratas diabéticas foi redução da pressão arterial. Diversos trabalhos mostram aumento da pressão arterial no diabetes (EPENS et al., 2006; KHAMAISI et al., 2003). No entanto, redução da pressão arterial já foi observada em ratos diabéticos (MAEDA et al., 1995; SCHAAN et al., 2004) e a hiperglicemia parece ser responsável por esta anormalidade (SCHAAN et al., 2004). O exato mecanismo pelo qual a hiperglicemia contribui para a redução da pressão arterial ainda é desconhecido, porém essa condição promove ativação de várias vias que podem estar envolvidas, incluindo ativação da proteína quinase $C$ (PKC), aumento da atividade da via dos poliois, formação de produtos de glicação avançada e estresse oxidativo (IDO et al., 1997; WILLIAMSON et al., 1993). Alta concentração de glicose induz expressão da iNOS em cardiomiócitos e células do músculo liso vascular e a inibição da $\mathrm{PKC} \beta_{2}$ suprime a expressão dessa enzima (NAGAREDDY et al., 2009b), a qual pode estar envolvida com a redução da pressão arterial no diabetes.

No presente trabalho, observamos aumento da expressão de iNOS em aorta de ratas diabéticas e da concentração plasmática de NO, o tratamento dessas ratas com L-NIL durante 30 dias preveniu o aumento da concentração plasmática de $\mathrm{NO} e$ a redução da pressão arterial. Uma vez que o tratamento com L-NIL não melhorou os parâmetros metabólicos, mostra que a redução da pressão arterial em ratas diabéticas se deve diretamente ao aumento da atividade da iNOS e não é decorrente das alterações metabólicas, embora o aumento da expressão da iNOS seja induzido por alta concentração de glicose (NAGAREDDY et al., 2009b). Aumento da expressão da iNOS também foi observado em tecidos cardíaco, vascular e renal de ratos diabéticos (BARDELL; MACLEOD, 2001; BONJUGA et al., 2004; NAGAREDDY et al., 2005, 2006). A inibição da iNOS também preveniu a redução da pressão arterial em ratos diabéticos, mas apenas após 8 semanas de tratamento com L-NIL (NAGAREDDY et al., 2009a). No trabalho de Nagareddy e colaboradores (2009a), os autores observaram que após 8 semanas da indução do diabetes há também redução na frequência cardíaca em ratos e o tratamento com LNIL foi eficaz em prevenir também esta redução. Apesar de 30 dias de diabetes promover aumento da expressão da iNOS e reduzir a pressão arterial, não é 
suficiente para promover alteração da frequência cardíaca, como mostrado no presente trabalho e em outro (SCHAAN et al., 2004).

O tratamento de ratas diabéticas com insulina apenas melhorou parcialmente a redução da pressão arterial sistólica e não teve efeito na pressão arterial diastólica, que continuou reduzida. Trabalhos mostram que o tratamento de ratos diabéticos com insulina é eficaz em corrigir a redução da pressão arterial, com concomitante melhora da glicemia (KATOVICH et al., 1995). Uma possível explicação por não observarmos um efeito significativo do tratamento com insulina na pressão arterial de ratas diabéticas é o fato de que, o esquema de tratamento utilizado no presente estudo, não ter sido eficaz em normalizar a glicemia por longo período. Outra explicação é o fato destas ratas permanecerem por um período em hipoglicemia, pois foi demonstrado que após um estresse hipotensor, a sensibilidade barorreflexa e a resposta simpática estão atenuadas em animais que passaram por períodos de hipoglicemia (ADLER et al., 2009). No nosso estudo, a anestesia utilizada para implantação do cateter foi a cetamina e xilasina, que promove redução da pressão arterial em ratos normotensos e normoglicêmicos (RODRIGUES et al., 2006).

Semelhantemente ao observado no presente estudo, redução da contração vascular induzida por agonistas adrenérgicos foi observada também em ratos diabéticos (HEAD et al., 1987; PFAFFMAN et al., 1982; NAGAREDDY et al., 2005, 2009a). Tanto em fêmeas quanto em machos diabéticos, a redução da resposta contrátil de aorta pode ser explicada pelo fato que agonistas adrenérgicos induzem menor mobilização de cálcio do retículo sarcoplasmático do que em animais controles (MA et al., 2008; SARTORETTO, 2009). Redução da expressão dos receptores de 1,4,5-trifosfato de inositol foi observada em aorta de ratos diabéticos (MA et al., 2008) e pode ser a causa da redução da contração vascular nesses animais. No entanto, outros mecanismos podem estar envolvidos, uma vez que, observamos no presente estudo que em aorta de ratas diabéticas há redução da contração vascular induzida também por alta concentração de potássio, que promove contração por induzir despolarização da membrana dos miócitos e abertura de canais de cálcio dependentes de voltagem.

Em doenças como a obesidade e o diabetes, observa-se uma inflamação crônica de baixa intensidade que pode acarretar em complicações micro e macrovasculares em pacientes diabéticos e obesos (LOWE et al., 2013; VIRDIS et 
al., 2011; WOODWARD et al., 1999; YUDKIN et al., 1999). Em modelos animais de diabetes e obesidade também se observa prejuízo na função vascular, como por exemplo, redução na contração e dilatação, em decorrência do aumento da inflamação vascular (NAGAREDDY et al., 2009a; ZHANG et al., 2011). No presente trabalho, observamos que há aumento da expressão proteica da iNOS na parede da aorta, como já observado em machos diabéticos (NAGAREDDY et al., 2005, 2006, 2009a), além de aumento na concentração plasmática de NO e na expressão proteica da IL-1ß, estes resultados mostram que há um aumento na inflamação vascular em ratas diabéticas, o que poderia estar prejudicando a função vascular nestes animais.

A indução da iNOS, capaz de promover uma liberação sustentada de NO, é uma resposta a uma variedade de agentes e citocinas em vários tipos de células. Foi observado que a IL-1 $\beta$ estimula a liberação de uma grande quantidade de $\mathrm{NO}$ em células do músculo liso vascular in vitro (BEASLEY et al., 1991; PACHECO et al., 2000). Alta concentração de glicose promove ativação do fator NF-kB, que liga-se no promotor da iNOS e induz expressão da enzima, em células epiteliais do cristalino humano (JIA et al., 2013). Por outro lado, alta concentração de glicose induz a expressão de IL-1 $\beta$, em células endoteliais da retina e monócitos, via ativação de PKC e NF-KB (DASU et al., 2007; LIU et al., 2012). Estes resultados indicam que alta concentração de glicose seja responsável pelo aumento na expressão de IL-1 $\beta$ e de iNOS. No entanto, em nosso trabalho, observamos que a alta concentração de glicose não parece ser a única responsável pelo aumento da iNOS/NO e IL-1 $\beta$, visto que o tratamento com insulina, mesmo promovendo alguns períodos de redução da glicemia, não foi eficaz em corrigir completamente esse parâmetro, mas corrigiu os parâmetros inflamatórios em ratas diabéticas. Na sepse, o tratamento com insulina promove redução da expressão da iNOS e de citocinas pró-inflamatórias sem alterar a glicemia (BRIX-CHRISTENSEN et al., 2004; CHEN et al., 2006), mostrando que a insulina pode ter efeito anti-inflamatório. No presente estudo, o tratamento com LNIL, além de reduzir a concentração plasmática de NO, reduziu também a expressão da citocina IL-1 $1 \beta$ em aorta de ratas diabéticas. Apesar de ter sido observado que a expressão de citocinas inflamatórias, tais como TNF- $\alpha$ e IL-1 $\beta$ precede a expressão da iNOS (LIN et al., 2006; SU et al., 2007), a produção excessiva de NO via iNOS pode provocar a liberação de IL-1 $\beta$, pois o uso de inibidores da iNOS também promoveu redução da concentração plasmática de IL-1 $\beta$ 
(ALDRICH; SEVICK-MURACA 2013; SU et al., 2007). Portanto, estes resultados mostram que a hiperglicemia induz a expressão de fatores inflamatórios, que podem induzir expressão adicional desses fatores, amplificando a inflamação no diabetes.

As ações da insulina não são restritas apenas ao metabolismo de carboidratos, proteínas e lipídeos e, portanto, é difícil discriminar se as alterações observadas em diabéticos são consequências da hiperglicemia ou da falta de insulina. Em aorta de ratos diabéticos, a redução da resposta vasoconstritora foi corrigida pela insulina somente em dose que normalizou a glicemia desses ratos (KOBAYASHI; KAMATA, 1999), indicando que a hiperglicemia é a responsável pelas alterações. No entanto, o tratamento com a insulina utilizado no presente estudo foi capaz de corrigir a resposta contrátil à noradrenalina e à fenilefrina, mesmo não sendo capaz de corrigir totalmente os parâmetros metabólicos em ratas diabéticas. Assim, nossos resultados sugerem que em fêmeas diabéticas a hiperglicemia pode não ser a única responsável pela redução da resposta contrátil.

Takahashi e colaboradores (2008) mostraram que a redução da resposta à fenilefrina em aorta de ratos diabéticos ocorre devido ao aumento na expressão da iNOS e não ao aumento da glicose, pois em aortas incubadas com LPS há redução da contração para a fenilefrina, enquanto que a contração em aortas incubadas apenas com alta concentração de glicose não difere da contração de aortas incubadas com baixa concentração de glicose. Os efeitos agudos danosos do NO, produzido a partir da iNOS, podem ser exemplificados com o que ocorre no choque séptico, onde a ativação da iNOS promove vasodilatação intensa, severa hipotensão, depressão cardíaca e falência de múltiplos órgãos (FERDINANDY et al., 2000; PARRILLO, 1993) A inibição aguda da iNOS corrigiu a redução da contração induzida pela noradrenalina em artérias mesentéricas de ratos diabéticos (BARDELL; MACLEOD, 2001; NAGAREDDY et al., 2005). No entanto, em nosso trabalho observamos que a inibição aguda da iNOS aumentou a resposta à noradrenalina em aorta de ratas diabéticas, mas não para os níveis de contração de ratas controles. Portanto, outros mecanismos induzidos pelo aumento da geração de NO podem estar envolvidos na redução da capacidade contrátil em aorta de ratas diabéticas, e não apenas um efeito agudo direto do NO sobre a contração vascular. Mudanças secundárias ao aumento da geração de NO no sistema vascular podem contribuir para a redução da contração vascular em aorta de ratas diabéticas. Por exemplo, a formação de peroxinitrito, que pode induzir modificações pós-tradução, 
poderia promover mudanças na função de proteínas ou receptores envolvidos na contração vascular (BORBELY et al., 2005; CHOI et al., 2011; PACHER et al., 2005; TAKAKURA et al., 2002)

Nagarredy e colaboradores (2009a) mostraram que tratamento durante 8 semanas com inibidor da iNOS reduz a expressão de nitrotirosina, um marcador de peroxinitrito, e aumenta a resposta pressórica à metoxamina em ratos diabéticos. Em nosso estudo, observamos que tratamento de ratas diabéticas durante 4 semanas com inibidor da iNOS corrigiu a redução da resposta contrátil. No entanto, esse efeito do tratamento com inibidor da iNOS só foi observado na contração induzida pela noradrenalina e fenilefrina, mostrando que aumento da iNOS/NO compromete etapas que não são comuns à resposta contrátil induzida por agonistas adrenérgicos e por alta concentração de potássio, por exemplo, a interação do agonista com o receptor. Foi demonstrado que o peroxinitrito pode reduzir a ligação das catecolaminas aos receptores alfa-adrenérgicos (TAKAKURA et al., 2002). Além disso, foi observado que células mesangiais renais incubadas com citocinas, tais como IL-1ß, apresentam redução da expressão gênica dos receptores alfaadrenérgicos (BUCHER et al., 2003). Portanto, visto que a produção de NO e a expressão de IL-1 $\beta$ foram reduzidas após o tratamento com insulina ou L-NIL, um dos mecanismos responsáveis pela correção da contração vascular induzida por agonistas adrenérgicos em aorta de ratas diabéticas poderia ser a melhora da expressão ou sinalização dos receptores adrenérgicos. No entanto, mais experimentos precisam ser realizados para confirmar esta hipótese.

A s-nitrosilação pode comprometer a função vascular, visto que, em aorta de camundongos, a indução in vitro da s-nitrosilação promoveu redução na vasoconstrição (CHOl et al., 2011). Nosso trabalho é o primeiro a mostrar que em aorta de ratas diabéticas; há aumento na expressão de proteínas s-nitrosiladas. Trabalhos já mostraram que, em machos, o diabetes pode promover s-nitrosilação, por exemplo, do receptor de insulina (CARVALHO-FILHO et al., 2005) e da hemoglobina glicada (PADRÓN et al., 2000). Uma que vez, em nosso trabalho, os tratamentos reduziram a s-nitrosilação de proteínas, concomitantemente com a redução da produção de NO e aumento na contração vascular, esta modificação pós-tradução induzida pelo excesso de NO pode ser responsável pela redução da capacidade contrátil em aorta de ratas diabéticas. 
O mecanismo pelo qual o diabetes leva ao aumento da iNOS/NO não é conhecido, mas a perda da proteção do estrógeno pode estar envolvida. Em fêmeas, o efeito protetor exercido pelo estrógeno no sistema cardiovascular, por exemplo, melhorando a função vascular por aumentar a liberação de fatores relaxantes (BOLEGO et al., 1997; MAJMUDAR et al., 2000; YANG et al., 2000), é perdido em condições de alta concentração de glicose e no diabetes. Alterações do padrão de expressão e/ou ativação dos subtipos de receptores de estrógeno podem ser responsáveis, pelo menos em parte, pela perda do efeito protetor do estrógeno no diabetes.

Agonista do ESR2 (CIGNARELLA et al., 2006) e a ativação do ESR2 pelo estrógeno (TSUTSUMI et al., 2008) induzem a expressão de enzimas inflamatórias, incluindo a iNOS, em células do músculo liso vascular. Por outro lado, ratas que não expressam o receptor ESR2 apresentam redução na expressão da iNOS em aorta (LIANG et al., 2003). Assim, aumento da expressão do ESR2 poderia acarretar em aumento na expressão da iNOS. O estrógeno regula a expressão dos seus receptores em células endoteliais, aumentando a expressão do ESR1 e diminuindo a expressão do ESR2 (IHIONKHAN et al., 2002). No entanto, quando células endoteliais são colocadas em um meio contendo alta concentração de glicose, o estrógeno induz um padrão diferente de expressão dos seus receptores, com redução na expressão do ESR1 e aumento do ESR2 (CHAKRABARTI; DAVIDGE 2009). Em nosso estudo, observamos aumento da imunomarcação para o receptor ESR2 em aorta de ratas diabéticas, que poderia contribuir com a redução da resposta a agonistas adrenérgicos, por induzir aumento da expressão da iNOS. Suportamos esta hipótese visto que foi observado que o ESR2 esta envolvido com a redução da contração vascular em aorta de camundongos normoglicêmicos via iNOS (ZHU et al., 2002). Além disso, o tratamento com insulina, ao mesmo tempo em que corrigiu a contração aos agonistas adrenérgicos e a expressão da iNOS, corrigiu a imunomarcação para o ESR2.

Apesar de observarmos aumento na expressão do receptor de estrógeno ESR2, a inibição aguda deste receptor não promoveu aumento da resposta contrátil à noradrenalina em aorta de ratas diabéticas. Já foi demonstrado que o uso de agonistas do ESR2 induz redução na contratilidade vascular (LAHM et al., 2008; MA et al., 2010) e observou-se que este foi um efeito não-genômico sobre o influxo de cálcio (MA et al., 2010). No entanto, os efeitos do ESR2 sobre a resposta 
vasoconstritora em aorta de ratas diabéticas parecem ser crônicos, por exemplo, regulando a expressão da iNOS.

Em nosso trabalho, mostramos que há aumento da expressão proteica do receptor GPER no músculo liso de aorta de ratas diabéticas. Diferentemente do ESR1 e ESR2 que são receptores nucleares, o GPER é um receptor transmembrana acoplado à proteína G (MEYER et al., 2011). É expresso no sistema cardiovascular de humanos e animais de ambos os sexos (PROSSNITZ; BARTON, 2011), sugerindo que, assim como o ESR1 e ESR2, o GPER tem um papel no controle do tônus vascular. Animais com ausência do gene GPER mostram aumento da sensibilidade das proteínas contráteis ao cálcio (MEYER et al., 2011) e da contratilidade dependente de endotélio (MEYER et al., 2012), enquanto que o agonista seletivo do GPER G-1 reduz o aumento da concentração de cálcio intracelular induzido pela serotonina em células do músculo liso vascular (HAAS et al., 2009) e promove relaxamento na artéria coronária sem endotélio via ativação dos canais de potássio (YU et al., 2011). Produção de NO é outro mecanismo pelo qual a ativação do receptor GPER regula o tônus vascular, uma vez que, ativação desse receptor leva a fosforilação da eNOS e aumento da concentração de NO em células endoteliais (LI et al., 2012). Com estes trabalhos, observamos que o GPER reduz o tônus vascular, reduzindo a contratilidade tanto via cálcio quanto via NO, e que aumento da expressão desse receptor poderia contribuir para a redução da resposta contrátil em aorta de ratas diabéticas. Portanto, um envolvimento do aumento da expressão do GPER sobre a redução da contração vascular não pode ser descartado. 


\section{CONCLUSÃO}

Nossos resultados permitem concluir que em aorta de ratas diabéticas:

1 - a redução da resposta contrátil mediada por receptor adrenérgico depende da via iNOS/geração de NO/s-nitrosilação;

2 - a redução da resposta contrátil induzida por alta concentração de potássio não envolve a via iNOS/geração de NO/s-nitrosilação;

3 - o aumento da expressão dos receptores de estrógeno, ESR2 e GPER, podem contribuir para a redução da capacidade contrátil, mas o envolvimento do receptor de estrógeno ESR2 depende de mecanismos que não são bloqueados agudamente;

4 - a insulina modula negativamente a expressão da iNOS/geração de NO, das proteínas s-nitrosiladas e dos receptores ESR2 e GPER, efeito que pode contribuir com a restauração da contração induzida por agonistas adrenérgicos. 


\section{REFERÊNCIAS*}

ADLER, G. K.; BONYHAY, I.; FAILING, H.; WARING, E.; DOTSON, S.; FREEMAN, R. Antecedent hypoglycemia impairs autonomic cardiovascular function: implications for rigorous glycemic control. Diabetes, v. 58, n. 2, p. 360-366, 2009.

AKAMINE, E. H.; HOHMAN, T. C.; NIGRO, D.; CARVALHO, M. H.; DE CÁSSIA TOSTES, R.; FORTES, Z. B. Minalrestat, an aldose reductase inhibitor, corrects the impaired microvascular reactivity in diabetes. J. Pharmacol. Exp. Ther., v. 304, n. 3, p. 1236-1242, 2003.

ALDRICH, M. B.; SEVICK-MURACA, E. M. Cytokines are systemic effectors of lymphatic function in acute inflammation. Cytokine, v. 64, n. 1, p. 362-369, 2013.

ALVAREZ, Y.; BRIONES, A. M.; HERNANZ, R.; PÉREZ-GIRÓN, JV, ALONSO, M. J.; SALAICES, M. Role of NADPH oxidase and iNOS in vasoconstrictor responses of vessels from hypertensive and normotensive rats. Br. J. Pharmacol., v. 153, n. 5, p. 926-935, 2008.

ARNUSH, M.; HEITMEIER, M. R.; SCARIM, A. L.; MARINO, M. H.; MANNING, P. T.; CORBETT, J. A. IL-1 produced and released endogenously within human islets inhibits beta cell function. J. Clin. Invest., v. 102, n. 3, p. 516-526, 1998.

BARDELL, A. L.; MACLEOD, K. M. Evidence for inducible nitric-oxide synthase expression and activity in vascular smooth muscle of streptozotocin-diabetic rats. J. Pharmacol. Exp. Ther., v. 296, n. 2, p. 252-259, 2001.

BARRETT-CONNOR, E.; WINGARD; D. L. Sex differential in ischemic heart disease mortality in diabetics: a prospective population-based study. Am. J. Epidemiol., v. 118, n. 4, p. 489-496, 1983.

BEASLEY, D.; SCHWARTZ, J. H.; BRENNER, B. M. Interleukin 1 induces prolonged $\mathrm{L}$-arginine-dependent cyclic guanosine monophosphate and nitrite production in rat vascular smooth muscle cells. J. Clin. Invest., v. 87, n. 2, p. 602-608, 1991.

BIAN, K.; MURAD, F. Nitric oxide (NO)--biogeneration, regulation, and relevance to human diseases. Front. Biosci., v. 8, p. d264-d278, 2003.

BOLEGO, C.; CIGNARELLA, A.; RUZZA, R.; ZAAROUR, C.; MESSI, E.; ZANISI, M.; PUGLISI, L. Differential effects of low- and high-dose estrogen treatments on vascular responses in female rats. Life Sci., v. 60, n. 25, p. 2291-2302, 1997.

BOLEGO, C.; CIGNARELLA, A.; ZANCAN, V.; PINNA, C.; ZANARDO, R.; PUGLISI, $\mathrm{L}$. Diabetes abolishes the vascular protective effects of estrogen in female rats. Life Sci., v. 64, n. 9, p. 741-749, 1999.

*De acordo com:

ASSOCIAÇÃO BRASILEIRA DE NORMAS TÉCNICAS. NBR 6023: informação e documentação: referências: elaboração. Rio de Janeiro, 2002. 
BOlEGo, C.; CIGNARELlA, A.; SANVITO, P.; PELOSI, V.; PELLEGATTA, F.; PUGLISI, L.; PINNA, C. The acute estrogenic dilation of rat aorta is mediated solely by selective estrogen receptor- $\alpha$ agonists and is abolished by estrogen deprivation. $\mathbf{J}$ Pharmacol. Exp. Ther., v. 313, n. 3, p. 1203-1208, 2005.

BOlego, C. ; VEGETO, E.; PINNA, C.; MAGGI, A. ; CIGNARELLA, A. Selective agonists of estrogen receptor isoforms: new perspectives for cardiovascular disease. Arterioscler. Thromb. Vasc. Biol., v. 26, n. 10, p. 2192-2199, 2006.

BOJUNGA, J. ; DRESAR-MAYERT, B. ; USADEL, K. H. ; KUSTERER, K. ; ZEUZEM, $S$. Antioxidative treatment reverses imbalances of nitric oxide synthase isoform expression and attenuates tissue-cGMP activation in diabetic rats. Biochem. Biophys. Res. Commun., v. 316, n. 3, p. 771-780, 2004.

BORBELY, A.; TOTH, A.; EDES, I.; VIRAG, L.; PAPP, J. G.; VARRO, A.; PAULUS, W. J.; VAN DER VELDEN, J.; STIENEN, G. J.; PAPP, Z. Peroxynitrite-induced alpha-actinin nitration and contractile alterations in isolated human myocardial cells. Cardiovasc. Res., v. 67, n. 2, p. 225-233, 2005.

BRIX-CHRISTENSEN, V.; ANDERSEN, S. K.; ANDERSEN, R.; MENGEL, A.; DYHR, T.; ANDERSEN, N. T.; LARSSON, A.; SCHMITZ, O.; ØRSKOV, H.; TØNNESEN, E. Acute hyperinsulinemia restrains endotoxin-induced systemic inflammatory response: an experimental study in a porcine model. Anesthesiology, v. 100, n. 4, p. 861 870, 2004.

BUCHER, M.; KEES, F.; TAEGER, K.; KURTZ, A. Cytokines down-regulate alpha1adrenergic receptor expression during endotoxemia. Crit. Care Med., v. 31, n. 2, p. 566-571, 2003.

CAMERON, N. E.; COTTER, M. A. Impaired contraction and relaxation in aorta from streptozotocin-diabetic rats: role of polyol pathway. Diabetologia, v. 35, n.11, p. 1011-1019, 1992.

CARMINES, P. K.; OHISHI, K.; IKENAGA, H. Functional impairment of renal afferent arteriolar voltage-gated calcium channels in rats with diabetes mellitus. J. Clin. Invest., v. 98, n. 11, p. 2564-2571, 1996.

CARVALHO-FILHO, M. A.; UENO, M.; HIRABARA, S. M.; SEABRA, A. B.; CARVALHEIRA, J. B.; DE OLIVEIRA, M. G.; VELLOSO, L. A.; CURI, R.; SAAD, M. $\mathrm{J}$. S-nitrosation of the insulin receptor, insulin receptor substrate 1 , and protein kinase B/Akt: a novel mechanism of insulin resistance. Diabetes, v. 54, n. 4, p. 959967, 2005.

CERIELLO, A.; QUAGLIARO, L.; D'AMICO, M.; DI FILIPPO, C.; MARFELLA, R.; NAPPO, F.; BERRINO, L.; ROSSI, F.; GIUGLIANO, D. Acute hyperglycemia induces nitrotyrosine formation and apoptosis in perfused heart from rat. Diabetes , v. 51, n. 4, p. 1076-1082, 2002. 
CHAKRABARTI, S.; DAVIDGE, S. T. High glucose-induced oxidative stress alters estrogen effects on ERalpha and ERbeta in human endothelial cells: reversal by AMPK activator. J. Steroid. Biochem. Mol. Biol., v. 117, n. 4-5, p. 99-106, 2009.

CHANG, K. C.; CHUNG, S. Y.; CHONG, W. S.; SUH, J. S.; KIM, S. H.; NOH, H. K.; SEONG, B. W.; KO, H. J.; CHUN, K. W. Possible superoxide radical-induced alteration of vascular reactivity in aortas from streptozotocin-treated rats. $\mathbf{J}$. Pharmacol. Exp. Ther., v. 266, n. 2, p. 992-1000, 1993.

CHEN, H. I.; YEH, D. Y.; LIOU, H. L.; KAO, S. J. Insulin attenuates endotoxininduced acute lung injury in conscious rats. Crit. Care Med., v. 34, n. 3, p. 758-764, 2006.

CHENG, X. ; PANG, C. C. Increased vasoconstriction to noradrenaline by $1400 \mathrm{~W}$, inhibitor of iNOS, in rats with streptozotocin-induced diabetes. Eur. J. Pharmacol., v. 484, n. 2-3, p. 263-268, 2004.

CHOI, H.; TOSTES, R. C.; WEBB, R. C. S-nitrosylation Inhibits protein kinase Cmediated contraction in mouse aorta. J. Cardiovasc. Pharmacol., v. 57, n. 1, p. 65$71,2011$.

CIGNARELLA, A.; MINICI, C.; BOLEGO, C.; PINNA, C.; SANVITO, P.; GAION, R. M.; PUGLISI, L. Potential pro-inflammatory action of resveratrol in vascular smooth muscle cells from normal and diabetic rats. Nutr. Metab. Cardiovasc. Dis., v. 16, n. 5, p. 322-329, 2006.

CORBETT, J. A.; KWON, G.; MARINO, M. H.; RODI, C. P.; SULLIVAN, P. M.; TURK, J.; MCDANIEL, M. L. Tyrosine kinase inhibitors prevent cytokine-induced expression of iNOS and COX-2 by human islets. Am. J. Physiol., v. 270, n. 6, pt. 1, p. C1581C1587, 1996.

CUNHA, F. Q.; ASSREUY, J.; MOSS, D. W.; REES, D.; LEAL, L. M.; MONCADA, S.; CARRIER, M.; O'DONNELL, C. A.; LIEW, F. Y. Differential induction of nitric oxide synthase in various organs of the mouse during endotoxaemia: role of TNF-alpha and IL-1-beta. Immunology, v. 81, n. 2, p. 211-215, 1994.

DARBLADE, B.; PENDARIES, C.; KRUST, A.; DUPONT, S.; FOUQUE, M. J.; RAMI, J.; CHAMBON, P.; BAYARD, F.; ARNAL, J. F. Estradiol alters nitric oxide production in the mouse aorta through the alpha-, but not beta-, estrogen receptor. Circ. Res., v. 90, n. 4, p. 413-419, 2002.

DASU, M. R.; DEVARAJ, S.; JIALAL, I. High glucose induces IL-1beta expression in human monocytes: mechanistic insights. Am. J. Physiol. Endocrinol. Metab., v. 293, n. 1, p. E337-E346, 2007.

De VRIESE, A. S.; VERBEUREN, T. J.; Van de VOORDE, J.; LAMEIRE, N. H.; VANHOUTTE, P. M. Endothelial dysfunction in diabetes. Br. J. Pharmacol., v. 130, n. 5, p. 963-974, 2000. 
EPPENS, M. C.; CRAIG, M. E.; CUSUMANO, J.; HING, S.; CHAN, A. K.; HOWARD, N. J.; SILINK, M.; DONAGHUE, K. C. Prevalence of diabetes complications in adolescents with type 2 compared with type 1 diabetes. Diabetes Care., v. 29, n. 6, p. 1300-1306, 2006.

FERDINANDY, P.; DANIAL, H.; AMBRUS, I.; ROTHERY, R. A.; SCHULZ, R. Peroxynitrite is a major contributor to cytokine-induced myocardial contractile failure. Circ. Res., v. 87, n. 3, p. 241-247, 2000.

FORTES, Z. B.; GARCIA-LEME, J.; SCIVOLETTO, R. Influence of diabetes on the reactivity of mesenteric microvessels to histamine, bradykinin and acetylcholine. Br. J. Pharmacol., v. 78, n. 1, p. 39-48, 1983a.

FORTES, Z. B.; GARCIA-LEME, J.; SCIVOLETTO, R. Vascular reactivity in diabetes mellitus: role of the endothelial cell. Br. J. Pharmacol., v. 79, n. 3, p. 771-781, 1983b.

FORTES, Z. B.; GARCIA-LEME, J.; SCIVOLETTO, R. Vascular resctivity in diabetes mellitus: possible role of insulin on the endothelial cell. Br. J. Pharmacol., v. 83, n. 3, p. 635-643, 1984.

FORTES, Z. B.; SCIVOLETTO, R.; GARCIA-LEME, J. Functional changes in the microcirculation of alloxan-induced diabetic rats. Gen. Pharmacol., v. 20, n. 5, p. 615-620, 1989.

FOSTER, M. W.; MCMAHON, T. J.; STAMLER, J. S. S-nitrosylation in health and disease. Trends Mol. Med., 2003; v. 9, n. 4, p. 160-168, 2003.

FOSTER, M. W.; HESS, D. T.; STAMLER, J. S. Protein S-nitrosylation in health and disease: a current perspective. Trends Mol. Med., v. 15, n. 9, p. 391-404, 2009.

FURCHGOTT, R. F. Endothelium-derived relaxing factor: discovery, early studies, and identification as nitric oxide. Biosci. Rep., v. 19, n. 4, p. 235-251, 1999.

GANDO, S.; HATTORI, Y.; AKAISHI, Y.; NISHIHIRA, J.; KANNO, M. Impaired contractile response to beta adrenoceptor stimulation in diabetic rat hearts: alterations in beta adrenoceptors-G protein-adenylate cyclase system and phospholamban phosphorylation. J. Pharmacol. Exp. Ther., v. 282, n. 1, p. 475-484, 1997.

GOEL, A.; ZHANG, Y.; ANDERSON, L.; RAHIMIAN, R. Gender difference in rat aorta vasodilation after acute exposure to high glucose: involvement of protein kinase $\mathrm{C}$ beta and superoxide but not of Rho kinase. Cardiovasc. Res., v. 76, n. 2, p. 351360, 2007.

GOEL, A.; THOR, D.; ANDERSON, L.; RAHIMIAN, R. Sexual dimorphism in rabbit aortic endothelial function under acute hyperglycemic conditions and gender-specific responses to acute 17beta-estradiol. Am. J. Physiol. Heart Circ. Physiol., v. 294, n. 6, p. H2411-H2420, 2008. 
GUZMÁN, C. B.; WALSH, M.; REDDY, V.; DONTHIREDDY, V.; MAHMOOD, F.; BODE, A.; TURNER, J. R.; JACOBER, S. J.; SOWERS, J. R. Altered myosin lightchain phosphorylation in resting platelets from premenopausal women with diabetes. Metabolism., v. 50, n. 2, p. 151-156, 2001.

HAAS, E.; BHATTACHARYA, I.; BRAILOIU, E.; DAMJANOVIĆ, M.; BRAILOIU, G. C.; GAO, X.; MUELLER-GUERRE, L.; MARJON, N. A.; GUT, A.; MINOTTI, R.; MEYER, M. R, AMANN K., AMMANN, E.; PEREZ-DOMINGUEZ, A.; GENONI, M.; CLEGG, D. J.; DUN, N. J.; RESTA, T. C.; PROSSNITZ, E. R.; BARTON, M. Regulatory role of $G$ protein-coupled estrogen receptor for vascular function and obesity. Circ. Res., v. 104, n. 3, p. 288-291, 2009.

HALLINAN, E. A.; TSYMBALOV, S.; DORN, C. R.; PITZELE, B. S.; HANSEN, D. W. JR; MOORE, W. M.; JEROME, G. M.; CONNOR, J. R.; BRANSON, L. F.; WIDOMSKI, D. L.; ZHANG, Y.; CURRIE, M. G.; MANNING, P. T. Synthesis and biological characterization of L-N(6)-(1-iminoethyl)lysine 5-tetrazole-amide, a prodrug of a selective iNOS inhibitor. J. Med. Chem., v. 45, n. 8, p. 1686-1689, 2002.

HARRIS, K. H.; MACLEOD, K. M. Influence of the endothelium on contractile responses of arteries from diabetic rats. Eur. J. Pharmacol., v. 153, n. 1, p. 55-64, 1988.

HATTORI, Y.; KAWASAKI, H.; KAZUHIRO, A.; KANNO, M. Superoxide dismutase recovers altered endothelium-dependent relaxation in diabetic rat aorta. Am. J. Physiol., v. 261, n. 4, pt. 2, p. H1086-H94, 1991.

HEAD, R. J.; LONGHURST, P. A.; PANEK, R. L.; STITZEL, R. E. A contrasting effect of the diabetic state upon the contractile responses of aortic preparations from the rat and rabbit. Br. J. Pharmacol., v. 91, n. 2, p. 275-286, 1987.

HEWITT, S. C.; HARRELL, J. C.; KORACH, K. S. Lessons in estrogen biology from knockout and transgenic animals. Annu. Rev. Physiol., v. 67, p. 285-308, 2005.

HEYGATE, K. M.; LAWRENCE, I. G.; BENNETT, M. A.; THURSTON, H. Impaired endothelium-dependent relaxation in isolated resistance arteries of spontaneously diabetic rats. Br. J. Pharmacol., v. 116, n. 8, p. 3251-3259, 1995.

HIMPENS, B.; MISSIAEN, L.; CASTEELS, R. Ca2+ homeostasis in vascular smooth muscle. J. Vasc. Res., v. 32, n. 4, p. 207-219, 1995.

HU, G.; DECODE Study Group. Gender difference in all-cause and cardiovascular mortality related to hyperglycaemia and newly-diagnosed diabetes. Diabetologia, $\mathrm{v}$. 46, n. 5, p. 608-617, 2003.

INTERNACIONAL DIABETES FEDERATION (IDF). Versão online do IDF diabetes atlas. 6. ed. Disponível em: <www.idf.org/diabetesatlas>. Acesso em: 2 dez. 2013.

IDO, Y.; KILO, C.; WILLIAMSON. J. R. Cytosolic NADH/NAD+, free radicals, and vascular dysfunction in early diabetes mellitus. Diabetologia., v. 40, n. Suppl 2, p. S115-S117, 1997. 
IHIONKHAN, C. E.; CHAMBLISS, K. L.; GIBSON, L. L.; HAHNER, L. D.; MENDELSOHN, M. E.; SHAUL, P. W. Estrogen causes dynamic alterations in endothelial estrogen receptor expression. Circ. Res., v. 91, n. 9, p. 814-820, 2002.

ISCHIROPOULOS, H. Biological tyrosine nitration: a pathophysiological function of nitric oxide and reactive oxygen species. Arch. Biochem. Biophys., v. 356, n. 1, p. $1-11,1998$.

JAFFREY, S. R.; SNYDER, S. H. The biotin switch method for the detection of Snitrosylated proteins. Sci. STKE., n. 86, p. I1, 2001

JIA, J.; LIU, Y.; ZHANG, X.; LIU, X.; QI, J. Regulation of iNOS expression by NF-kB in human lens epithelial cells treated with high levels of glucose. Invest. Ophthalmol. Vis. Sci., v. 54, n. 7, p. 5070-5077, 2003.

JÖRNS, A.; MUNDAY, R.; TIEDGE, M.; LENZEN, S. Comparative toxicity of alloxan, $\mathrm{N}$-alkylalloxans and ninhydrin to isolated pancreatic islets in vitro. J. Endocrinol., v. 155, n. 2, p. 283-293, 1997.

KATOVICH, M. J.; HANLEY, K.; STRUBBE, G.; WRIGHT, B. E. Effects of streptozotocin-induced diabetes and insulin treatment on blood pressure in the male rat. Proc. Soc. Exp. Biol. Med., v. 208, n. 3, p. 300-306, 1995.

KEEGAN, A.; JACK, A. M.; COTTER, M. A.; CAMERON, N. E. Effects of aldose reductase inhibition on responses of the corpus cavernosum and mesenteric vascular bed of diabetic rats. J. Cardiovasc. Pharmacol., v. 35, n. 4, p. 606-613, 2000.

KELLY-COBBS, A. I.; PRAKASH, R.; COUCHA, M.; KNIGHT, R. A.; LI, W.; OGBI, S. N.; JOHNSON, M.; ERGUL, A. Cerebral myogenic reactivity and blood flow in type 2 diabetic rats: role of peroxynitrite in hypoxia-mediated loss of myogenic tone. $\mathbf{J}$. Pharmacol. Exp. Ther., v. 342, n. 2, p. 407-415, 2012.

KHAMAISI, M.; WEXLER, I. D.; SKRHA, J.; STROJEK, K.; RAZ, I.; MILICEVIC, Z.Cardiovascular disease in type 2 diabetics: epidemiology, risk factors and therapeutic modalities. Isr. Med. Assoc. J., v. 5, n. 11, p. 801-806, 2003.

KIM, S. H.; PARK, K. W.; KIM, Y. S.; OH, S.; CHAE, I. H.; KIM, H. S.; KIM, C. H. Effects of acute hyperglycemia on endothelium-dependent vasodilation in patients with diabetes mellitus or impaired glucose metabolism. Endothelium, v. 10, n. 2, p. 65-70, 2003.

KNEPPER, L. E.; GIULIANI, M. J. Cerebrovascular disease in women. Cardiology, v.86, n. 4, p. 339-348, 1995.

KOBAYASHI, T.; KAMATA, K. Effect of insulin treatment on smooth muscle contractility and endothelium-dependent relaxation in rat aortae from established STZ-induced diabetes. Br. J. Pharmacol., v. 27, n. 4, p. 835-842, 1999. 
LAHM, T.; CRISOSTOMO, P. R.; MARKEL, T. A.; WANG, M.; WANG, Y.; TAN, J.; MELDRUM, D. R. Am. J. Physiol. Regul. Integr. Comp. Physiol., v. 295, n. 5, p. R1486-R1493, 2008.

LEGATO, M. J.; GELZER, A.; GOLAND, R.; EBNER, S. A.; RAJAN, S.; VILLAGRA, V.; KOSOWSKI, M. Writing Group for The Partnership for Gender-Specific. Genderspecific care of the patient with diabetes: review and recommendations. Gend. Med., v. 3, n. 2, p. 131-158, 2006.

LI, Y.; QI, J.; LIU, K.; LI, B.; WANG, H.; JIA, J. Peroxynitrite-induced nitration of cyclooxygenase-2 and inducible nitric oxide synthase promotes their binding in diabetic angiopathy. Mol. Med., v. 16, n. 9-10, p. 335-342, 2010.

LI, Z. L.; LIU, J. C.; LIU, S. B.; LI, X. Q.; YI, D. H.; ZHAO, M. G. Improvement of vascular function by acute and chronic treatment with the GPR30 agonist G1 in experimental diabetes mellitus. PLoS One, v. 7, n. 6, 2012.

LIANG, M.; EKBLAD, E.; LYDRUP, M. L.; NILSSON, B. O. Combined lack of estrogen receptors alpha and beta affects vascular iNOS protein expression. Cell Tissue Res., v. 313, n. 1, p. 63-70, 2003.

LIN, N. T.; YANG, F. L.; LEE, R. P.; PENG, T. C.; CHEN, H. I. Inducible nitric oxide synthase mediates cytokine release: the time course in conscious and septic rats.. Life Sci., v. 78, n. 10, p. 1038-1043, 2006.

LINDSAY, R. M.; PEET, R. S.; WILKIE, G. S.; ROSSITER, S. P.; SMITH, W.; BAIRD, J. D.; WILLIAMS, B. C. In vivo and in vitro evidence of altered nitric oxide metabolism in the spontaneously diabetic, insulin-dependent BB/Edinburgh rat. $\mathbf{B r}$. J. Pharmacol., v. 120, n. 1, p. 1-6, 1997.

LIU, X.; TAKEDA, N.; DHALLA, N. S. Myosin light-chain phosphorylation in diabetic cardiomyopathy in rats. Metabolism., v. 46, n. 1, p. 71-75, 1997.

LIU, Y.; BIARNÉS COSTA, M.; GERHARDINGER, C. IL-1 $1 \beta$ is upregulated in the diabetic retina and retinal vessels: cell-specific effect of high glucose and IL-1 $\beta$ autostimulation. PLoS One, v. 7, n. 5, p. e36949, 2012.

LOWE, G.; WOODWARD, M.; HILLIS, G.; RUMLEY, A.; LI, Q.; HARRAP, S.; MARRE, M.; HAMET, P., PATEL, A.; POULTER, N.; CHALMERS, J. Circulating Inflammatory Markers and The Risk of Vascular Complications and Mortality in People With Type 2 Diabetes Mellitus and Cardiovascular Disease or Risk Factors: The Advance Study. Diabetes, 2013. [Epub ahead of print].

MA, L. ; ZHU, B. ; CHEN, X. ; LIU, J.; GUAN, Y. ; REN, J. Abnormalities of sarcoplasmic reticulum $\mathrm{Ca2}+$ mobilization in aortic smooth muscle cells from streptozotocin-induced diabetic rats. Clin. Exp. Pharmacol. Physiol., v. 35, n. 5-6, p. 568-573, 2008. 
MA, Y.; QIAO, X.; FALONE, A. E.; RESLAN, O. M.; SHEPPARD, S. J.; KHALIL, R. A. Gender-specific reduction in contraction is associated with increased estrogen receptor expression in single vascular smooth muscle cells of female rat. Cell Physiol. Biochem., v. 26, n. 3, p. 457-470, 2010.

MACLEOD, K. M. The effect of insulin treatment on changes in vascular reactivity in chronic, experimental diabetes. Diabetes, v. 34, n. 11, p. 1160-1167, 1985.

MACMICKING, J. D.; NATHAN, C.; HOM, G.; CHARTRAIN, N.; FLETCHER, D. S.; TRUMBAUER, M.; STEVENS, K.; XIE, Q. W.; SOKOL, K.; HUTCHINSON, N., et al. Altered responses to bacterial infection and endotoxic shock in mice lacking inducible nitric oxide synthase. Cell, v. 81, n. 4, p. 641-650, 1995.

MACMILLAN-CROW, L. A.; THOMPSON, J. A. Tyrosine modifications and inactivation of active site manganese superoxide dismutase mutant (Y34F) by peroxynitrite. Arch. Biochem. Biophys., v. 366, n. 1, p. 82-88, 1999.

MAEDA, C. Y.; FERNANDES, T. G.; TIMM, H. B.; IRIGOYEN, M. C. Autonomic dysfunction in short-term experimental diabetes. Hypertension, v. 26, n. 6, pt. 2, p. 1100-1104, 1995.

MAGGI, A.; CIGNARELLA, A.; BRUSADELLI, A.; BOLEGO, C.; PINNA, C.; PUGLISI, $L$. Diabetes undermines estrogen control of inducible nitric oxide synthase function in rat aortic smooth muscle cells through overexpression of estrogen receptor-beta. Circulation, v. 108, n. 2, p. 211-217, 2003.

MAJMUDAR, N. G.; ROBSON, S. C.; FORD, G. A. Effects of the menopause, gender, and estrogen replacement therapy on vascular nitric oxide activity. J. Clin. Endocrinol. Metab., v. 85, n. 4, p. 1577-1583, 2000.

MARCONDES, F. K.; BIANCHI, F. J. and TANNO, A. P.. Determination of the estrous cycle phases of rats: some helpful considerations. Braz. J. Biol. [online], vol.62, n.4a, p. 609-614, 2002.

MARSHALL, H. E.; MERCHANT, K.; STAMLER, J. S. Nitrosation and oxidation in the regulation of gene expression. FASEB J., v. 14, n. 13, p. 1889-1900, 2000.

MARTÍNEZ-RUIZ, A.; CADENAS, S.; LAMAS, S. Nitric oxide signaling: classical, less classical, and nonclassical mechanisms. Free Radic. Biol. Med., v. 51, n. 1, p. 1729, 2011.

MAYHAN, W. G.; SUN, H.; IRVINE, S. D. Influence of gender on dilation of the basilar artery during diabetes mellitus. Brain Res., v. 930, n. 1-2, p. 182-190, 2002.

MEYER, M. R.; PROSSNITZ, E. R.; BARTON, M. The G protein-coupled estrogen receptor GPER/GPR30 as a regulator of cardiovascular function. Vascul. Pharmacol., v. 55, n. 1-3, p. 17-25, 2011. 
MEYER, M. R.; AMANN, K.; FIELD, A. S.; HU, C.; HATHAWAY, H. J.; KANAGY, N. L.; WALKER, M. K.; BARTON, M.; PROSSNITZ, E. R. Deletion of G protein-coupled estrogen receptor increases endothelial vasoconstriction. Hypertension, v. 59, n. 2, p. 507-512, 2012.

MOMBOULI, J.; VANHOUTE, P. M. Endothelial dysfunction: from physiology to therapy. J. Mol. Cell Cardiol., v. 31, n. 1, p. 61-74, 1999.

MONCADA, S.; PALMER, R. M.; HIGGS, E. A. Nitric oxide: physiology, pathophysiology, and pharmacology. Pharmacol. Rev., n. 43, n. 2, p. 109-142, 1991.

MOORE, W. M.; WEBBER, R. K.; JEROME, G. M.; TJOENG, F. S.; MISKO, T. P.; CURRIE, M. G. L-N6-(1-iminoethyl)lysine: a selective inhibitor of inducible nitric oxide synthase. J. Med. Chem., v. 37, n. 23, p. 3886-3888, 1994.

NAGAREDDY, P. R.; XIA, Z.; MCNEILL, J. H.; MACLEOD, K. M. Increased expression of iNOS is associated with endothelial dysfunction and impaired pressor responsiveness in streptozotocin-induced diabetes. Am. J. Physiol. Heart Circ. Physiol., v. 289, n. 5, p. H2144-H2152, 2005.

NAGAREDDY, P. R.; XIA, Z.; MACLEOD, K. M.; MCNEILL, J. H. N-acetylcysteine prevents nitrosative stress-associated depression of blood pressure and heart rate in streptozotocin diabetic rats. J. Cardiovasc. Pharmacol., v. 47, n. 4, p. 513-520, 2006.

NAGAREDDY, P. R.; MCNEILL, J. H.; MACLEOD, K. M. Chronic inhibition of inducible nitric oxide synthase ameliorates cardiovascular abnormalities in streptozotocin diabetic rats. Eur. J. Pharmacol., v. 611, n. 1-3, p. 53-59, 2009a.

NAGAREDDY, P. R.; SOLIMAN, H.; LIN, G.; RAJPUT, P. S.; KUMAR, U.; MCNEILL, J. H.; MACLEOD, K. M. Selective inhibition of protein kinase $C$ beta(2) attenuates inducible nitric oxide synthase-mediated cardiovascular abnormalities in streptozotocin-induced diabetic rats. Diabetes, v. 58, n. 10, p. 2355-2364, 2009b.

NASSAR, T.; KADERY, B.; LOTAN, C.; DA'AS, N.; KLEINMAN, Y.; HAJ-YEHIA, A. Effects of the superoxide dismutase-mimetic compound tempol on endothelial dysfunction in streptozotocin-induced diabetic rats. Eur. J. Pharmacol., v. 436, n. 12, p. 111-118, 2002.

OKON, E. B.; SZADO, T.; LAHER, I.; MCMANUS, B.; VAN BREEMEN, C. Augmented contractile response of vascular smooth muscle in a diabetic mouse model. J. Vasc. Res., v. 40, n. 6, p. 520-530, 2003.

PACHECO, M. E.; MARÍN, J.; MANSO, A. M.; RODRÍGUEZ-MARTÍNEZ, M. A.; BRIONES, A.; SALAICES, M.; REDONDO, J. Nitric oxide synthase induction by ouabain in vascular smooth muscle cells from normotensive and hypertensive rats. $\mathbf{J}$. Hypertens., v. 18, n. 7, p. 877-884, 2000.

PACHECO, M. E.; BELTRÁN, A.; REDONDO, J.; MANSO, A. M.; ALONSO, M. J.; SALAICES, M. High glucose enhances inducible nitric oxide synthase expression. 
Role of protein kinase C-betall.. Eur. J. Pharmacol., v. 538, n. 1-3, p. 115-123, 2006.

PACHER, P.; SCHULZ, R.; LIAUDET, L.; SZABO, C. Nitrosative stress and pharmacological modulation of heart failure. Trends Pharmacol. Sci., v. 26, n. 6, p. 302-310, 2005.

PADRÓN, J.; PEIRÓ, C.; CERCAS, E.; LLERGO, J. L.; SÁNCHEZ-FERRER, C. F. Enhancement of S-nitrosylation in glycosylated hemoglobin. Biochem. Biophys. Res. Commun., v. 271, n. 1, p. 217-221, 2000.

PANNIRSELVAM, M.; VERMA, S.; ANDERSON, T. J.; TRIGGLE, C. R. Cellular basis of endothelial dysfunction in small mesenteric arteries from spontaneously diabetic ( $\mathrm{db} / \mathrm{db}-/-)$ mice: role of decreased tetrahydrobiopterin bioavailability. Br. J. Pharmacol., v. 136, n. 2, p. 255-263, 2002.

PARRILLO, J. E. Pathogenetic mechanisms of septic shock. N. Engl. J. Med., v. 328, n. 20, p. 1471-1477, 1993.

PFAFFMAN, M. A.; BALL, C. R.; DARBY, A.; HILMAN, R. Insulin reversal of diabetes-induced inhibition of vascular contractility in the rat. Am. J. Physiol., v. 242, n. 4, p. H490-H495, 1982.

PIEPER, G. M.; PELTIER, B. A. Amelioration by L-arginine of a dysfunctional arginine/nitric oxide pathway in diabetic endothelium. J. Cardiovasc. Pharmacol., v. 25, n. 3, p. 397-403, 1995.

PROSSNITZ, E. R.; BARTON, M. The G-protein-coupled estrogen receptor GPER in health and disease. Nat. Rev. Endocrinol., v. 7, n. 12, p. 715-726, 2011.

REBOLLEDO, A.; AYALA-PAREDES, F.; MILESI, V.; GRASSI, A. O.; RINALDI, G. J. Short-term streptozotocin-induced diabetes induces pressure decrease associated with reduced aortic ${ }^{45} \mathrm{Ca}^{2+}$ uptake and selective depression of the sustained noradrenergic contraction. Diabetes Metab., v. 27, n. 1, p. 40-48, 2001.

REVANKAR, C. M.; CIMINO, D. F.; SKLAR, L. A.; ARTERBURN, J. B.; PROSSNITZ, E. R. A transmembrane intracellular estrogen receptor mediates rapid cell signaling. Science, v. 307, n. 5715, p. 1625-1630, 2005.

RINALDI, G. J. Blood pressure fall and increased relaxation of aortic smooth muscle in diabetic rats. Diabetes Metab., v. 31, n. 5, p. 487-495, 2005.

RODRIGUES, S. F.; DE OLIVEIRA, M. A.; MARTINS, J. O.; SANNOMIYA, P.; DE CÁSSIA TOSTES, R.; NIGRO, D.; CARVALHO, M. H.; FORTES, Z. B. Differential effects of chloral hydrate- and ketamine/xylazine-induced anesthesia by the s.c. route. Life Sci., v. 79, n. 17, p. 1630-1637, 2006.

ROMERO-CALVO, I.; OCÓN, B.; MARTÍNEZ-MOYA, P.; SUÁREZ, M. D.; ZARZUELO, A.; MARTÍNEZ-AUGUSTIN, O.; DE MEDINA, F. S. Reversible Ponceau 
staining as a loading control alternative to actin in Western blots. Anal Biochem., v. 401, n. 2, p. 318-320, 2010.

ROPELLE, E. R.; PAULI, J. R.; CINTRA, D. E.; DA SILVA, A. S.; DE SOUZA, C. T.; GUADAGNINI, D.; CARVALHO, B. M.; CARICILLI, A. M.; KATASHIMA, C. K.; CARVALHO-FILHO, M. A.; HIRABARA, S.; CURI, R.; VELLOSO, L. A.; SAAD, M. J.; CARVALHEIRA, J. B. Targeted disruption of inducible nitric oxide synthase protects against aging, S-nitrosation, and insulin resistance in muscle of male mice. Diabetes, v. 62, n. 2, p. 466-470, 2013.

RYDÉN, L. ; STANDL, E. ; BARTNIK, M. ; VAN DEN BERGHE, G. ; BETTERIDGE, J. ; DE BOER, M. J. ; COSENTINO, F. ; JÖNSSON, B. ; LAAKSO, M. ; MALMBERG, K. ; PRIORI, S. ; OSTERGREN, J.; TUOMILEHTO, J. ; THRAINSDOTTIR, I. ; VANHOREBEEK, I. ; STRAMBA-BADIALE, M. ; LINDGREN, P. ; QIAO, Q. ; PRIORI, S. G. ; BLANC, J. J. ; BUDAJ, A. ; CAMM, J. ; DEAN, V. ; DECKERS, J. ; DICKSTEIN, K. ; LEKAKIS, J. ; MCGREGOR, K. ; METRA, M. ; MORAIS, J. ; OSTERSPEY, A. ; TAMARGO, J. ; ZAMORANO, J. L. ; DECKERS, J. W. ; BERTRAND, M. ; CHARBONNEL, B. ; ERDMANN, E. ; FERRANNINI, E. ; FLYVBJERG, A. ; GOHLKE, H. ; JUANATEY, J. R. ; GRAHAM, I. ; MONTEIRO, P. F. ; PARHOFER, K. ; PYÖRÄLÄ, K. ; RAZ, I. ; SCHERNTHANER, G. ; VOLPE, M., ; WOOD, D.; Task Force on Diabetes and Cardiovascular Diseases of the European Society of Cardiology (ESC); European Association for the Study of Diabetes (EASD). Guidelines on diabetes, pre-diabetes, and cardiovascular diseases: executive summary. The Task Force on Diabetes and Cardiovascular Diseases of the European Society of Cardiology (ESC) and of the European Association for the Study of Diabetes (EASD). Eur. Heart J., v. 28, n. 1, p. 88-136, 2007.

SAENZ DE TEJADA, I.; GOLDSTEIN, I.; AZADZOI, K.; KRANE, R. J.; COHEN, R. A. Impaired neurogenic and endothelium-mediated relaxation of penile smooth muscle from diabetic men with impotence. N. Engl. J. Med., v. 320, n. 16, p. 1025-1030, 1989.

SARTORETTO, S. M.; SANTOS-EICHLER, R.; DE CÁSSIA, A. T. R.; CARVALHO, M. H.; AKAMINE, E. H.; FORTES, Z. B. Involvement of endothelium in the maintenance of vasoconstrictor response in aortas of diabetic female rats: role of nitric oxide and endothelin. J. Diabetes, v. 5, n. 2, p. 197-206, 2012.

SARTORETTO, S. M. Estudo das alterações da resposta vasoconstritora em aortas de ratas diabéticas e os mecanismos envolvidos. 2009. $115 \mathrm{f}$. Dissertação (Mestrado em Farmacologia) - Instituto de Ciências Biomédicas, Universidade de São Paulo, 2009.

SCHAAN, B. D.; DALL'AGO, P.; MAEDA, C. Y.; FERLIN, E.; FERNANDES, T. G.; SCHMID, H.; IRIGOYEN, M. C. Relationship between cardiovascular dysfunction and hyperglycemia in streptozotocin-induced diabetes in rats. Braz. J. Med. Biol. Res., v. 37, n. 12, p. 1895-1902, 2004.

SCHÄFER, A.; FRACCAROLLO, D.; PFÖRTSCH, S.; FLIERL, U.; VOGT, C.; PFRANG, J.; KOBSAR, A.; RENNÉ, T.; EIGENTHALER, M.; ERTL, G.; BAUERSACHS, J. Improvement of vascular function by acute and chronic treatment 
with the PDE-5 inhibitor sildenafil in experimental diabetes mellitus. Br. J. Pharmacol., v. 153, n. 5, p. 886-893, 2008.

SHARMA, K.; DEELMAN, L.; MADESH, M.; KURZ, B.; CICCONE, E.; SIVA, S.; HU, T.; ZHU, Y.; WANG, L.; HENNING, R.; MA, X.; HAJNOCZKY, G. Involvement of transforming growth factor-beta in regulation of calcium transients in diabetic vascular smooth muscle cells. Am. J. Physiol. Renal Physiol., v. 285, n. 6, p. F1258-F1270, 2003.

SOLIMAN, H.; CRAIG, G. P.; NAGAREDDY, P.; YUEN, V. G.; LIN, G.; KUMAR, U.; MCNEILL, J. H.; MACLEOD, K. M. Role of inducible nitric oxide synthase in induction of RhoA expression in hearts from diabetic rats. Cardiovasc. Res., v. 79, n. 2, p. 322-330, 2008.

SOWERS J. R. Diabetes mellitus and cardiovascular disease in women. Arch. Int. Med., v. 158, n. 6, p. 617-621, 1998.

STAMLER, J. S.; SIMON, D. I.; OSBORNE, J. A.; MULLINS, M. E.; JARAKI, O.; MICHEL, T.; SINGEL, D. J.; LOSCALZO, J. S-nitrosylation of proteins with nitric oxide: synthesis and characterization of biologically active compounds. Proc. Natl. Acad. Sci., v. 89, n. 1, p. 444-448, 1992.

SU, C. F.; YANG, F. L.; CHEN, H. I. Inhibition of inducible nitric oxide synthase attenuates acute endotoxin-induced lung injury in rats. Clin. Exp. Pharmacol. Physiol., v. 34, n. 4, p. 339-346, 2007.

TAKAHASHI, Y.; NAKANO, T.; WAKABAYASHI, I. Increased induction of inducible nitric oxide synthase expression in aortae of type 2 diabetes rats. J. Pharmacol. Sci., v. 107, n. 2, p. 190-200, 2008.

TAKAKURA, K.; TANIGUCHI, T.; MURAMATSU, I.; TAKEUCHI, K.; FUKUDA, S. Modification of alpha1 -adrenoceptors by peroxynitrite as a possible mechanism of systemic hypotension in sepsis. Crit. Care Med., v. 30, n. 4, p. 894-899, 2002.

TER STEEGE, J. C.; VAN DE VEM, M. W.; FORGET, P. P.; BROUCKAERT, P.; BUURMAN, W. A. The role of endogenous IFN-gamma, TNF-alpha and IL-10 in LPSinduced nitric oxide release in a mouse model. Cytokine, v. 10, n. 2, p. 115-123, 1998.

TESFAMARIAM, B.; PALACINO, J. J.; WEISBROD, R. M.; COHEN, R. A. Aldose reductase inhibition restores endothelial cell function in diabetic rabbit aorta. $\mathbf{J}$. Cardiovasc. Pharmacol., v. 21, n. 2, p. 205-211, 1993.

TESFAMARIAM, B.; JAKUBOWSKI, J. A.; COHEN R. A. Contraction of diabetic rabbit aorta due to endothelium-derived PGH2/TXA2. Am. J. Physiol., v. 257, n. 5 Pt 2, p. H1327-H1333, 1989.

THIEMERMANN C. The role of the L-arginine: nitric oxide pathway in circulatory shock. Adv. Pharmacol., v. 28, p. 45-79, 1994. 
TOLEDO, D. P.; AKAMINE, E.; NIGRO, D.; PASSAGLIA, R. C. T.; CARVALHO, M. H. C.; FORTES, Z. B. Microvascular reactivity in experimental diabetes: responses of male and female rats. Inflamm. Res., v. 52, n. 5, p. 191-198, 2003.

TSUTSUMI, S.; ZHANG, X.; TAKATA, K.; TAKAHASHI, K.; KARAS, R. H.; KURACHI, H.; MENDELSOHN, M. E. Differential regulation of the inducible nitric oxide synthase gene by estrogen receptors 1 and 2. J. Endocrinol., v. 199, n. 2, p. 267-273, 2008.

TURKO, I. V.; MURAD, F. Protein nitration in cardiovascular diseases. Pharmacol. Rev., v. 54, n. 4, p. 619-634, 2002.

VAN DER VLIET, A.; OÕNEIL, C. A.; EISERICH, J. P.; CROSS, C. E. Oxidative damage to extracellular fluids by ozone and possible protective effects of thiols. Arch. Biochem. Biophys., v. 321, n. 1, p. 43-50, 1995.

VEGETO, E.; BONINCONTRO, C.; POLLIO, G.; SALA, A.; VIAPPIANI, S.; NARDI, F.; BRUSADELLI, A.; VIVIANI, B.; CIANA, P.; MAGGI, A. Estrogen prevents the lipopolysaccharide-induced inflammatory response in microglia. J. Neurosci., v. 21, n. 6, p. 1809-1818, 2001.

VIRDIS, A.; SANTINI, F.; COLUCCI, R.; DURANTI, E.; SALVETTI, G.; RUGANI, I.; SEGNANI, C.; ANSELMINO, M.; BERNARDINI, N.; BLANDIZZI, C.; SALVETTI, A.; PINCHERA, A.; TADDEI, S. Vascular generation of tumor necrosis factor- $\alpha$ reduces nitric oxide availability in small arteries from visceral fat of obese patients. J. Am. Coll. Cardiol., v. 58, n. 3, p. 238-247, 2011.

WANG, R.; WU, Y.; TANG, G.; WU, L.; HANNA, S. T. Altered L-type Ca(2+) channel currents in vascular smooth muscle cells from experimental diabetic rats. Am. J. Physiol. Heart Circ. Physiol., v. 278, n. 3, p. H714-H722, 2000.

WILLIAMSON, J. R.; CHANG, K.; FRANGOS, M.; HASAN, K. S.; IDO, Y.; KAWAMURA, T.; NYENGAARD, J. R.; VAN DEN ENDEN, M.; KILO, C.; TILTON, R. G. Hyperglycemic pseudohypoxia and diabetic complications. Diabetes, v. 42, n. 6 , p. 801-813, 1993.

WOODWARD, M.; RUMLEY, A.; TUNSTALL-PEDOE, H.; LOWE, G. D. O. Associations of blood rheology and interleukin- 6 with cardiovascular risk factors and prevalent cardiovascular disease. Br. J. Haematol., v. 104, n. 2, p. 246-257, 1999

WU, F.; WILSON, J. X. Peroxynitrite-dependent activation of protein phosphatase type 2A media ates microvascular endothelial barrier dysfunction. Cardiovasc. Res., v. 81 , n. 1 , p. $38-45,2009$.

XAVIER, F. E.; DAVEL, A. P.; ROSSONI, L. V.; VASSALLO, D. V. Time-dependent hyperreactivity to phenylephrine in aorta from untreated diabetic rats: role of prostanoids and calcium mobilization. Vascul. Pharmacol., v. 40, n. 1, p. 67-76, 2003. 
XU, J.; WANG, S.; ZHANG, M.; WANG, Q.; ASFA, S.; ZOU, M. H. Tyrosine nitration of PA700 links proteasome activation to endothelial dysfunction in mouse models with cardiovascular risk factors. PLoS One., v. 7, n. 1, p. e29649, 2012.

YANG, S.; BAE, L.; ZHANG, L. Estrogen increases eNOS and NOx release in human coronary artery endothelium. J. Cardiovasc. Pharmacol., v. 36, n. 2, p. 242-247, 2000.

YU, X.; MA, H.; BARMAN, S. A.; LIU, A. T.; SELLERS, M.; STALLONE, J. N.; PROSSNITZ, E. R.; WHITE, R. E.; HAN, G. Activation of G protein-coupled estrogen receptor induces endothelium-independent relaxation of coronary artery smooth muscle. Am. J. Physiol. Endocrinol. Metab., v. 301, n. 5, p. E882-E888, 2011.

YUDKIN, J. S.; STEHOUWER, C. D.; EMEIS, J. J.; COPPACK, S. W. C-reactive protein in healthy subjects: associations with obesity, insulin resistance, and endothelial dysfunction: a potential role for cytokines originating from adipose tissue? Arterioscler. Thromb. Vasc. Biol., v. 19, n. 4, p. 972-978, 1999.

ZARZYCKI, W.; ZIENIEWICZ, M. Reproductive disturbances in type 1 diabetic women. Neuro Endocrinol. Lett., v. 26, n. 6, p. 733-738, 2005.

ZHANG, H.; POTTER, B. J.; CAO, J. M.; ZHANG, C. Interferon-gamma induced adipose tissue inflammation is linked to endothelial dysfunction in type 2 diabetic mice. Basic Res. Cardiol., v. 106, n. 6, p. 1135-1145, 2011.

ZHU, B. H.; GUAN, Y. Y.; MIN, J.; HE, H. Contractile responses of diabetic rat aorta to phenylephrine at different stages of diabetic duration. Acta Pharmacol. Sin., v. 22, n. 5, p. 445-449. 2001.

ZHU, Y.; BIAN, Z.; LU, P.; KARAS, R. H.; BAO, L.; COX, D.; HODGIN, J.; SHAUL, P. W.; THOREN, P.; SMITHIES, O.; GUSTAFSSON, J. A.; MENDELSOHN, M. E. Abnormal vascular function and hypertension in mice deficient in estrogen receptor beta. Science, v. 295, n. 5554, p. 505-508, 2002.

ZOCRATO, L. B.; CAPETTINI, L. S.; REZENDE, B. A.; SILVA, J. F.; RODRIGUESMACHADO, Mda, G.; CORTES, S. F.; LEMOS, V. S. Increased expression of endothelial iNOS accounts for hyporesponsiveness of pulmonary artery to vasoconstrictors after paraquat poisoning. Toxicol. In. Vitro, v. 24, n. 3, p. 10191025, 2010.

ZOU, M. H. Peroxynitrite and protein tyrosine nitration of prostacyclin synthase. Prostaglandins Other Lipid. Mediat., v. 82, n. 1-4, p. 119-127, 2007. 
APÊNDICES 


\section{APÊNDICE A - Tabela dos parâmetros metabólicos das ratas diabéticas 15 dias após a indução do diabetes}

Parâmetros biológicos das ratas controles e diabéticas 15 dias após a indução do diabetes.

\begin{tabular}{ccc}
\hline & Controle & Diabética \\
\hline Ganho de peso (g) & $\begin{array}{c}24,9 \pm 3,6 \\
(n=6)\end{array}$ & $\begin{array}{c}-4,1 \pm 4,2^{*} \\
(n=10)\end{array}$ \\
Glicemia (mg/dL) & $\begin{array}{c}135,10 \pm 5,49 \\
(n=8)\end{array}$ & $\begin{array}{c}532,90 \pm 18,81^{*} \\
(n=8)\end{array}$ \\
Ração (g/24hs) & $\begin{array}{c}7,27 \pm 0,39 \\
(n=6)\end{array}$ & $\begin{array}{c}19,89 \pm 0,57^{*} \\
(n=9)\end{array}$ \\
Água (mL/24hs) & $\begin{array}{c}12,96 \pm 0,45 \\
(n=6)\end{array}$ & $\begin{array}{c}85,52 \pm 5,01^{*} \\
(n=9)\end{array}$ \\
Urina (mL/24hs) & $\begin{array}{c}5,34 \pm 0,52 \\
(n=6)\end{array}$ & $\begin{array}{c}65,99 \pm 4,49 * \\
(n=9)\end{array}$ \\
& &
\end{tabular}

Os resultados estão expressos como média \pm epm. O número de ratas utilizadas em cada grupo encontra-se entre parênteses. ${ }^{*} \mathrm{p}<0,05$ vs Controle.

Fonte: Sartoretto (2013) 


\section{APÊNDICE B - Expressão do RNAm para a iNOS}

Expressão do RNAm para a iNOS em aorta de ratas controles (CT) e diabéticas (DB).

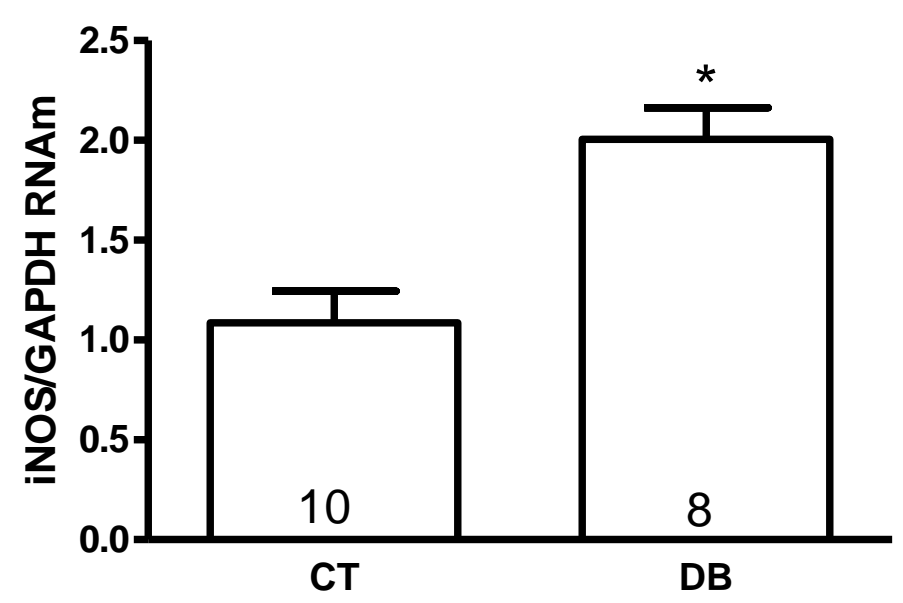

Os valores estão expressos como média \pm epm. A expressão do RNAm do GAPDH foi utilizado para normalização. Os números dentro das barras representam número de ratas utilizadas em cada grupo. ${ }^{*} \mathrm{p}<0,05$ vs CT.

Fonte: Sartoretto (2013) 
APÊNDICE C - Expressão do RNAm para os receptores de estrógeno, ESR2 e GPER

Expressão do RNAm para os receptores de estrógeno, ESR2 (A) e GPER (B), em aorta de ratas controles (CT) e diabéticas (DB).

A)

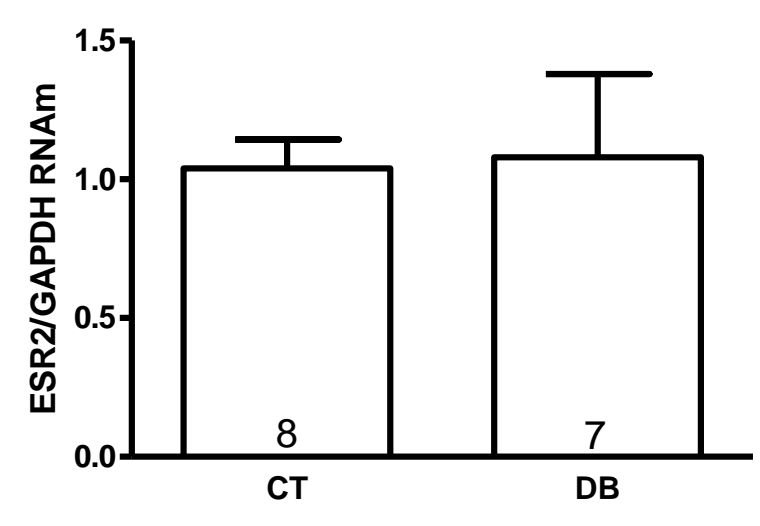

B)

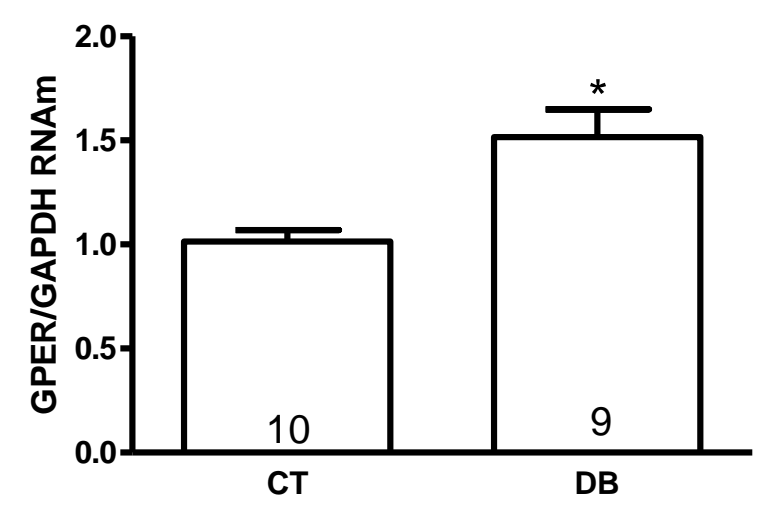

Os valores estão expressos como média \pm epm. A expressão do RNAm do GAPDH foi utilizado para normalização. Os números dentro das barras representam número de ratas utilizadas em cada grupo. ${ }^{*} \mathrm{p}<0,01$ vs CT.

Fonte: Sartoretto (2013) 